\title{
Romanian adolescents : health-risk behaviours and smoking prevention
}

Citation for published version (APA):

Lotrean, L. M. (2009). Romanian adolescents : health-risk behaviours and smoking prevention. [Doctoral Thesis, Maastricht University]. Risoprint. https://doi.org/10.26481/dis.20091113II

Document status and date:

Published: 01/01/2009

DOI:

10.26481/dis.20091113\|

Document Version:

Publisher's PDF, also known as Version of record

\section{Please check the document version of this publication:}

- A submitted manuscript is the version of the article upon submission and before peer-review. There can be important differences between the submitted version and the official published version of record.

People interested in the research are advised to contact the author for the final version of the publication, or visit the DOI to the publisher's website.

- The final author version and the galley proof are versions of the publication after peer review.

- The final published version features the final layout of the paper including the volume, issue and page numbers.

Link to publication

\footnotetext{
General rights rights.

- You may freely distribute the URL identifying the publication in the public portal. please follow below link for the End User Agreement:

www.umlib.nl/taverne-license

Take down policy

If you believe that this document breaches copyright please contact us at:

repository@maastrichtuniversity.nl

providing details and we will investigate your claim.
}

Copyright and moral rights for the publications made accessible in the public portal are retained by the authors and/or other copyright owners and it is a condition of accessing publications that users recognise and abide by the legal requirements associated with these

- Users may download and print one copy of any publication from the public portal for the purpose of private study or research.

- You may not further distribute the material or use it for any profit-making activity or commercial gain

If the publication is distributed under the terms of Article $25 \mathrm{fa}$ of the Dutch Copyright Act, indicated by the "Taverne" license above, 


\section{Romanian adolescents: health-risk behaviours and smoking prevention}




\section{Romanian adolescents: health-risk behaviours and smoking prevention}

\section{Dissertation}

To obtain the degree of Doctor at the Maastricht University, on the authority of the Rector Magnificus,

$$
\text { Prof. dr. G.P.M.F. Mols, }
$$

in accordance with the decision of the Board of Deans, to be defended in public on

Friday 13 November 2009 at 10.00 hours

by

Lucia Maria Lotrean 
Promoters:

Prof.dr. H. de Vries

Prof.dr. C. Ionut (luliu Hatieganu University of Medicine and Pharmacy, Romania)

Copromoter:

Dr. I. Mesters

Assessment committee:

Prof. dr. N.K. de Vries (chairman)

Prof.dr.G.J.Kok

Prof. dr B.vd Borne

Dr. M. Ausems

Prof. dr L. Lechner (Open University Netherlands)

\section{Descrierea CIP a Bibliotecii Naţionale a României LOTREAN, LUCIA MARIA}

Romanian adolescents : health-risk behaviours and smoking prevention / Lucia Maria Lotrean. - Cluj-Napoca : Risoprint, 2009

Bibliogr.

ISBN 978-973-53-0143-9

159.922 .8

The thesis was performed at the Faculty of Health, Medicine and Life Science (FHML), Maastricht University, Care And Public Health Research Institute (Caphri).

The studies presented in this study were conducted with financial support from The National University Research Council (CNCSIS) from Romania, The International Union against Cancer through a UICC Cancer technology Transfer Fellowship, The Royal Embassy of Netherlands in Romania through a Matra KAP grant and The Netherlands Organization for international cooperation in higher education through a Huygens scholarship. 


\section{Contents}

Chapter 1.

Chapter 2.

Chapter 3.

Chapter 4.

Chapter 5.

Chapter 6.

Chapter 7.

Appendix

References

Summary

Samenvatting

Acknowledgements

Curriculum vitae
General introduction

Assessment of health-risk behaviours and their interrelationship among Romanian young people relationship among Romanian adolescents; a longiludinal study

Tobacco use among Romanian youth

Predictability of smoking onset among Romanian adolescents programme on video for Romanian adolescents 


\section{Chapter 1}

General introduction 


\section{Introduction}

The leading causes of mortality and morbidity among youth can be traced to a relatively small number of preventable health-risk behaviours that are often initiated during youth and extended into adulthood (Lippe et al., 2007; Hibell et al., 2004). Many of these risk behaviours also contribute substantially to social problems such as family dysfunction, crime and school dropout (Grunbaum et al., 2003).

Prevalence of preventable health-risks differs per country, as will the determinants of such behaviours (Currie, 2004; Hibell et al., 2004). This thesis will study the Romanian youth as related to the prevalence and the determinants of diverse preventable health-risk behaviours. The selected behaviours are some of the most relevant and common health-risk behaviours among youngsters (Currie, 2004): smoking, alcohol use, illicit drug use, violence-related behaviour and sexual behaviour.

This thesis starts with exploring patterns of diverse health-risk behaviours among Romanian young people and examining if an accumulation and a relationship between health-risk behaviours exist. In the second part, the thesis will focus on the prevention of smoking. The focus on smoking has been determined by the fact that both our studies from the first part of the thesis, as well as other recent studies from Romania underline that adolescent smoking is an important public health problem and that tobacco use is one of the first risk behaviours youngsters will most likely be engaged in (Bucur, 1999; Laza and Lotrean, 2003; Centre for Health Policies and Services, 2004). The choice to focus on smoking prevention also has been influenced by the fact that at the European level excellent networks exist for smoking prevention, thus facilitating the exchange of programmes that have been tested and have shown to be effective. A final reason to focus on smoking prevention has been that different Romanian governmental and non-governmental organizations have also expressed their interest in supporting the development and implementation of a smoking prevention programme among Romanian adolescents.

First, in the general introduction, we will start describing the broader context of this thesis by providing background information on Romania. Second, we will provide an overview of the prevalence and consequences of several health-risk behaviours among young people in general and in Romania in particular. These health-risk behaviours pertain to a wide range of behaviours from substance use to violence and sex-related behaviours. Third, we will describe health promotion planning models that can be used to address public health problems in a more systematic way. Fourth, we will then make the transition to the focus on a particular behaviour - smoking, and describe how social cognitive models can be used to analyse the determinants of smoking. Fifth, we will provide an overview of various smoking prevention strategies that can be used, and introduce the school setting as our access point to reach our Romanian youngsters. Lastly, we will provide an overview of the chapters and depict a brief rationale for the design of the studies described in this thesis.

\section{Background information on Romania}

Romania is a country located in South-East Europe. It shares borders with the Republic of Moldavia, Ukraine and the Black Sea in the east, with Bulgaria in the south, with Serbia in the south and south-west, with Hungary in the west and with Ukraine in the north (see fig. $1.1)$. It has an area of 238,391 square $\mathrm{km}\left(9.1,699\right.$ square miles) ranking $12^{\text {th }}$ in Europe. The population size of Romania is of $21,689,181$ people whose ethnic structure is as follows: 
Romanian 89.5\%; Hungarian 6.6\%; Roma (Gypsy) 2.5\%; other ethnic groups 1.4\% (European Commission, 2007).

The country is divided into 41 counties (including the Municipality of Bucharest, the capital of Romania), comprising 263 towns and cities, as well as 2,685 communes with 13,285 villages. A percentage of $55 \%$ of the Romanian population lives in urban areas and the rest of population lives in rural areas.

Romania is a presidential republic and the official language is Romanian. After the fall of the communist regime in 1989, Romania started a process of political, economic and socio-cultural changes, which led in 2007 to the admission of Romania into the European Union.

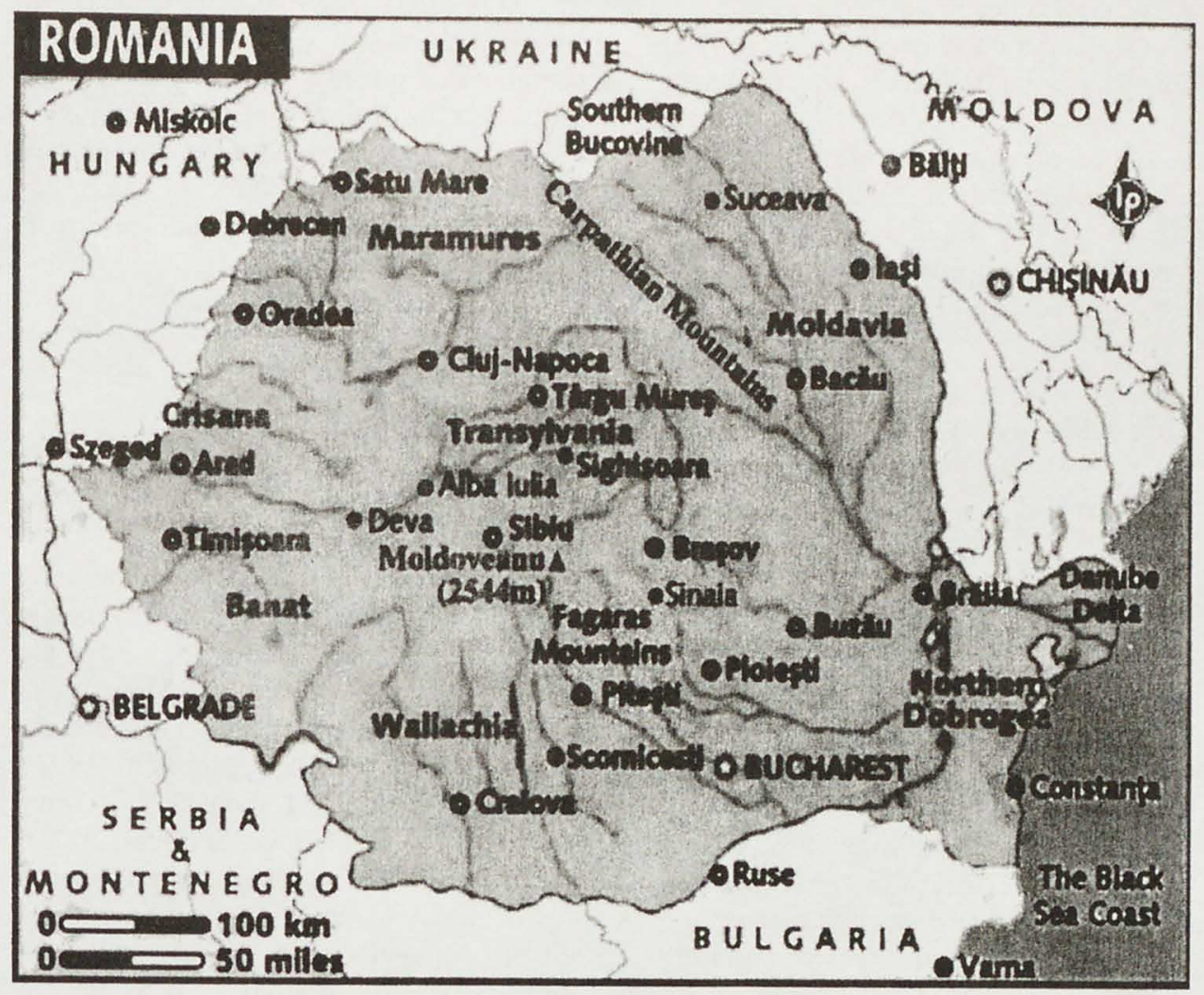

Figure 1.1 Map of Romania

In Romania the school system comprises four types of education levels: elementary schools (students aged 7 to 11), junior high schools or secondary schools (students' age 11 to 15 years), senior high schools (15-19 year-old students) and university (students starting from 19 years of age).

Table 1.1 presents the rate of school enrolment of Romanian young people, with attention to rural/urban differences. 
Table 1.1 The rate of school enrolment of Romanian young people "

\begin{tabular}{lccc}
\hline \multicolumn{1}{c}{ Education level } & $\begin{array}{c}\text { Total } \\
\%\end{array}$ & $\begin{array}{c}\text { Urban } \\
\%\end{array}$ & $\begin{array}{c}\text { Rural } \\
\%\end{array}$ \\
\hline Primary school & $108.2^{\mathrm{b}}$ & 108.5 & 107.9 \\
Junior high school & 92.2 & 96.0 & 88.0 \\
Senior high school & 54.6 & 89.8 & $8.6^{\mathrm{c}}$ \\
University & 29.9 & - & - \\
\hline
\end{tabular}

a- Source: National Institute of Statistics, Romania (World Bank, 2007).

b-The inclusion in primary school starts at 7 years of age, but in some years the parents had the possibility to decide if their children would start school at 6 years of age or at 7 years of age. Hence some children started school at 7 years old, others at 6 years old. The rate of enrolment in primary school was calculated by reporting the number of children enrolled in primary school to the number of children aged 7 to 11 . This has lead to an overestimation of the school enrolment in the primary school. A similar situation was encountered for the rate of school enrolment in the junior high school.

c-Some of the Romanian young people from rural areas go to senior high school in urban areas, which increases to around $25 \%$ their inclusion in senior high school.

\section{Health-risk behaviours}

\section{Tobacco use}

Smoking is related to several diseases, such as different types of cancer (lip, mouth and lung cancer), chronic obstructive respiratory disorder, coronary heart disease and cerebrovascular accident (National Center for Disease Control and Prevention, 1993; Doll, 1998; Peto et al., 2000). On average, smokers die nearly seven years earlier than non-smokers (US Department of Health and Human Services, 1994a). Smoking triples the risk of dying from heart disease among the middle-aged (National Center for Disease Control and Prevention, 1993). Cigarette smoking accounts for at least $30 \%$ of all cancer deaths and about $87 \%$ of lung cancer deaths are caused by smoking (US Department of Health and Human Services, 2000).

The adverse health consequences do not apply only to adult smokers, but also to youngsters. There is evidence that health problems associated with smoking are a function of the duration (years) and intensity (amount) of use. The younger one begins to smoke, the more likely one is to be a regular smoker as an adult. Early onset of smoking increases the potential longer duration of use and the risk of a range of more serious health consequences. Earlier initiation of smoking is also associated with heavier smoking both in adolescence and adulthood. Because of their established nicotine addiction, heavier users are the least likely to quit smoking and are more likely to experience tobacco related health problems (US Department of Health and Human Services, 1994a; Pierce and Gilpin, 1996).

Besides negative long-term health consequences, there are short-term health effects of smoking among young people as well. Cigarette smoking among adolescents reduces the rate of lung development and the level of maximum lung function that can be achieved. Young smokers are likely to be less physically fit than non-smokers, with fitness levels inversely related to the duration and intensity of smoking. Smoking also increases the risk of an unfavourable lipid profile that may be a precursor of coronary heart diseases (US Department of Health and Human Services, 1994a). 
Smoking is a major preventable cause of premature death and disability throughout the world (Shafey et al., 2003). In Europe, each year tobacco use is considered responsible for more than 1.2 million deaths, 700,000 of which occur in the countries of Central and Eastern Europe (World Health Organization, 2002a). In Romania smoking is responsible for more than 32,000 deaths annually (Shafey et al., 2003).

Although the vast majority of smoking-related deaths occur in middle-aged and elderly people, smoking behaviour is undeniably established in adolescence (US Department of Health and Human Services, 1994a; Shafey et al., 2003). The European School Project on alcohol, tobacco and drug use (ESPAD) carried out in 30 European countries showed that in many European countries, $50-80 \%$ of 16 year-old students had smoked cigarettes at least once in their lifetime, and those who had smoked 40 times or more were mainly found in countries where the lifetime prevalence was high. In Austria, the Czech Republic, Greenland, Germany, Lithuania and Russia (Moscow) about $40 \%$ of the students had smoked 40 times or more in their lifetime. The lowest prevalence rates were found in Turkey (13\%), Malta (16\%), Iceland and Portugal (18\% each) (Hibell et al., 2004).

In Romania, a study showed that in 2003 a percentage of $64 \%$ of 16 year-old Romanian school students reported smoking at least once during their lifetime, an increase of $11 \%$ being noticed when compared with the year 1999 (Romanian Ministry of Health, 2004).

When viewed from a lifestyle perspective, adolescent smoking is also associated with the other types of health-risk behaviours mentioned in this chapter: drinking alcohol, illicit drug use, violence and unsafe sexual behaviour. Moreover, tobacco is generally the first drug used by young people who subsequently resort to drug use that may include alcohol, marijuana and harder drugs (Kandel and Faust, 1975; US Department of Health and Human Services, 1994a).

The serious consequences of adolescent smoking, in terms of both health and behaviour, suggest that prevention of adolescent smoking is very important and should be given priority when considering comprehensive preventive actions. Despite this, few smoking prevention activities have been undertaken in Romania. Therefore, studies are needed in order to investigate the determinants of smoking onset among Romanian adolescents and to develop smoking prevention programmes for the relevant age groups starting from primary school up to 21 years of age.

\section{Alcohol use}

Alcohol use is related to a wide range of physical, mental and social harms (Jernigan, 2001). Most health professionals agree that alcohol affects practically every organ in the human body. Alcohol consumption has been linked to more than 60 disease conditions in a series of meta-analyses. It has been demonstrated that continuous alcohol use can result in health problems such as liver disease, lung disease, pancreatic disease, neuropsychological deficits, endocrine system disorders, traumatic injuries, compromised immune function, and cognitive impairment (English et al., 1995; Gmel et al., 2006; Ridolfo and Stevenson, 2001; Single, 1997).

The link between alcohol consumption and consequences depends a) on the two main dimensions of alcohol consumption: average volume of consumption and patterns of drinking; and b) on the mediating mechanisms: biochemical effects, intoxication, and dependence. Direct biochemical effects of alcohol may influence chronic disease either in a beneficial (e.g. protection against blood clot formation in moderate consumption (Zakhari, 1997), which is protective for coronary heart disease) or harmful way (e.g. toxic effects on acinar cells triggering pancreatic damage (Apte et al., 1997). Alcohol intoxication is a 
powerful mediator mainly for acute outcomes, such as accidents, intentional injuries or deaths, domestic conflict and violence (Klingemann and Gmel, 2001; Gmel et al., 2006). Alcohol dependence is a powerful mechanism sustaining alcohol consumption and thus impacting on both chronic and acute consequences of alcohol (Drummond, 1990), though it is also a consequence of drinking itself.

Adverse health outcomes resulting from alcohol use are common among young people and many alcohol-related deaths occur relatively early in life. They also include intentional and unintentional injuries (like alcohol-related traffic accidents), both of which are related to pattems of drinking. The negative social consequences include missing school, falling behind in schoolwork, unplanned and unprotected sexual activity, arguments with friends, destructive behaviour and trouble with the police (Hibell et al., 2004).

Alcohol use represents an important public health problem in Europe. Around 600,000 Europeans died of alcohol-related causes in 2002, representing $6.3 \%$ of all premature deaths in the World Health Organization European Region. More than 63,000 of those deaths concerned young people aged 15-29 years. These figures, among others, demonstrate the magnitude of the problem of alcohol abuse among the youngsters of Europe, a region that, according to World Health Organization, has alcohol consumption "twice as high as the world average" (Jernigan, 2001).

According to ESPAD findings, the pattern of alcohol consumption among young people varied among regions and countries. They revealed that the highest rates of 16 yearold students reporting use of alcohol 40 times or more in lifetime were found in countries such as Denmark, Austria, the Czech Republic, Isle of Man, the Netherlands and the United Kingdom (43-50\%). The lowest proportion was reported from Turkey (7\%) followed by Greenland, Iceland, Norway and Portugal (13-15\%) (Hibell et al., 2004). The percentage of 16 year-old students from Romania who had consumed any alcohol over the previous 12 months was close to the average of all ESPAD countries ( 80 versus $83 \%$ ).

The prevalence of drunkenness seemed most prevalent in countries in the western parts of Europe, such as Denmark, Ireland, Isle of Man and the United Kingdom, where between $20-30 \%$ of 16 year-old students reported drunkenness more than 20 times in their life. Very few students reported frequent drunkenness in Mediterranean countries such as Cyprus, France, Greece, Portugal, Romania and Turkey (less than 3\% reported that they had been drunk 20 times or more in their life) (Hibell et al., 2004). The percentage of 16 year-old students from Romania who reported drunkenness over the previous 12 months was substantially lower (36\%) compared to ESPAD data (53\%) (Hibell et al., 2004), but it meant an increase of $9 \%$ in four years (from 1999 to 2003) (Hibell et al., 2000).

These findings underline the importance of preventing unhealthy alcohol use among Romanian adolescents. More research is needed to better understand alcohol consumption patterns among Romanian adolescents as well as the factors, which influence them, and the actions needed for future prevention initiatives.

\section{Illicit drug use}

The concept "illicit drug" includes marijuana or hashish, amphetamines, LSD or other hallucinogens, crack, cocaine; ecstasy and heroin. Drug use has important health and social consequences (Hibell et al, 2004). The health effects of drugs depend on the type of drug, way of administration, quantity, frequency of use and the health status of the user. Illicit drug use represents a threat to health and mental stability. Adolescents who use cannabis are at greater risk to develop a number of health problems including attention deficit disorders, anxiety disorders, phobias and depression (Arseneault et al., 2002; Fergusson et al., 2003; 
Patton et al., 2002). At the same time, teens who begin drug use at an early age are at risk of developing addiction and continued drug habits into and through adulthood. Additionally, drug use increases the odds of death from accidental or intentional drug overdoses, as well as engagement in other unsafe behaviours such as driving under the influence, having unprotected sex, being involved in delinquent behaviour and dropping out of school (Brook et al., 1999; Johnston et al., 1997; Hibell et al., 2004). Moreover, intravenous drug use is associated with an increased risk of acquiring HIV/AIDS and other infectious diseases such as hepatitis B and C, due to the sharing of used needles (Garfein et al., 1996).

Despite the illegality of cannabis use in most countries and regions, it is the most widely used substance for both adults and adolescents, after alcohol and tobacco (Johnston et al., 1997; Hibell et al., 2004). The European School Project on alcohol, tobacco and drug use (ESPAD) study showed that the vast majority of 16 year-old students that have tried any illicit drug, have used marijuana or hashish. Thus, the number of students reporting cannabis use was almost identical with the total prevalence of illicit drug use. Cannabis use was mainly reported from countries in the central and western parts of Europe, where more than one third of the students have used it. The high prevalence countries included the Czech Republic, France, Ireland, Isle of Man, Switzerland and the United Kingdom (38-44\%). The low prevalence countries (less then 10\%) were found in the north as well as the south of Europe. In Romania, few 16 year-old students (3\%) reported the use of marijuana or hashish, which is much below the ESPAD average (21\%) (Hibell et al., 2004).

The use of cannabis during the last 30 days may indicate regular use. The ESPAD study showed that in some countries about one fifth of the students reported this, whereas in others, much lower prevalence rates were noted. The countries with the highest 30 days prevalence included the Czech Republic, France, Isle of Man, Switzerland and the United Kingdom (19-22\%). The six countries with the lowest figures include the Faroe Islands, Romania, Sweden ( $1 \%$ each), Cyprus, Greece and Turkey (2\% each) (Hibell et al., 2004).

There were also students who used illicit drugs other than marijuana and hashish. Overall, the prevalence rates of these substances were relatively low. The ESPAD average was $6 \%$ with a range of $2-11 \%$ (Hibell et al., 2004). In Romania, the proportion of students who reported the use of any illicit drug other than cannabis was also lower than the average ( $2 \%$ compared to $6 \%$ ) (Hibell et al., 2004).

These data show that the problem of illicit drug use by Romanian adolescents is lower than in other European countries. Nevertheless, an insight in the determinants of such behaviour might be of interest to develop evidence-based health promotion actions, needed in order to prevent the development of illicit drug use to a higher extent in the future in Romania.

\section{Violence-related behaviours}

The World Health Organization's World Report on Violence and Health defines violence as the intentional use of physical force or power, threatened or actual, against oneself, another person or against a group or community that either results in or has a high likelihood of resulting in injury, death, psychological harm, maldevelopment or deprivation (World Health Organization, 2002b). Each year, over 1.6 million people worldwide lose their lives to violence. Violence is among the leading causes of death for people aged 15-44 years worldwide, accounting for $14 \%$ of deaths among males and $7 \%$ of deaths among females. For every person who dies as a result of violence, many more are injured and suffer from a range of physical, sexual, reproductive and mental health problems. Moreover, violence places a massive burden on national economies, costing countries billions of US dollars each 
year in health care, law enforcement and lost productivity (World Health Organization, 2002b).

For several reasons, young people engage in violence-related behaviours. Bullying and fighting depict different types of involvement in violence during adolescence. Bullying involves negative physical or verbal action that has hostile intent, causes distress to the victims, is repeated over time and involves a power differential between bullies and their victims. Repeated bullying consolidates the power relations between bullies and their victims and the children who are being bullied become increasingly unable to defend themselves. Fighting is an aggressive behaviour but unlike bullying, usually involves people of similar age and equal strength (Currie, 2004).

Along with the immediate effects, bullying and fighting have long-term negative consequences for all involved: the bullies or fighters, victims, and those who observe the interaction. Retrospective reports have found that children who are bullies tend to be bullies as adults and to have children who are bullies; similarly, children who are victimized tend to have children who are victimized. The same combination of power and aggression found in playground bullying is a key component of sexual and workplace harassment, dating and marital aggression, and abuse of children and elderly people. Several researches indicate that childhood violence-related behaviour is associated with antisocial behaviour in adulthood, such as criminality, and with limited opportunities to attain socially desired objectives, such as stable employment and long-term relationships. Moreover, violence among young people generates life-long costs, because they become involved in multiple systems, such as mental health services, juvenile justice, special education and social services (Olweus, 1987; Harel, 1999; World Health Organization, 2002b; Currie, 2004).

The Health Behaviour in School-aged Children study (HBSC) performed among 11-15 year-old students from several European countries showed that, on average, $39 \%$ of all young people reported involvement in at least one physical fight in the previous year. The rates vary across countries and regions $(24-53 \%$ in 11 -year-olds, $26-52 \%$ in 13 -year-olds and $20-48 \%$ in 15 -year-olds). The mean percentages for the three age groups were $42 \%$, $40 \%$ and $34 \%$, respectively (Currie, 2004). No Romanian prevalence data are available.

In conclusion, bullying and fighting may be one step along a continuum of aggressive behaviour, combining the use of power and aggression. The involvement of young people in violence-related behaviour has serious health and social consequences and implies high costs for individuals, families, schools and society. Since no Romanian data are available, studies exploring violence-related behaviour need to be carried out in this country in order to determine if and which prevention activities for Romanian adolescents may be needed.

\section{Sexual behaviour}

Sexual health is a substantial part of adolescents' general, social and personal well-being. It can be described as the positive integration of the physical, emotional, intellectual and social aspects of sexuality (Currie, 2004). One of the primary developmental aspects of adolescence is the consolidation of identity in general and sexual identity in particular. The development of sexuality in adolescence involves physical changes associated with puberty, psychological changes and interpersonal events. Fortunately, most adolescents go through these changes without significant problems. Nevertheless, there are adolescents who are at risk because they do not have the information, skills, health services and support they need to be able to make well informed, responsible decisions regarding their sexual behaviour (World Health Organization, 2005). 
The first intercourse at young age is linked to unplanned, unprotected sex and therefore to a greater risk of unintended pregnancy and sexually transmitted diseases. Moreover, early first intercourse can also correlate with other modes of risk taking. Alcohol and drug use have a clear association with early first intercourse, which is then likely to be unintended and unprotected (Currie, 2004).

The HBSC study demonstrated variations across countries and regions regarding the sexual behaviour of young people. The percentage of 15 year-old people, who reported having had sexual intercourse, ranged from $15 \%$ in Poland to $75 \%$ in Greenland. In some countries and regions, mainly in Eastern and Central Europe, plus Spain, less than a fifth of young people reported ever having had sexual intercourse. At the upper end of the spectrum, in England, Greenland, Scotland, Ukraine and Wales, a third or more have had sexual intercourse (Currie, 2004). While no more than $70 \%$ of sexually active young people used a condom the last time they had sexual intercourse in some countries such as Finland and Sweden, in other countries (e.g. Greece, Spain) $80-90 \%$ of sexually active young people did so (Currie, 2004). Due to the fact that the target group of the HBSC study was only 15 yearold people and in several countries the majority of young people have not yet started to be sexually active by this age, this study could not provide a complete picture of age at the initiation of sexual activity and the sex-related behaviour of young people.

In Romania, no data are available with regard to sexual behaviour of 15 year-old adolescents, but a national study showed that, among young people aged 15 to 24 , half of the girls and $60 \%$ of the boys have started their sexual life; around one third of the unmarried sexually active young people declared having used condoms during their last sexual intercourse (Romanian Ministry of Health, 2005).

Unsafe sex practices can lead to unwanted pregnancy and unsafe abortions, as well as to several sexually transmitted diseases (STD). Worldwide, more than 14 million adolescent women give birth each year. A large proportion of these pregnancies are unwanted, and the World Health Organization estimated that as many as 4.4 million abortions are sought by adolescent girls each year (World Health Organization, 1997). In Romania, during the communist regime, abortions were illegal, as the Romanian government of that time had made the increase of the population one of its objectives. In 1990, after the fall of the communist regime, abortions became legal in Romania and, at the same time, one of the most important methods of contraception. Recently, the number of abortions has started to decrease, but it is still quite high, with 70.000 women aged 15-24 years opting for an abortion in 2003 (UNFPA, 2006).

Every year, more than 333 million cases of STD are diagnosed in the world and out of these, at least one third, are young people (World Health Organization, 2005). In Romania, similar to other countries of Eastern Europe, there were an increasing number of sexually transmitted diseases in the years after 1990, which demonstrates unsafe sexual behaviour (Brădean, 1999; Mihailide, 1999). For instance, the incidence rates of syphilis increased from 19.8 new cases $/ 100.000$ inhabitants in 1989 to 32.3 new cases $/ 100.000$ inhabitants in 1998 and to 52 new cases/100.000 inhabitants in 2001(Brădean, 1999; Mihailide, 1999;Romanian Ministry of Health, 2005).

Besides, young people are at risk of acquiring the HIV infection because of their high rates of partner change and unprotected sex, or because of their involvement in sexual relationship with a regular partner having a promiscuous sexual life or abusing injected drugs (Kirby, 1995). According to the estimates of The Joint United Nations Programme on HIV/AIDS, worldwide around 37.2 million adults and 2.3 million children was living with HIV at the end of 2006. Around half of the people who acquire HIV, become infected before they turn 25 (UNAIDS, 2006). The AIDS epidemic in Eastern Europe and Central Asia is rapidly expanding. Some 270,000 people were infected with HIV in 2006 (compared to 
160,000 during 2004), bringing the total number of people living with the virus to around 1.7 million (UNAIDS, 2006).

In Romania, a steady increase of the HIV/AIDS incidence among people aged 15 to 49 was registered after 1994. The incidence rates of HIV/AIDS among people older than 15 years increased from 0.4 new cases $/ 100.000$ inhabitants in 1994 to 1.4 new cases $/ 100.000$ inhabitants in 2005(Romanian Multisectoral HIV/AIDS Commission, 2005). The sexual transmission of HIV continues to spread the epidemic among young adults, this data being confirmed by corroboration with the annual increases in the incidence rates of syphilis (Romanian Multisectoral ifIV/AIDS Commission, 2005).

In sum, the key public health concerns for teenage sexual health include young age intercourse and unsafe sex, resulting in unwanted pregnancy and unsafe abortions, sexually transmitted diseases and HIV/AIDS, which could be largely prevented through appropriate interventions. This implies a need for a further analysis of the sexual health-risk behaviours of Romanian young people, as well as for the development of evidence-based interventions aimed at the promotion of the adoption of healthy sexual practices.

\section{Relationship between health-risk behaviours}

Several lines of research have resulted from the desire to prevent health-risk behaviours among adolescents. One examines the risk markers and risk factors for these behaviours, including demographic characteristics, psychosocial factors and environmental factors (Lowry et al., 1996; Turner et al., 1993; Irwin et al., 1992; Oman et al., 2002, Reddy et al., 2007) in order to target interventions.

The second line of research examines the progression of health-risk behaviours. Several studies have demonstrated that certain health-risk behaviours (e.g. drug use) are preceded by others (e.g. tobacco or alcohol use), following a relatively consistent pattern (Kandel and Yamaguchi, 1993; Kaplan et al., 2003; Adelmann, 2005; Lewinsohn et al., 1999). The implication of this type of research is that preventing early behaviours in a chain of experimentation may reduce the likelihood that later behaviours will occur.

The third line of research focuses on the interrelationship of risk behaviours. That is, adolescents who engage in one type of health-risk behaviour, such as substance use, are more likely to engage in another type, such as unprotected sexual intercourse (Ku et al., 1992; Kulbok and Cox, 2002; Shrier et al., 1996; Takakura et al., 2001b) or injury-related behaviours (Alexander et al., 1992; Orpinas et al., 1995).

Several studies have documented the presence of multiple risk behaviours among different populations of young people (Basen-Engquist et al., 1996; Brener and Collins, 1998; Bartlett et al., 2005, Mpofu et al., 2006). Jessor's problem behaviour theory suggests that multiple risk behaviours may occur as a function of a single behavioural syndrome, with clear risk factors within 5 broad areas: biological and genetics, social environment, perceived environment, personality and behaviour (Jessor, 1991; Donovan and Jessor, 1985). It follows that interventions should address the underlying risk factors for this syndrome.

Other studies have found that health-related behaviours are multidimensional, but the examined behaviours as well as the precise number of dimensions involved and their behavioural content varied between studies (Basen-Engquist et al., 1996; Ebin et al., 2001; Takakura et al., 2001a; Kulbok and Cox, 2002; Bartlett et al., 2005).

Jessor also argues that an early age of onset of health-risk behaviours is associated with an increased likelihood that adolescents will engage in multiple risk behaviours as they progress through adolescence. A variety of studies on adolescent health from different 
countries and regions have also documented this fact (Brener and Collins, 1998; Durant et al., 1999; Aarons et al., 1999; Paavola et al., 2004).

In Romania, several studies have showed that many adolescents engage in several health-risk behaviours before reaching adulthood (Centre for Health Policies and Services, 2004; Romanian Ministry of Health, 2004; Lotrean and Laza, 2001), but little information is available regarding the relationship between the health-risk behaviours and its associations with several risk factors.

The interrelation between these behaviours could imply the development of one broader health promotion programme targeting all behaviours. However, this also implies the availability of evidence-based prevention strategies for each of the behaviours. In fact, in order to develop effective programmes for healthy lifestyle promotion among Romanian young people it is helpful to develop, implement and compare the advantages and disadvantages of the programmes which focus only on a specific behaviour with more generic programmes which try to prevent several risk-behaviours (Neumark-Sztainer et al., 1997; Wetzels et al., 2003; Flay et al., 2004, Werch et al., 2005). At the same time, when the programmes imply the combination of different health education messages (abstinence from smoking and moderation in alcohol use for instance), research is needed on whether it is feasible and effective to combine the two messages under the same framework. Since neither theory-driven programmes focusing only on one health-risk behaviour, nor any generic programmes focusing on several health-risk behaviours were available in Romania at the beginning of this thesis, and in line with our capacity, we have decided to restrict our efforts for health promotion among Romanian adolescents to the implementation and evaluation of a programme focusing on smoking.

Hence, the next part of the general introduction presents health promotion planning models and describes how social cognitive models can be used to analyse the determinants of smoking. It also presents factors found to be associated with smoking among adolescents as well as strategies needed for smoking prevention.

\section{Planning models for health education and promotion}

In order to develop effective health education and promotion activities, a planning model is needed in order to distinguish the most important phases and to carefully plan the activities. The advantage of a planning model is that many relevant aspects are dealt with in a systematic way and that it provides an overview of the most important issues that need to receive attention. A planning model therefore stimulates planning ahead and may prevent the development of ineffective programmes and campaigns. For instance, campaigns may have little or even reverse effects if they do not focus on the relevant factors that determine the individuals' unhealthy behaviours. Therefore, a systematic approach is advocated, which pays attention to the issues relevant for analysing the problem, the programme development and the programme diffusion and institutionalisation. The present thesis was inspired by the I-Plan Model (De Vries, 1998).

The I-Plan Model, previously known as the ABC Planning Model, incorporates insights from the PRECEDE-PROCEED Model (Green and Kreuter, 1991), the Community Change Model (Bracht, 1990) and the Diffusion of Innovations Model (Rogers, 1983). It consists of three phases, namely: Analysis, Behavioural Intervention and Continuation (De Vries, 1998).

With respect to the Analysis phase, one can distinguish four important issues or steps or sub-phases. The first step in the Analysis phase is the problem identification. This refers to the identification of health and social problems that need attention. The next issue is 
to analyse which behaviours and environmental factors are related to these health problems. The following step is to identify the target groups: which groups engage most often in unhealthy behaviours. These groups are the groups relevant to receive health education, as they will be at a high risk of developing illnesses. Once the target group is selected, behaviour can be studied at the micro or individual level, at the meso or organizational level and at the macro or socio-cultural and political level. The fourth issue is to analyse why people engage in unhealthy behaviours. Behavioural research indicates that the following factors are important as determinants of behaviour: environmental or demographic factors (e.g. age, socio-economic status, religion, gender) and cognitive factors, such as attitudes, social influences and self-efficacy expectations.

The Analysis phase also includes an exploration of the needs of and the channels through which the target group can be accessed, known as an Access Point Analysis.

In the Behavioural Intervention phase of the I-Plan Model the results of the Analysis phase are used to formulate goals for the programme, such as smoking prevention at the individual level, non-smoking school policies at the meso level and enforcement of the ban on underage sales at the macro level. These goals are then translated into programme objectives; three types of programme objectives are developed, namely health, behavioural and motivational objectives. Thereafter, the programme is developed by combining theoretical methods, such as learning assertiveness skills with practical methods of delivery such as posters, videos and group discussions. This is followed by the pilot testing to refine the programme, the programme implementation and an evaluation of its effectiveness. Several levels of evaluations can be undertaken, namely the process evaluation to ascertain to which extent the programme was implemented and the programme evaluation by the target group and the programme providers; the effect evaluation on the outcome variables and behavioural evaluation such as the improvement in self-efficacy; and an evaluation of the cost effectiveness of the programme.

The Continuation Phase of the I-Plan Model involves the use of an intersectoral collaborative group, which represents the various stakeholders who may have an interest in the utilization of the programme, in developing diffusion strategies and supportive mechanisms to ensure the wide scale use of the programme.

\section{The Integrated Model for Change}

Health behaviours are increasingly viewed from a psychosocial perspective to account for the personal variables that influence such behaviours (Torres and Fernandez, 1995). One approach to improve the effectiveness of antismoking strategies would be to target the cognitions specified by psychosocial models, such as the Integrated Model of Change (IChange Model) (De Vries et al., 2003c).

This model is derived from the Attitude-Social Influence-Self-Efficacy Model that can be considered as an integration of the ideas of Ajzen's Theory of Planned Behaviour (Ajzen, 1991), Bandura's Social Cognitive Theory (Bandura, 1977), Prochaska's Transtheoretical Model (Prochaska and Velicer, 1997), the Health Belief Model (Glanz et al., 2002) and the goal setting theories. The I-Change Model has been shown to be useful to explain various health behaviours and smoking behaviour in particular, as well as to develop and evaluate smoking prevention programmes in different European countries (De Vries et al., 1994; De Vries et al., 1995; Dijkstra et al., 1999; Holm et al., 2003; De Vries et al., 2003b; De Vries et al., 2006b, Vitoria et al., 2006).

The model assumes that the most important determinant of behaviour is the 'behavioural intention, which in turn is influenced by three proximal factors, namely one's 
overall evaluation of the behaviour (attitude), one's beliefs concerning the beliefs and behaviours of significant others (social influences) and the control that people perceive themselves to have over performing a behaviour (self-efficacy).

While similar in format to the Theory of Planned Behaviour, the I-Change Model differs in several ways (De Vries \& Mudde, 1998; De Vries et al., 2003c). First, attitudes and social norms are not measured by multiplicative functions, but are entered separately into the regression equations (Evans, 1991). Second, the model assesses attitudes by measuring both the pros and cons of behaviour. Third, it distinguishes three types of social influences, namely social norms, direct pressure or support and the perceived behaviour of others. Fourth, self-efficacy expectations are measured rather than perceived control, as described in the Social Learning Theory (Bandura, 1977), by measuring confidence to perform the desired behaviour in various situations. Fifth, the model acknowledges the existence of three phases: awareness, motivation and action, each with different predictors. Sixth, the model recognises four types of distal or predisposing factors that influence behavioural intention through proximal factors, namely behavioural (previous experience with the same and related behaviour, e.g. alcohol and use of other substances), psychological (e.g. depression, risk behaviour), biological (e.g. gender, age) and social and cultural factors (e.g. social climate, socio-economic status).

In this thesis, the I-Change model was used as a theoretical framework to study the motivational factors related to smoking among Romanian young people and to develop and evaluate a smoking prevention programme for Romanian adolescents.

\section{Factors associated with smoking among adolescents}

Three major reviews, namely by Conrad, Flay and Hill (1992), The US Surgeon General's Report (1994) and Tyas and Pederson (1998) have documented the factors associated with adolescent smoking. Besides, several other studies using both cross-sectional and longitudinal designs have focused on the factors associated with smoking. The factors found by several studies to be associated with smoking are classified on the basis of the concepts of the I-Change Model. Proximal factors will be presented first - attitudes, social influences, self-efficacy, action plans and behavioural intentions - and then attention will be paid to distal factors, such as behavioural, psychological, biological, social and cultural factors.

Many studies have found that intention to smoke was closely related to future smoking behaviour (Godin and Kok, 1996; De Vries et al., 1995; Wakefield et al., 2004). Positive attitudes toward smoking have been found to be associated with an increased likelihood of smoking (Botvin et al., 1992; Eiser et al., 1991; Zhu et al., 1996, Holm et al., 2003; Vitoria et al., 2006). Although some studies have found the beliefs about the negative health effects of smoking to be protective (Prochorov and Alexandrov, 1992; Tuakly et al., 1990), many studies do not support this finding (McNeil et al., 1988; Virgili et al., 1991).

In terms of social influences, it is the perceived behaviour of important others (parents, friend, siblings in particular), which has been studied in a wide range of contexts and in a large number of studies (Conrad et al., 1992; US Department of Health and Human Services, 1994a; Tyas and Pederson, 1998). Studies have found a significantly increased risk of adolescent smoking with increased parental smoking. Parental attitudes toward smoking, specifically their children smoking, were also related to adolescent smoking. There was also a support for the relationship between sibling smoking and increased adolescent smoking. By far, the most consistent finding was the relationship between peer smoking and adolescent smoking, by peer understanding friends, best friends, girlfriends, boyfriends, classmates. In fact, several studies have showed that when controlling for peer influence, the effect of 
parental smoking resulted non-significant (Tyas and Pederson, 1998). It is, however, unclear whether peers' influences only result in smoking or if adolescents who smoke select other smoking peer as friends. Several studies (Engels et al., 1997; Wang et al., 1999; De Vries et al., 2003a; De Vries et al., 2006a) have demonstrated that peer influence in smoking onset may have been overestimated, while parental influences may have been underestimated; consequently the peer selection mechanism may be an additional explanation of smoking onset besides peer pressure. More research, however, is still needed since only relatively young adolescents participated in the studies, and it may be conceivable that peer influences may become increasingly important in older adolescents. Moreover, different studies have showed that besides the smoking behaviour of parents, anti-smoking parenting practices such as parental reactions to smoking, house rules, frequency and content of communication about smoking can play an important influence on children smoking cognition and behaviour (Engels and Willemsen, 2004; Engels et al., 2005; Huver et al., 2007).

Self-efficacy has been found to be associated with smoking, the self-efficacy to refuse cigarettes in certain high-risk situations (e.g. when a friend offers a cigarette) being particularly relevant (Sussman et al., 1987; Conrad et al., 1992; De Vries et al., 1995; Nebot et al., 2004; Kim, 2005).

The action plan factor has proved to be relevant when regarding smoking cessation (Hoving et al., 2006), but researches did not pay much attention to this factor in explaining smoking onset or preventing smoking onset among young people. Since this thesis used an international questionnaire developed for the European Smoking Prevention Framework Approach (ESFA), that did not include this factor either (De Vries et al., 2003b; Kremers et al, 2004a; Holm et al., 2003; Vitoria et al., 2006), in order to facilitate international comparisons, this thesis did not assess this factor in the analysis of factors associated with smoking onset. The international comparison, however, falls beyond the scope of this thesis.

With regard to the distal predisposing factors, the behavioural factors that have consistently been found to be associated with smoking behaviour were the low levels of academic achievement (e.g. Allison, 1992; Jackson et al., 1994, Arillo-Santillan et al., 2002), previous smoking experience (e.g. De Vries et al., 1995) and the use of other substances (Lo et al., 1993; McDermott et al., 1992; Oakley et al., 1992; Vitoria et al., 2006). Other relevant factors are several psychological factors, such as stress (e.g. Bonaguro and Bonaguro, 1987; Byrne et al., 1995) and experiences of low self-esteem (e.g. Young and Werch, 1990; Glendining and Inglis, 1999). With regard to biological factors, smoking initiation and prevalence typically rise with increasing age (e.g Camp et al., 1993; Wang et al., 1994). Several researches have also showed that certain smokers might be predisposed to nicotine addiction through the effects of genetic factors (Walton et al., 2001). At the same time, adolescent smoking has been found to be related to societal and cultural factors, such as low socio-economic family status (Lowry et al., 1996; Scarinci et al., 2002; Soteriades and DiFranza, 2003), low education level of the parents (Soteriades and DiFranza, 2003), more money to spend among adolescents (West et al., 2007), religious involvement and values (Heath et al., 1999) and living in a single parent home (Tucker et al., 2003). Sports sponsorship by tobacco companies (Vaidya et al., 1999), smoking restrictions in home (Proescholdbell et al., 2000), workplace (Farkas et al., 2000) and public places (Chaloupka and Wechsler, 1997), price policy for tobacco products (World Bank, 1999) as well as images of smoking in films (McCool et al., 2001) are also concepts that have been found to be associated with adolescent smoking behaviour. 


\section{Smoking prevention among adolescents}

\section{School-based interventions}

School-based programmes offer an opportunity to prevent the initiation of tobacco use among adolescents, having several advantages (US Department of Health and Human Services, 1994b). In many countries, health education is part of the school curriculum, which facilitates the inclusion of the smoking prevention activities in this curriculum (Murray et al., 1992; Wenter et al., 2002). At the same time, school-based smoking prevention programmes can reach wide audiences and there are opportunities for interpersonal communication, which is important for the fine-tuning of the message. Nevertheless, there are also several limitations. Numerous academic and non-academic demands placed on schools as well as the broad range of different health topics might impede a thorough implementation of all programmes. Besides, the implementation of school-based smoking prevention programmes depends not only on limited time, but also on sometimes insufficiently trained personnel (Murray et al., 1992).

Several studies present different more or less effective school-based smoking prevention programmes that have been developed and implemented worldwide (Bruvold, 1993; Cuijpers, 2002; Lantz et al., 2000, Stead et al., 1996; Thomas and Perera, 2006; Tobler and Straton, 1997). Many smoking prevention programmes have proved positive short-time effects, but the long-term impact of school-based educational interventions is of concern. It appears that the effects tend to dissipate with time, with effects generally persisting in the range of $1-4$ years (US Department of Health and Human Services, 1994a, 2000; Lantz et al., 2000; Thomas and Perera, 2006; Best et al., 1988). However, most programmes cannot but have limited effects when only a limited number of lessons are used (De Vries, 2007). Programme "boosters" or subsequent interventions appear to enhance the staying power of the intervention effects (Dijkstra et al., 1999, Aussems et al., 2002; Lantz et al., 2000), although the most appropriate content of and timing for these booster sessions is not known. Programmes that embrace a "social influences" model tend to be the most effective, especially when enhanced by an extensive community-based health education programme (Vartiainen et al., 1986; Perry et al., 1992; De Vries et al., 2006b; Lantz et al., 2000).

\section{Mass media campaigns}

Mass media strategies have been used for public education regarding a variety of public health issues, including tobacco use prevention and control. Mass media efforts are viewed as particularly appropriate for reaching youth, who are often heavily exposed to and greatly interested in media messages (Lantz et al., 2000). Moreover, media-based health promotion efforts have the potential to reach large segments of the population, especially those who are less educated, and to lower barriers of participation in health-related programmes (Jason, 1998; Macaskill et al., 1992). Mass media campaigns can provide high visibility for the message they want to present and the campaign planners can exercise control over the time of exposure and the selection of the messages that are disseminated. Nevertheless, according to the Surgeon General's report (1994) an obvious limitation of the mass media campaigns is the one-way communication with minimal feedback loop or opportunities for interactions. At the same time, high quality mass media materials are expensive and airtime for campaign messages destined for radio and television is also costly. 
Lantz and colleagues (2000) have concluded in their review that sophisticated mass media campaigns that involve essential elements of social marketing and are theoretically driven may have an effect on the attitudes and behaviours of youth regarding tobacco use, although the impact of such campaigns is challenging to evaluate and has not yet been demonstrated. They also suggest that mass media interventions increase their chance of having an impact if the following conditions are met: (1) the campaign strategies are based on sound social marketing principles; (2) the effort is large and intense enough; (3) target groups are carefully differentiated; (4) messages for specific target groups are based on empirical findings regarding the needs and interests of the group; and (5) the campaign is of sufficient duration.

\section{Community programmes}

The increased understanding of the combined effects of environmental, social, and cultural conditions on tobacco and other substance use has resulted in an emphasis on interventions that include comprehensive, community-based approaches. Such an approach targets multiple systems, institutions, or channels simultaneously, and employs multiple strategies. In general, community interventions have multiple components and involve the use of community resources to influence both individual behaviour and community norms and the practices related to adolescent tobacco use (Lantz et al., 2000).

In trials, community-based approaches are compared with no intervention, with school-based programmes or with mass media campaigns. Despite several methodological problems common to a number of studies about community programmes, such as high dropout rates and inappropriate use of analysis, some evidence for effectiveness was found for certain community programmes, but it is still a limited understanding of whether community interventions are effective and, of equal importance, which of their components are most useful in reducing youth tobacco use (Lantz et al., 2000; Sowden et al., 2003).

An important finding is that the effectiveness of school-based programmes appears to be enhanced when they are included in broad-based community efforts in which parents, mass media and community organizations are involved, and in which the social policy or social environment as well as individual knowledge, attitudes, and behaviours are targeted for change (US Department of Health and Human Services, 1994a, 2000).

\section{Macro-level strategies to limit exposure and access of young people to tobacco products}

Of all consumer products, cigarettes are the most heavily advertised and marketed. There is great concern that tobacco advertising and marketing - including the distribution of promotional products such as clothing, sporting equipment and gear for outdoor activities - is positively associated with youth smoking. Using both theory and the existing empirical evidence, researchers conclude that partial bans have little effect because they afford cigarette companies the opportunity to switch advertising expenditures to other promotional media and methods. In contrast, they find that complete bans could reduce tobacco consumption by approximately $6 \%$, an amount that may seem small but could still have an important public health impact (Lantz et al., 2000).

Different studies on young adult smoking behaviour have found evidence that clean indoor air laws may reduce teenage cigarette consumption (Wasserman et al., 1991; Chaloupka and Wechsler, 1997). The reasons why such laws may be effective in reducing youth smoking may be because they reduce the opportunities available for smoking as well 
as because clean indoor air laws may be a useful vehicle for creating a cultural norm that suggests smoking is socially unacceptable.

Research on the impact of school policies has also found that schools with strict smoking prevention policies had significantly lower smoking rates than schools with less strict policies and less emphasis on smoking prevention (De Vries, 2000; US Department of Health and Human Services, 1994b).

While several studies suggest that the enforcement of youth access laws can lead to reductions in illegal sales to minors, the evidence that this actually translates into reduced tobacco consumption is limited (Forster and Wolfson, 1998). Furthermore, it is clear that in the face of increased enforcement of youth access laws, tobacco remains an alluring and addictive substance of great appeal to youth. What can be said with the evidence at hand is that youth access interventions can lead to a general reduction in illegal sales of cigarettes to minors. Whether this will translate into reduced and sustained reductions in youth tobacco use remains to be seen (Lantz et al., 2000).

Price policies can also have preventive effect. The evidence on the degree to which teenagers are responsive to changes in cigarette prices is mixed, but the general consensus is that higher prices are an effective deterrent to youth smoking. Higher prices discourage initiation among young smokers and encourage cessation among current smokers (US Department of Health and Human Services, 1994a; Lantz et al., 2000). The World Bank considers price increases as the most effective and cost effective deterrent - especially for young people and others with low incomes, who must, of necessity, be highly priceresponsive. It estimates that a price rise of $10 \%$ decreases consumption by about $8 \%$ in low and middle-income countries (World Bank, 1999).

In sum, although the detrimental consequences of smoking became obvious more than 40 years ago, unfortunately it seems that there is still no magic bullet for tobacco control. In order to be effective, smoking prevention has to address target groups at the micro-level (the individual level, i.e. youngsters), at the meso-level (the organizational level i.e. the family and the school) and at the macro-level (the policy level, i.e. those involved in developing and implementing policies at regional and national levels) (De Vries, 1999).

\section{Outline of the project}

\section{Objectives}

In 2003, at the outset of this project, few data were available in Romania regarding healthrelated behaviours of Romanian young people. Moreover, smoking was assumed to be one of the first risk behaviours youngsters would most likely be engaged in; nevertheless, no study had focused on factors associated with smoking behaviour among Romanian young people in order to develop appropriate smoking prevention intervention. The educational activities on smoking prevention had been mainly based on information related to smoking dangers and they had been infrequently used. No theory-driven smoking prevention programmes had been implemented either and no effect evaluation of a smoking prevention programme had been conducted by that time.

Hence, this thesis has the following objectives:

1. To assess the prevalence of health-risk behaviours among Romanian young people

2. To investigate the relationship existing between several health-risk behaviours

3. To assess gender differences with regard to health-related behaviours and their interrelationship 
4. To investigate the factors related to the smoking behaviour of Romanian adolescents

5. To develop and evaluate a smoking prevention programme for Romanian adolescents

\section{Designs}

The I-Plan Model provided the overarching framework for the development of our smoking prevention programme. This thesis focused on the Analysis phase and Behavioural Intervention phase of the model. The I-Change Model provided the theoretical underpinning for the study of the motivational factors related to smoking prevention.

Data presented in this thesis were collect in three phases. Table 1.2 shows the sample, the area and the period when data were collected and the research objectives, which were addressed.

First, a cross-sectional study was conducted between November 2003-February 2004 among Romanian young people from junior high schools (students' age 11 to 15 years), senior high schools (students aged 15 to 19) and universities (19-25 year-old students) of two counties, namely Cluj and Hunedoara, situated in the north-western part of Romania. The study investigated several health-related behaviours as well as their relationship among Romanian young people.

Second, a longitudinal study was carried out in May-June 2004, respectively MayJune 2005 among senior high school students of Cluj-Napoca, a city with approximately 330,000 inhabitants from Cluj county. This study focused on factors cross-sectionally and longitudinally associated with smoking among Romanian adolescents aged 15 to 17 .

Third, a school-based peer-led smoking prevention programme on video was adapted and implemented in Cluj-Napoca in 2006 among 13-14 year-old junior high school students.

The quite high prevalence of smoking among Romanian first-year high school students (aged 15 to 17 years), as it will be presented in the first chapters of this thesis, influenced the decision of implementing a smoking prevention programme among adolescents at younger ages when they are tempted to start smoking, but are not regular smokers yet. Several studies also underlined the importance of implementing smoking prevention programmes among adolescents before they become regular smokers (US Department of Health and Human Services, 1994b, 2000).

The programme used schools as places of intervention, because there are several advantages to the use of these settings for smoking prevention: a wide audience can be reached, health education is part of the curriculum in Romania, there are opportunities for interpersonal communications and lastly, the school setting is optimal for evaluation studies (US Department of Health and Human Services, 1994; Ausems et al., 2002). Nevertheless, a potential limitation of the school-based programmes is that their implementation depends on limited time and untrained personnel (Murray et al., 1992). Consequently, in order to offer the schools a clearly structured and easy-to-apply programme, a Dutch school-based peer-led smoking prevention programme which had shown significant effects (De Vries et al., 1992; 1994) was adapted and implemented. This approach had several advantages. The teachers did not have to spend much time discovering how to use and prepare the lessons, but they just had to attend a short training. Second, by using adolescents, who introduced the lessons on video, the programme was made attractive to students and improved their comprehension. Third, the use of peer-led activities improved the active participation of the students. Finally, 
the evaluation of the programme was facilitated by the fact that all the experimental schools had used the programme in the same way.

Since the use of internet for smoking prevention and health education among young people has been increasing in popularity, this approach was also taken into consideration. Nevertheless, the limited access of Romanian adolescents to computers and internet in schools at that time, as well as the limited budget available for the programme made impossible the implementation of a computer-based smoking prevention programme.

The pre-test for the intervention study was carried out in January-February 2006; the programme implementation took place during March and April, while the follow-up was conducted in October-November 2006.

Table 1.2 Overview of the studies

\begin{tabular}{|c|c|c|c|c|}
\hline $\begin{array}{l}\text { Chap- } \\
\text { ter }\end{array}$ & Objectives & $\begin{array}{l}\text { Period of data } \\
\text { collection }\end{array}$ & Study area & Sample \\
\hline 2 & $\begin{array}{l}\text { To assess the prevalence of } \\
\text { health-risk behaviours among } \\
\text { Romanian young people } \\
\text { To investigate the relationship } \\
\text { existing between several health- } \\
\text { risk behaviours } \\
\text { To assess gender differences with } \\
\text { regard to health-related } \\
\text { behaviours and their } \\
\text { interrelationship }\end{array}$ & $\begin{array}{l}\text { November } 2003- \\
\text { February } 2004\end{array}$ & $\begin{array}{l}\text { The Cluj } \\
\text { and } \\
\text { Hunedoara } \\
\text { counties }\end{array}$ & $\begin{array}{l}1598 \\
\text { junior high } \\
\text { school, } \\
\text { senior high } \\
\text { school and } \\
\text { university } \\
\text { students }\end{array}$ \\
\hline 3 & $\begin{array}{l}\text { To investigate the relationship } \\
\text { between alcohol an tobacco use } \\
\text { To asses the gender differences in } \\
\text { the alcohol and tobacco use } \\
\text { relationship }\end{array}$ & $\begin{array}{l}\text { May-June } 2004 \\
\text { May-June } 2005\end{array}$ & $\begin{array}{l}\text { Cluj- } \\
\text { Napoca } \\
\text { city }\end{array}$ & $\begin{array}{l}416 \text { senior } \\
\text { high } \\
\text { school } \\
\text { students }\end{array}$ \\
\hline 4 & $\begin{array}{l}\text { To investigate the factors related } \\
\text { to smoking behaviour of } \\
\text { Romanian young people }\end{array}$ & $\begin{array}{l}\text { Review of } \\
\text { literature } \\
\text { published } \\
\text { between 1990- } \\
2007\end{array}$ & Romania & $\begin{array}{l}11-24 \\
\text { year-old } \\
\text { Romanian } \\
\text { young } \\
\text { people }\end{array}$ \\
\hline 5 & $\begin{array}{l}\text { To investigate the factors related } \\
\text { to smoking behaviour of } \\
\text { Romanian young people }\end{array}$ & $\begin{array}{l}\text { May-June } 2004 \\
\text { May-June } 2005\end{array}$ & $\begin{array}{l}\text { Cluj- } \\
\text { Napoca } \\
\text { city }\end{array}$ & $\begin{array}{l}416 \text { senior } \\
\text { high } \\
\text { school } \\
\text { students }\end{array}$ \\
\hline 6 & $\begin{array}{l}\text { To develop and evaluate a } \\
\text { smoking prevention programme } \\
\text { for } \\
\text { Romanian adolescents }\end{array}$ & $\begin{array}{l}\text { January-February } \\
2006 \\
\text { October- } \\
\text { November } 2006\end{array}$ & $\begin{array}{l}\text { Cluj- } \\
\text { Napoca } \\
\text { city }\end{array}$ & $\begin{array}{l}1071 \\
\text { junior high } \\
\text { school } \\
\text { students }\end{array}$ \\
\hline
\end{tabular}




\section{Outline of the thesis}

The present thesis consists of two parts. The first part focuses on health-risk behaviours of Romanian young people. Chapter 2 presents the prevalence of health-related behaviours among Romanian young people. It also discusses the cross-sectional relationship existing between several health-risk behaviours and the age and gender differences regarding healthrelated behaviours. Chapter 3 assesses cross-sectional and prospective relations between alcohol and tobacco use among Romanian adolescents, granting special attention to possible gender differences.

The second part of the thesis focuses on smoking prevention. Chapter 4 reviews data regarding smoking prevalence, as well as individual and contextual influences on the smoking behaviour among Romanian young people. Chapter 5 reports on motivational factors associated with smoking behaviour among Romanian adolescents aged 15 to 17 , using both cross-sectional and longitudinal data.

Chapter 6 presents the process and effect evaluation of a peer-led smoking prevention programme on video implemented among 13-14 year-old Romanian adolescents.

Findings of part 1 and 2 of the thesis are summarized in chapter 7, which also addresses limitation of the study designs, recommendations for tobacco control and health education in Romania as well as implications for future research. 
Part 1

\section{Health-risk behaviours}




\section{Chapter 2}

Assessment of health-risk behaviours and their interrelationship among Romanian young people

Manuscript submitted for publication as: Lotrean, L.M., Laza V., Ionut, C., De Vries, H. Assessment of health-risk behaviours and their interrelationship among Romanian young people. 


\begin{abstract}
The first goal of this study was to assess the prevalence of different health-risk behaviours among Romanian young people. Next, the interrelationship between different healthcompromising behaviours, as well as age and gender differences with respect to healthrelated behaviours were examined. Self-administered questionnaires were completed by a sample of 1598 junior high school students, senior high school students and university students from urban and rural areas of two counties of Romania. The results showed that $31 \%$ of junior high school students, $59.7 \%$ of senior high school students and $64.8 \%$ of university students reported more than one risk behaviour. Many of the risk behaviours were likely to correlate with each other and the strongest correlation was found between smoking, alcohol-related behaviour and precocious sexual intercourse. Factor analysis revealed that among junior high school students all health-compromising behaviours loaded on one factor. In senior high school students and university students the risk behaviours split in two factors, based probably on their frequency and severity. Factor 1 comprised smoking, alcoholrelated behaviours as well as precocious sexual intercourse, while factor 2 included less common behaviours: violence, delinquency, illicit drug use. No gender differences were observed regarding the relationship between health-risk behaviours. The results stress the importance of developing prevention programmes for the behaviours discussed. Further research is needed to identify how to best offer these programmes: as stand-alone programmes or as an integrated set of programmes, and whether the same approach has to be taken for younger and older adolescents.
\end{abstract}




\section{Introduction}

The leading causes of mortality and morbidity among young people can be traced to several preventable health-risk behaviours that are often initiated during youth and may extend into adulthood (Brenner and Collins, 1998; Kolip and Schmidt, 1999; Lippe et al., 2007; Hibell et al., 2004). Many of these risk behaviours also contribute substantially to social problems such as family dysfunction, crime and school dropout (Grunbaum et al., 2003). Adolescence is a time of risk taking and experimentation and many studies have found a co-occurrence of several health-risk behaviours among young people from different countries (Basen-Engquist et al., 1996; Brener and Collins, 1998; Bartlett et al., 2005, Mpofu et al., 2006). Several researches also underlined that an early age of onset of health-risk behaviours is associated with an increased likelihood that adolescents will engage in multiple risk behaviours as they progress through adolescence (Jessor, 1991; Brener and Collins, 1998; Durant et al., 1999; Aarons et al., 1999; Paavola et al., 2004). Moreover, different studies showed that the relationship between several health-risk behaviours varied across age groups (Kulbok and Cox, 2002; Guilamo-Ramos et al., 2005).

Few studies described the distribution of health-related behaviours among Romanian young people and generally they restricted their investigations to a narrow range of problem bebaviours such as substance use (Romanian Ministry of Health, 2004; Abraham, 2005; National Center for Chronic Disease Prevention and Health Promotion, 2004a) or sexual behaviour (Lotrean and Laza, 2001; Romanian Ministry of Health, 2005). The results of the European School Survey Project on Alcohol and Other Drugs carried out in Romania in 2003 , showed that $64 \%$ of participating 16 year-old school students reported smoking at least once during their lifetime; an increase of $11 \%$ was noticed, compared with the year 1999. The same study shows that $52 \%$ of 16 year-old school students have experimented alcohol intoxication and 3\% have used cannabis at least once during lifetime; when comparing with 1999, the prevalence of alcohol acute intoxication increased with $20 \%$, while the prevalence of cannabis use doubled (Romanian Ministry of Health, 2004).

Moreover, as far as we know to date, no study has focused on the correlation between different health-risk behaviours among Romanian adolescents. Through a greater understanding of the linkages between health-related behaviours among different groups of young people, we may increase our knowledge of how to develop integrative approaches leading to the adoption of a healthy lifestyle.

Hence, our study has three goals. The first goal is to assess the prevalence of a wide range of health-related behaviours among Romanian young people, starting with substance use and continuing with sexual behaviour, as well as violence and delinquency-related behaviours. The second goal concerns the description of cross-sectional interrelationship between different health-compromising behaviours. The third goal entails the analysis of age and gender differences with respect to health-risk behaviours.

\section{Methods}

\section{Sample}

A cross-sectional study was conducted between November 2003 and February 2004 among 1598 young people, aged 11-25 years, from two counties - Cluj and Hunedoara - situated in the north-western part of Romania. One city was selected from each county (Cluj-Napoca for 
Cluj county and Deva for Hunedoara county) and one rural area (Cuzdrioara, respectively Criscior). In Romania the school system comprises four types of education levels: elementary school (7-11 year-old students), junior high school (age between 11 and 15 years), senior high school (age between 15 and 19 years) and university (students starting from 19 years of age).

In each of the two cities the study was performed in two junior high schools and in two senior high schools, which were randomly chosen. In the rural areas one junior high school and one senior high school were included in the study, since in these areas these were the only existing schools. In each of the selected high schools the study involved students from $1-2$ classes of each grade level.

Consent to participate was obtained from the school administration, the standard procedure in Romania. The principals of the selected schools were contacted personally by one of the members of the research team and were approached regarding the participation in a survey investigating health-related behaviours of young people. All principals agreed to participate.

In Cluj-Napoca the study was also carried out among university students randomly chosen from 8 dorms belonging to the 4 main universities of the town; 40 girls, respectively 40 boys living in the selected dorms were randomly chosen from each university. In Deva, the study involved 40 girls and 40 boys from the main town university, who were randomly chosen and asked to participate in the study during their university activity, because there were no dorms belonging to the university.

\section{Procedure}

All study subjects were asked to fill in an anonymous questionnaire, which took approximately 50 minutes. Study procedures were designed to protect student anonymity and allow for voluntary participation. Among junior and senior high school students the questionnaire was administered and collected in the classroom by members of the research team. Teachers were present in the classroom during the data collection, but they stayed in the front of the class and they did not take part in the questionnaires' collection. No refusals were recorded; non-response was exclusively due to absence during the day of assessment. University students from Cluj-Napoca filled in the questionnaire in the dorm and university students from Deva filled it in at home; the researchers collected them afterwards. The refusal rate was low $(2.7 \%)$ and the students who refused to participate were replaced with students chosen from the same university.

\section{Questionnaire}

The study questionnaire was constructed using previously administered questions drawn from several sources, including the Global Youth Tobacco Survey (The Global Youth Tobacco Survey Collaborative Group, 2002) and the Youth Risk Behavior Surveillance System (YRBSS) (National Center for Chronic Disease Prevention and Health Promotion, 2003). Additional items were specifically developed for this survey. Question content included items related to demographics, as well as a broad range of healthy and unhealthy behaviours, the presence or absence of which may have immediate or long-term effects on the health status of adolescents and young adults.

For this analysis we used 11 marker questions for health-related behaviours. Out of these, 7 assessed substance use among study subjects: smoking during lifetime (0-no, 1-yes), 
and in the last month ( 0 -no, 1-yes), use of alcohol (0-never, 1-less than once per month, 2monthly, but less than once per week, 3-at least one time per week), acute alcohol intoxication during lifetime (0-never, 1-once, 2-two or three times, 3-more than three times) and in the last month (0-no, 1-yes) as well as illicit drug use during lifetime (0-never, 1-once, 2-two or three times, 3-more than three times) and in the last month (0-no, 1-yes). Smoking behaviour was recoded in three categories ( 0 -never smoked, not even one puff, 1 -smoked at least once during lifetime, but not in the last month, 2-smoked in the last month) and aicohol acute intoxication and illicit drug use in five (0-never experimented, 1-experimented once during lifetime, but not in the last month, 2-experimented 2-3 times, but not in the last month, 3-experimented more than three times, but not in the last month, 4-experimented in the last month).

Other 2 questions asked students if they started their sexual life (0-they never had a sexual intercourse, 1-they had at least one sexual intercourse during lifetime) and age of beginning of sexual life; based on this, a new variable was created regarding precocious sexual intercourse (0-no sexual life or beginning of sexual life after 18 years old, 1-first sexual intercourse before the age of 18). The last questions assessed students' involvement in a fight in the last month (0-no, 1-once, 2-more than once) and if they had ever stolen or destroyed other people's things (0-never, 1-once, 2-few times, 3-many times).

The questionnaire for junior high school students did not include questions regarding illicit drug use and sexual behaviour, because many teachers considered them too sensitive for the younger age groups.

\section{Analyses}

The chi-square tests were used in order to evaluate the age and gender differences regarding the prevalence of different health-related behaviours.

In addition to examining single health-related behaviours, multiple risk behaviours were examined. The percentage of students who engaged in multiple risk behaviours was calculated by adding the number of the following risk behaviours reported by each student: (a) smoking at least once during lifetime, (b) experimented acute alcohol intoxication at least once during lifetime, (c) used illicit drugs at least once during lifetime, (d) precocious sexual intercourse, (e) participated in a physical fight in the last month, (f) destroyed or stole somebody's things at least once during lifetime. Senior high school and university students could engage in zero to six risk behaviours, while junior high school students could engage in maximum 4 risk behaviours, because they were not asked any questions about sexual behaviour and illicit drug use. The mean number of multiple risk behaviours was also calculated and independent sample $T$-tests were used to assess the age and gender differences regarding prevalence of multiple risk behaviours among the study subjects.

Bivariate correlations and factor analysis with oblimin rotation were used in order to examine the interrelationships between different health-related behaviours. According to Cohen, strong correlation was considered at $r>0.50$, while medium and small correlation was considered at $r>0.30$, respectively at $r>0.10$ (Cohen, 1994).

Data analysis was performed with SPSS-12 statistics programme. Significant results were reported at $\mathrm{p}<0.05$. 


\section{Results}

\section{Prevalence of health-related behaviours}

The study sample consisted of 630 junior high school students aged 11-15 years (324 boys and 306 girls, 498 from the urban area and 132 from the rural area), 568 senior high school students aged 15-19 years ( 281 boys and 287 girls, 325 from the urban area and 243 from the rural area) and 400 university students, aged 19 to 25 years ( 200 boys and 200 girls).

An overview of health-related behaviours by school enrolment is presented in Table 2.1. Overall, prevalence of lifetime smoking was $52.1 \%$, with fewer junior high school students having tried tobacco smoking than senior high school students, while no significant difference was noticed between senior high school students and university students. Prevalence of tobacco smoking in the last month was $25 \%$ among study subjects and it increased significantly with age.

Experimentation with alcohol intoxication during lifetime as well as use of alcohol at least once per month had quite the same prevalence as lifetime smoking in all three groups and, again, these behaviours were increasing significantly with age. Fewer students reported getting drunk in the last month than reported tobacco smoking in the last month, in all three groups. No difference was noticed between senior high school students and university students regarding alcohol intoxication in the last month.

A percentage of $16.2 \%$ of the study sample declared that they had stolen or destroyed things during lifetime and this behaviour increased with age. Around $20 \%$ of the study subjects reported fighting in the last month and this behaviour was most frequent among junior high school students.

A percentage of $7.4 \%$ of students reported having tried illegal drugs in the past, with more university students reporting illegal drug use vs. senior high school students. One third of senior high school students and university students reported having had sexual relations before the age of 18 , with no statistically significant differences between the two groups.

Table 2.2 presents the gender differences in the prevalence of health-risk behaviours among all three groups of students. It shows that in all the groups substance use, violence and stealing things during lifetime were statistically significant more frequent among boys than girls. The exception was smoking in the last month and lifetime use of drugs, where no gender differences were found among senior high school students. Precocious sexual intercourse was also more frequent among boys than girls both in senior high school students and university students.

\section{Prevalence of multiple risk behaviours}

Prevalence of engaging in multiple risk behaviours is presented in Table 2.3 . Only $45.4 \%$ of junior high school students, $17.7 \%$ of senior high school students and $12.5 \%$ of university students were not engaged in any risk behaviour. The prevalence of multiple risk behaviours increased from $31 \%$ in junior high school students to $59.7 \%$ among senior high school students and $64.8 \%$ in university students. The mean number of risk behaviours was statistically significant $(p<0.01)$ higher among senior high school students than among junior high school students (1.96 vs.1.03), while no significant difference was found between the senior high school and university students (1.96 vs. 2.13).

More girls than boys had no engagement in health-risk behaviours in all three groups (see Table 2.3). The mean number of health-risk behaviours was significantly higher 
( $\mathrm{p}<0.01)$ among boys than girls in junior high school (1.31 vs. 0.75$)$, senior high school (2.41 vs. 1.52), as well as university students (2.61 vs. 1.71 ).

Table 2.1 Health-related behaviours among Romanian young people

\begin{tabular}{|c|c|c|c|c|}
\hline \multirow{2}{*}{ Health-related behaviours } & Total & $\begin{array}{c}\text { Junior high } \\
\text { school }\end{array}$ & $\begin{array}{l}\text { Senior high } \\
\text { school }\end{array}$ & University \\
\hline & $\begin{array}{c}\mathrm{N}=1598^{\circ} \\
\%\end{array}$ & $\begin{array}{c}\mathrm{N}=630^{*} \\
\%\end{array}$ & $\begin{array}{c}\mathrm{N}=568^{* *} \\
\%\end{array}$ & $\begin{array}{c}\mathrm{N}=400^{* \hbar \star} \\
\%\end{array}$ \\
\hline Lifetime smoking & 52.1 & $30.6^{a . b}$ & 64.1 & 68.7 \\
\hline Smoking in the last month & 25.0 & $7.8^{a . b}$ & $32.2^{\mathrm{c}}$ & 42.0 \\
\hline $\begin{array}{l}\text { Use of alcohol at least once per } \\
\text { month }\end{array}$ & 50.4 & $31.3^{a . b}$ & $56.0^{\mathrm{c}}$ & 71.4 \\
\hline $\begin{array}{l}\text { Alcohol intoxication at least once } \\
\text { during lifetime }\end{array}$ & 50.2 & $31.5^{\mathrm{ab}}$ & $56.5^{\mathrm{c}}$ & 69.7 \\
\hline $\begin{array}{l}\text { Alcohol intoxication in the last } \\
\text { month }\end{array}$ & 5.3 & $2.3^{a . b}$ & 6.0 & 8.8 \\
\hline Use of illicit drugs during lifetime & $7.4^{r}$ & NA & $3.7^{\mathrm{c}}$ & 12.7 \\
\hline $\begin{array}{l}\text { Use of illicit drugs in the last } \\
\text { month }\end{array}$ & $0.2^{\vee}$ & NA & 0.2 & 0.3 \\
\hline Precocious sexual intercourse & $36.3^{\top}$ & NA & 38.0 & 33.8 \\
\hline Physical fight in the last month & 19.7 & $28.2^{a . b}$ & $18.0^{c}$ & 8.4 \\
\hline $\begin{array}{l}\text { Stealing or destroying other } \\
\text { people's things during lifetime }\end{array}$ & 16.2 & $12.8^{b}$ & $15.5^{\mathrm{c}}$ & 22.6 \\
\hline \multicolumn{5}{|c|}{$\begin{array}{l}\text { a-statistically significant difference between junior and senior high school students }(\mathrm{p}<0.05) \\
\text { b-statistically significant difference between junior high school students and university } \\
\text { students }(p<0.05 \text { ) } \\
\text { c-statistically significant difference between senior high school students and university } \\
\text { students ( }<<0.05 \text { ) } \\
\text { NA - data are not available } \\
\text { - the number varied between } 1598 \text { and } 1544 \text { due to missing answers to several questions } \\
- \text { the number varied between } 630 \text { and } 602 \text { due to missing answers to several questions } \\
\text {-the number varied between due } 568 \text { and } 561 \text { to missing answers to several questions } \\
- \text { - the number varied between } 400 \text { and } 381 \text { due to missing answers to several questions } \\
\text { the percentages are calculated for university and senior high school students }\end{array}$} \\
\hline
\end{tabular}




\begin{tabular}{|c|c|c|c|c|c|c|}
\hline & \multicolumn{2}{|c|}{ Junior high school } & \multicolumn{2}{|c|}{ Senior high school } & \multicolumn{2}{|c|}{ University } \\
\hline & $\begin{array}{c}\text { Girls } \\
\mathrm{N}=306^{\prime} \\
\%\end{array}$ & $\begin{array}{c}\text { Boys } \\
\text { N=324 } \\
\%\end{array}$ & $\begin{array}{c}\text { Girls } \\
\mathrm{N}=287^{\circ} \\
\%\end{array}$ & $\begin{array}{c}\text { Boys } \\
\mathrm{N}=281^{\circ \bullet} \\
\%\end{array}$ & $\begin{array}{c}\text { Girls } \\
\mathbf{N}=\mathbf{2 0 0 *} \\
\%\end{array}$ & $\begin{array}{c}\text { Boys } \\
\mathrm{N}=200^{* *} \\
\%\end{array}$ \\
\hline Lifetime smoking & $24.5^{\mathrm{d}}$ & 36.4 & $58.9^{d}$ & 69.4 & $63.5^{\mathrm{d}}$ & 74.0 \\
\hline $\begin{array}{l}\text { Smoking in the } \\
\text { last month }\end{array}$ & $4.9^{d}$ & 10.5 & 30.3 & 34.2 & $34.0^{d}$ & 50.0 \\
\hline $\begin{array}{l}\text { Use of alcohol at } \\
\text { least once per } \\
\text { month }\end{array}$ & $26.1^{d}$ & 36.5 & $42.4^{\mathrm{d}}$ & 69.8 & $55.8^{d}$ & 86.9 \\
\hline $\begin{array}{l}\text { Alcohol } \\
\text { intoxication at } \\
\text { least once during } \\
\text { lifetime }\end{array}$ & $25.3^{d}$ & 37.2 & $42.9^{\mathrm{d}}$ & 70.5 & $55.5^{d}$ & 84.0 \\
\hline $\begin{array}{l}\text { Alcohol } \\
\text { intoxication in the } \\
\text { last month }\end{array}$ & $0.3^{\mathrm{d}}$ & 4.2 & $2.4^{\mathrm{d}}$ & 9.6 & $2.0^{d}$ & 15.5 \\
\hline $\begin{array}{l}\text { Use of illicit } \\
\text { drugs during } \\
\text { lifetime }\end{array}$ & NA & NA & 2.4 & 5.0 & $7.6^{d}$ & 18.1 \\
\hline $\begin{array}{l}\text { Use of illicit } \\
\text { drugs in the last } \\
\text { month }\end{array}$ & NA & NA & 0.0 & 0.4 & 0.0 & 0.5 \\
\hline $\begin{array}{l}\text { Precocious sexual } \\
\text { intercourse }\end{array}$ & NA & NA & $28.6^{\mathrm{d}}$ & 47.7 & $18.5^{d}$ & 50.0 \\
\hline $\begin{array}{l}\text { Physical fight in } \\
\text { the last month }\end{array}$ & $17^{\mathrm{d}}$ & 39.1 & $10.2^{\mathrm{d}}$ & 26.3 & $4.5^{d}$ & 12.6 \\
\hline $\begin{array}{l}\text { Stealing or } \\
\text { destroying other } \\
\text { people's things } \\
\text { during lifetime }\end{array}$ & $8.1^{d}$ & 17.4 & $10.2^{d}$ & 21.0 & $21.1^{d}$ & 24.2 \\
\hline
\end{tabular}

d- statistically significant difference between boys and girls $(p<0.05)$

NA - data are not available

- the number varied between 306 and 297 due to missing answers to several questions

- - the number varied between 324 and 301 due to missing answers to several questions

- the number varied between 287 and 283 due to missing answers to several questions

- - the number varied between 281 and 274 due to missing answers to several questions

* - the number varied between 200 and 190 due to missing answers to several questions

** - the number varied between 200 and 182 due to missing answers to several questions 
Table 2.3 Prevalence of multiple risk behaviours

\begin{tabular}{cccc}
\hline $\begin{array}{c}\text { Number of risk } \\
\text { behaviours }\end{array}$ & $\begin{array}{c}\text { Junior high } \\
\text { school } \\
\text { \% }\end{array}$ & $\begin{array}{c}\text { Senior high } \\
\text { school } \\
\text { \% }\end{array}$ & University \\
\hline Total & $\mathbf{N}=\mathbf{5 8 1 ^ { \circ }}$ & $\mathbf{N = 5 5 8 ^ { \circ }}$ & $\mathbf{N}=\mathbf{3 7 5}^{\mathbf{D}}$ \\
0 & 45.4 & 17.7 & 12.5 \\
1 & 23.6 & 22.6 & 22.7 \\
2 & 16.9 & 24.4 & 26.4 \\
3 & 10.3 & 21.3 & 22.9 \\
4 & 3.8 & 10.2 & 9.1 \\
5 & - & 2.7 & 5.1 \\
6 & - & 1.1 & 1.3 \\
\hline Girls & $\mathbf{N}=291^{\circ}$ & $\mathbf{N}=285^{\circ}$ & $\mathbf{N}=198^{\circ}$ \\
0 & 56.7 & 23.8 & 17.2 \\
1 & 22.7 & 28.8 & 30.3 \\
2 & 11.0 & 27.4 & 31.3 \\
3 & 7.2 & 13.0 & 10.6 \\
4 & 2.4 & 4.9 & 6.6 \\
5 & - & 1.8 & 3.5 \\
6 & - & 0.3 & 0.5 \\
\hline Boys & $\mathbf{N}=290^{\circ}$ & $\mathbf{N}=\mathbf{2 7 3 ^ { \circ }}$ & $\mathbf{N}=177^{\circ}$ \\
0 & 34.1 & 11.4 & 7.3 \\
1 & 24.5 & 16.1 & 14.1 \\
2 & 22.8 & 21.2 & 20.9 \\
3 & 13.4 & 30.0 & 36.7 \\
4 & 5.2 & 15.8 & 11.9 \\
5 & - & 3.7 & 6.8 \\
6 & - & 1.8 & 2.3 \\
\hline
\end{tabular}

${ }^{0}$ due to missing answers to several questions, the number of students whose involvement in multiple risk behaviours could be assessed, decreased

\section{Associations between health-compromising behaviours}

Table 2.4 presents the association between the studied health-related behaviours among the students. Among junior high school students all behaviours had low or moderate correlation with each other and the strongest correlation was between smoking, alcohol use and alcohol intoxication.

In senior high school and university students smoking and alcohol-related behaviours as well as precocious sexual intercourse were also moderately correlated. In both groups there was a statistically significant correlation between illicit drug use and smoking, alcohol-related behaviours and precocious sexual intercourse, but the correlation was low, except the moderate correlation illicit drug use - alcohol intoxication.

The other two variables - fighting last month and destroying things - were correlated with each other in both senior high school students and university students. Among senior high school students, both variables were low correlated with all the other behaviours, with the exception that no correlation was found between destroying things at least once during lifetime and precocious beginning of sexual life. Among university students, fighting last month was low correlated with alcohol intoxication, illicit drug use and precocious beginning 
of sexual life. A similar situation was encountered for delinquency-related behaviour, except that no correlation was found with precocious sexual intercourse.

Running bivariate correlations separately for boys and girls within each of the three age groups, showed similar results; no significant gender differences could be observed.

Table 2.4 Bivariate correlations ${ }^{\mathrm{e}}$ between health-related behaviours

\begin{tabular}{|c|c|c|c|c|c|c|}
\hline & Smoking & $\begin{array}{l}\text { Alcohol } \\
\text { use }\end{array}$ & $\begin{array}{c}\text { Alcohol } \\
\text { intoxication }\end{array}$ & $\begin{array}{c}\text { Illicit } \\
\text { drug } \\
\text { use }\end{array}$ & $\begin{array}{l}\text { Precocious } \\
\text { sexual } \\
\text { intercourse }\end{array}$ & $\begin{array}{l}\text { Fighting } \\
\text { last } \\
\text { month }\end{array}$ \\
\hline \multicolumn{7}{|c|}{ Alcohol use } \\
\hline 1 & 0.27 & & & & & \\
\hline 2 & 0.35 & & & & & \\
\hline 3 & 0.36 & & & & & \\
\hline \multicolumn{7}{|c|}{$\begin{array}{l}\text { Alcohol } \\
\text { intoxication }\end{array}$} \\
\hline 1 & 0.37 & 0.40 & & & & \\
\hline 2 & 0.41 & 0.51 & & & & \\
\hline 3 & 0.40 & 0.49 & & & & \\
\hline \multicolumn{7}{|c|}{$\begin{array}{l}\text { Illicit drug } \\
\text { use }\end{array}$} \\
\hline 1 & $\mathrm{NA}$ & NA & NA & & & \\
\hline 2 & 0.18 & 0.15 & 0.27 & & & \\
\hline 3 & 0.22 & 0.23 & 0.36 & & & \\
\hline \multicolumn{7}{|c|}{$\begin{array}{l}\text { Precocious } \\
\text { sexual } \\
\text { intercourse }\end{array}$} \\
\hline 1 & NA & $\mathrm{NA}$ & $\mathrm{NA}$ & NA & & \\
\hline 2 & 0.33 & 0.22 & 0.35 & 0.12 & & \\
\hline 3 & 0.39 & 0.37 & 0.44 & 0.19 & & \\
\hline \multicolumn{7}{|c|}{$\begin{array}{l}\text { Fighting } \\
\text { last month }\end{array}$} \\
\hline 1 & 0.24 & 0.22 & 0.34 & NA & NA & \\
\hline 2 & 0.12 & 0.24 & 0.29 & 0.17 & 0.16 & \\
\hline 3 & NS & NS & 0.24 & 0.23 & 0.12 & \\
\hline \multicolumn{7}{|c|}{$\begin{array}{l}\text { Destroying } \\
\text { things }\end{array}$} \\
\hline 1 & 0.20 & 0.14 & 0.22 & $\mathrm{NA}$ & NA & 0.22 \\
\hline 2 & 0.13 & 0.14 & 0.21 & 0.19 & NS & 0.19 \\
\hline 3 & NS & NS & 0.25 & 0.25 & NS & 0.17 \\
\hline
\end{tabular}

e- All correlations with depicted correlation coefficient are significant: $\mathrm{P}<0.05$

NA - data are not available

NS - non-significant

1 - junior high school

2 - - senior high school

3 - university

A factor analysis with oblimin rotation was used in order to examine the existence of related behaviours. Using eigen values greater than one resulted in one factor solution for 
junior high school students and in two-factor solution for senior high school and university students. The results are presented in Table 2.5 for factor loading 0.40 and greater.

Among junior high school students, the first factor was made of all problem behaviours assessed among them: smoking, alcohol use and alcohol intoxication, fighting last month and destroying things during lifetime. Among both senior high school and university students the first factor comprised smoking, use of alcohol and alcohol intoxication, as well as precocious beginning of sexual life, while in the second factor loaded illicit drug use, fighting last month and destroying other people's things. Alcohol intoxication loaded on both factors, but the loading was greater for factor 1 .

Factor analysis was done separately for boys and girls from each of the three groups and similar results were obtained; no different patterns for boys and girls were found.

Table 2.5 Results of the factor analysis

\begin{tabular}{lccccc}
\hline \multicolumn{1}{c}{ Behaviour } & Junior high school & \multicolumn{2}{c}{ Senior high school } & \multicolumn{2}{c}{ University } \\
\hline & Factor 1 & Factor 1 & Factor 2 & Factor 1 & Factor 2 \\
\cline { 2 - 6 } Smoking & 0.66 & 0.74 & & 0.72 & \\
Alcohol use & 0.64 & 0.70 & & 0.73 & \\
$\begin{array}{l}\text { Alcohol } \\
\text { intoxication }\end{array}$ & 0.76 & 0.75 & 0.48 & 0.74 & 0.50 \\
$\begin{array}{l}\text { Illicit drug } \\
\text { use }\end{array}$ & NA & & 0.64 & & 0.66 \\
$\begin{array}{l}\text { Precocious } \\
\text { sexual }\end{array}$ & NA & 0.67 & & 0.73 & \\
$\begin{array}{l}\text { intercourse } \\
\text { Fighting last }\end{array}$ & 0.62 & & & & \\
month & & & 0.61 & & 0.62 \\
$\begin{array}{l}\text { Destroying } \\
\text { things }\end{array}$ & 0.49 & & 0.73 & & 0.73 \\
\hline
\end{tabular}

NA - data are not available

\section{Discussion}

The results of the study show that many Romanian junior and senior high school, as well as university students engage in behaviours that place them at risk for health and social problems. Consistent with previous studies (Paavola et al., 2004; Ellickson et al., 2001; Lazcano-Ponce et al., 2003; Sutherland and Shepherd, 2001), the likelihood of involvement in risk behaviours, such as substance use, increased with age, while, some risks, particularly violence-related, tended to be replaced rather than compounded over time (Brenner and Collins, 1998; Hibell et al., 2004).

Similar to other researches, many health-risk behaviours have been found to be interrelated rather than being a collection of independent activities (Brenner and Collins, 1998; Potthoff et al., 1998; Fetro et al., 2001; Anteghini et al., 2001; Shrier et al., 1996). Almost one third of the junior high school students and around $60 \%$ of the senior high school, as well as university students were involved in more than one risk behaviour. This shows that engagement in multiple risk behaviours starts in junior high school and increases with age, being already well established in senior high school. 
Furthermore, we found that various health-compromising behaviours correlated. The strongest correlation was between smoking and alcohol-related behaviours in junior high school students and between smoking, alcohol and sex-related behaviours in senior high school and university students. This type of interrelationship is also documented by studies from other countries (Takakura et al., 2001b; Everett et al., 2000; Anteghini et al., 2001; Shrier et al., 1996; Cooper, 2002). There were also correlations between other healthcompromising behaviours (e.g. between illicit drug use and violence and delinquency-related behaviours or between illicit drug use, smoking and alcohol abuse), but weaker.

Factor analysis was used to further examine the relationship among health-related behaviours. Several previous studies showed that a single common factor accounted for the positive correlations among a number of adolescent problem behaviours (Donovan and Jessor, 1985; Jessor, 1991). The results of the factor analysis in our study revealed that for junior high school students, no clear differentiation seemed to exist between healthcompromising behaviours. This may suggest that at this age students involved in one risk behaviour are at greater risk of becoming involved in other health-compromising behaviours as well.

There were also studies that found that health behaviours are multidimensional, but the examined behaviours, as well as the precise number of dimensions involved and their behavioural content varied between studies (Basen-Engquist et al., 1996; Ebin et al., 2001; Takakura et al., 2001a; Kulbok and Cox, 2002; Bartlett et al., 2005). This pattern was found in our study among senior high school students and university students where we identified two factors. Similar to other studies (Ebin et al., 2001) we interpret factor 1 and 2 as distinguishing between common and uncommon engagement in problem behaviours. Factor 1 comprised smoking, use of alcohol and alcohol intoxication as well as precocious sexual intercourse, behaviours, which were most frequently encountered and which are possibly part of the normal experimentation period that often characterizes adolescent behaviour at this age. Factor 2 included less common behaviours among the study subjects (violence, delinquency, illicit drug use), which may have more severe consequences regardless the developmental stage.

Several studies showed that gender differences with regard to health-related behaviours vary within countries and regions (Hibell et al., 2004; Currie, 2004). If, traditionally, young boys were more often engaged in risk behaviours than girls, in some countries the differences dissipated (The Global Youth Tobacco Survey Collaborative Group, 2002; Hibell et al., 2004; Currie, 2004). In Romania, in all three groups, health-risk behaviours were generally more frequent among boys than girls, but no significant gender differences were found with regard to the relationship between health-compromising behaviours.

ilh The :findings in this study have several implications for public health professionals, health!educators and researchers. First, given the age-related changes seen in health behavioutrs, i'iealth promotion intervention for Romanian young people must be sensitive to developmental changes and appropriately timed. Additional research is needed to understand better the appropriate type and timing of interventions as well as the content of messages to address several healthrisk behaviours.

Second, the association between several health-related behaviours among Romanian adolescents raises the question of whether to address the promotion of healthy lifestyles among youth in one overall programme or by dealing with them as separate topics and whether the same approach has to be taken for younger and older adolescents. As other studies suggested (Neumark-Sztainer et al., 1997; Takakura et al., 2001a), the categorization of behaviours into factors could assist in designing and implementing appropriate health promotion interventions among young people, helping to better address the range of healthrelated behaviours among them. Hence, focusing on behaviours, such as illicit drug use, 
without also addressing other related behaviours, such as violence or delinquency, may be less effective than health education programmes that are comprehensive. At the same time, combination of smoking prevention programmes with activities, which prevent alcohol abuse or promote a healthy sexual behaviour, could be also more effective than programmes, which are focused only on one type of behaviour. However, the advantages and disadvantages of more generic programmes are not clear at this time (Wetzels et al., 2003; Flay et al., 2004; Werch et al., 2005). In order to draw any conclusions regarding how these behaviours should best be addressed, intervention studies are necessary, in which different approaches are compared.

Third, similar to other studies (Neumark-Sztainer et al., 1997; Currie, 2004) our results show the importance of identifying high-risk youth and targeting them with comprehensive prevention programmes. Creative ways of reaching high-risk youth need to be considered, both regarding the types of messages offered, and settings for health promotion intervention programmes. Furthermore, this study suggests that prevention efforts aimed at high-risk youth during early adolescence need such a multi-problem focus, because this co-occurrence of problem behaviours is already evident among junior high school students.

Fourth, no important differences with regard to the relationship between healthrelated behaviours were found between boys and girls, suggesting that the content of the comprehensive health promotion programmes needs no gender specific approach.

Fifth, health care providers must also be aware of the interrelationship existing between health-risk behaviours in order to identify, treat and prevent them correctly. Such an approach has been successfully used to identify probable substance use among smoking pregnant adolescent girls (Archie et al., 1997).

This study is subject to limitations. First, due to its cross-sectional nature, the associations reported here should be interpreted with caution and nothing may be assumed about causality or temporal precedence. Second, the conclusions are based on a sample of 1598 young people from both the rural and the urban area of two counties of Romania. Third, this study involved junior and senior high school students as well as university students, but no adolescents who dropped out of school and are probably more likely to engage in health-risk behaviours. Hence, future studies should use national representative samples and must try to include out of school young people as well. Fourth, another common limitation with most studies on this topic is the reliance on adolescents' self-reports. Although some respondents may not report truthfully, the likelihood of honest responses is maximized in this survey by conducting it anonymously.

In spite of these limitations, this current study is probably the first research that assessed the relationship existing between different health-risk behaviours among Romanian youth. It confirms the complexity of Romanian adolescents' health-related behaviours and shows the necessity of future research in this area in order to develop appropriate health promotion interventions. 
42 


\section{Chapter 3}

Gender differences regarding the alcohol-tobacco relationship among Romanian adolescents; a longitudinal study

Manuscript published as: Lotrean, L.M., Kremers, S., Ionut, C., De Vries, H. (2009). Gender differences regarding the alcohol-tobacco relationship among Romanian adolescents; a longitudinal study. European Journal of Public Health, 19, 285-289. 


\begin{abstract}
The objective of this study was to assess cross-sectional and prospective relations between alcohol and tobacco use among Romanian adolescents, giving special attention to possible gender differences. The data were obtained from a two-wave one-year longitudinal study carried out among 403 Romanian high school students aged 15 to 17 (mean age 15.9; SD $=0.3$ ). Questionnaires were used to assess smoking behaviour and alcohol use. Both behaviours were classified into two categories: adolescents using the substance at least once/month; adolescents not using the substance or using it less than monthly. Logistic regression was used to determine which substance was the best predictor of the subsequent use of the other substance. Alcohol and cigarette use were found to be linked reciprocally and this interrelationship differed across genders. Among girls smoking behaviour predicted alcohol use better than the alcohol predicted smoking behaviour. For the boys we found a reversed pattern in which alcohol consumption predicted smoking better than the other way around. It is important for future studies of adolescent substance use to investigate systematically the gender differences in the tobacco-alcohol relationship.
\end{abstract}




\section{Introduction}

Cigarette and alcohol use have important health, social and economic consequences (Hanna et al., 2001; Cooper, 2002; Mayor, 2001; Giancola, 2002). In addition, a combination of excessive alcohol consumption and tobacco use may have synergistic effects on the risk of developing cancer and cardiovascular diseases (Schlecht et al., 1999). Insights into the relationship between alcohol and tobacco use in adolescents will help to inform preventive interventions.

Four general classes of theories have been proposed to account for co-occurring of alcohol and tobacco use: (1) alcohol use causes tobacco use; (2) tobacco use causes alcohol use; (3) alcohol use and tobacco use influence each other reciprocally, and (4) alcohol and tobacco use are a function of common third variables (Jackson et al., 2002).

Several studies, mainly from North America and Western Europe tried to assess the co-occurrence of alcohol and tobacco use among adolescents (Torabi et al., 1993; Sutherland and Willner, 1998; Wetzels et al., 2003; Weitzman and Chen, 2005; Faeh et al., 2006; Mathers et al., 2006). A consistent finding of these studies is that alcohol and tobacco use are linked reciprocally. While some prospective studies suggested that alcohol use predicted cigarette use more strongly than the converse (Kandel and Faust, 1975; Andrews et al., 1991; Ellickson et al., 1992; Jackson et al., 2002) other longitudinal studies identified that cigarette use was particularly important for subsequent involvement in alcohol use (Fleming et al., 1989; Duncan et al., 1998; Lewinsohn et al., 1999; Field et al., 2002; Wetzels et al., 2003).

In laboratory studies, smokers reported more desire to smoke and more enjoyment of their cigarette while drinking than while not drinking (Sayette et al., 2005; King et al., 2005). Recent evidence also suggests that nicotine administration may inspire increased alcohol consumption in men (Perkins et al., 2000; Barrett et al., 2006). Additionally, nicotine administration is associated with increased ethanol consumption in animals (Blomqvist et al., 1996).

Various studies showed international differences in the relationship between alcohol and tobacco use (Dormitzer et al., 2004; Scheer and Unger, 1997; Wetzels et al., 2003). Nevertheless, to the best of our knowledge, to date no longitudinal studies regarding alcoholtobacco relationship have been performed in Eastern Europe.

Several studies focused also on gender differences regarding the above described patterns, but few of them used a prospective design. Some of the studies, which focused on gender differences, concluded that there are no clear differences between boys and girls regarding the relationship between alcohol and tobacco use (Kandel and Faust, 1975), while others suggested that these differences might exist (Weitzman et al., 2005; Wetzels et al., 2003; Hoffman et al., 2001).

The European School Project on alcohol, tobacco and drug use (ESPAD) showed that in $200364 \%$ of participating 16 year-old Romanian school students reported smoking at least once during their lifetime. The prevalence of smoking in the last month was $29 \%$ (Hibell et al., 2004). Both lifetime smoking and smoking in the last month were more frequent among boys $(70 \%$, respectively $32 \%$ ) than girls (59\%, respectively $26 \%$ ). A percentages of $88 \%$ of the students ( $85 \%$ of the girls and $93 \%$ of the boys) used alcohol at least once during lifetime. In total, $55 \%$ o of the students $(64 \%$ of the boys and $48 \%$ of the girls) declared that they drank alcohol at least once in the last month (Hibell et al., 2004).

Another previous cross-sectional study showed that in Romanian tobacco use was strongly associated with alcohol use among Romanian adolescents both among boys and girls (Lotrean et al., 2008), but prospective data are not available. 
The first goal of this study is therefore to assess cross-sectional and prospective relations between alcohol and tobacco use among Romanian adolescents. The second goal is to examine possible gender differences regarding the alcohol-tobacco relationship.

\section{Methods}

\section{Sample and procedure}

Data were gathered in two waves among Romanian students from five senior high schools from Cluj-Napoca, a city with approximately 330,000 inhabitants situated in the northwest Romania. A baseline measurement (T1) was conducted in May/June 2004 among students from 19 first-grade high school classes and a follow-up measurement (T2) was performed 12 months later.

Data were collected at schools, using a self-administered questionnaire. The research team administered the questionnaires. Classroom completion of the questionnaire took approximately 50 minutes. Teachers were present in the classroom during the data collection, but they stayed in the front of the class and they were not involved in the questionnaires' collection in order to assure confidentiality. Consent to participate was obtained from the school administration - the standard procedure in Romania.

Students were asked to participate and read an introductory letter. They were assured that the researchers would treat their questionnaires in confidence and it was explained that they could refuse to participate. Students put their completed questionnaires in an envelope, sealed it and the researchers collected the envelopes. No explicit refusals were recorded. Non-response was exclusively due to absence at the day of assessment; accurate records of the absence rate are lacking from our data.

The study included 473 students at the first measurement and 482 students at the second. A number of 416 students participated in both measurements; out of these $66.5 \%$ were girls. The dropouts $(\mathrm{N}=57)$ did not differ significantly from the rest of the sample regarding gender, smoking or alcohol use behaviour. Due to missing or incomplete data on key variables, 13 cases were excluded. The final study sample used for analyses thus consisted of 403 students ( 137 boys and 266 girls) who participated in both measurements. Students were between 15 and 17 years old and their mean age was $15.9(\mathrm{SD}=0.3)$ years at T1.

\section{Questionnaire}

The questionnaire was based on the version used for OCTOPUS, a European three-country study (Ausems et al., 2002) and for The European Smoking Prevention Framework Approach (ESFA), a collaboration of six European countries (De Vries et al., 2003c).

Adolescent smoking behaviour was assessed by classifying participants in one of two categories. Adolescents were categorized as smokers (smoking at least once a month) or as non-smokers (not smoking or smoking less than once/month). Self-reports were crossvalidated by the responses of the adolescents on questions about current smoking and lifetime smoking. In the case of incongruent answers, the adolescent was allocated the most unfavourable response (De Vries et al., 2003c).

Regarding alcohol use, students were asked to indicate how often they drank alcohol, on a five point scale ranging from never to at least once a week. As with smoking behaviour, adolescents were then classified in two categories: non-users (subjects who do not 
use alcohol or use it less than monthly) and users (subjects who drink alcohol at least once/month).

\section{Analyses}

A logistic regression analysis was used to compare participating subjects and dropouts (those not participating in the second measurement) with data of the first measurement regarding gender, tobacco use and alcohol use as predictors of dropout.

In order to assess the interrelationship between alcohol and tobacco use two types of analyses were performed. Due to possible gender differences, the analyses were performed separately for boys and girls. First, prevalence of alcohol and tobacco use as well as the cooccurrence between the two health-risk behaviours was assessed at baseline and at follow-up. Chi square tests were used to assess the gender differences at both waves. Secondly, logistic regressions analyses were performed to study the prospective relations between alcohol and tobacco use. In the first analysis the dependent variable was initiation of alcohol use at T2 among non-users of alcohol at $\mathrm{Tl}$; the independent variable was tobacco use at the first wave. In the second analysis, the dependent variable was initiation of smoking at $\mathrm{T} 2$ among the non-smokers at $\mathrm{Tl}$; the independent variable was alcohol use at the first wave.

Data analysis was performed with the SPSS-12 statistics programme. Significant results are reported at $\mathrm{p}<0.05$.

\section{Results}

\section{Alcohol and tobacco use}

As can be seen from Table $3.1,22.6 \%$ of the girls and $33.6 \%$ of the boys were smoking at least once a month at T1. At T2 the smoking prevalence increased to $28.9 \%$ among girls and to $42.3 \%$ among boys (see Table 3.2). Prevalence of alcohol use at least once per month increased from $18.8 \%$ to $25.6 \%$ among girls, and from $51.8 \%$ to $64.2 \%$ among boys.

Both smoking and alcohol use were significantly more frequent among male subjects than among female subjects at $\mathrm{Tl}$ ( $\mathrm{p}<0.05$ for smoking and $\mathrm{p}<0.001$ for alcohol use) as well as at T2 ( $<<0.01$ for smoking and $p<0.001$ for alcohol use). The increase in the prevalence of smoking and alcohol use between the two waves was apparent both among girls and boys. At both measurements alcohol use was more prevalent than smoking among boys, while among girls it was the other way around.

Table 3.1 Tobacco and alcohol use among the study sample at T1

\begin{tabular}{lllll}
\hline & $\begin{array}{l}\text { Total } \\
\mathbf{N}=\mathbf{4 0 3}\end{array}$ & $\begin{array}{l}\text { Girls } \\
\mathbf{N}=\mathbf{2 6 6}\end{array}$ & $\begin{array}{l}\text { Boys } \\
\mathbf{N}=137\end{array}$ & Chi $^{2}$ test $^{2}$ \\
\hline None & $59.1 \%$ & $68.0 \%$ & $41.6 \%$ & $\mathrm{p}<0.001$ \\
Only alcohol & $14.6 \%$ & $9.4 \%$ & $24.8 \%$ & $\mathrm{p}<0.001$ \\
Only smoking & $10.9 \%$ & $13.2 \%$ & $6.6 \%$ & $\mathrm{p}<0.05$ \\
Both & $15.4 \%$ & $9.4 \%$ & $27.0 \%$ & $\mathrm{p}<0.001$ \\
\hline
\end{tabular}

a - $\mathrm{Chi}^{2}$ test was performed in order to compare boys and girls 
Table 3.2 Tobacco and alcohol use among the study sample at $\mathrm{T} 2$

\begin{tabular}{lllll}
\hline & $\begin{array}{l}\text { Total } \\
\mathbf{N}=\mathbf{4 0 3}\end{array}$ & $\begin{array}{l}\text { Girls } \\
\mathbf{N}=\mathbf{2 6 6}\end{array}$ & $\begin{array}{l}\text { Boys } \\
\mathbf{N}=\mathbf{1 3 7}\end{array}$ & Chi $^{2}$ test $^{\mathbf{b}}$ \\
\cline { 2 - 5 } None & $50.6 \%$ & $61.7 \%$ & $29.2 \%$ & $\mathrm{p}<0.001$ \\
Only alcohol & $15.9 \%$ & $9.4 \%$ & $28.5 \%$ & $\mathrm{p}<0.001$ \\
Only smoking & $10.9 \%$ & $12.8 \%$ & $7.3 \%$ & $\mathrm{p}<0.1$ \\
Both & $22.6 \%$ & $16.1 \%$ & $35.0 \%$ & $\mathrm{p}<0.001$ \\
\hline
\end{tabular}

$\mathrm{b}-\mathrm{Chi}^{2}$ test was performed in order to compare boys and girls

\section{Co-occurrence of alcohol and tobacco use}

Regarding co-occurrence of alcohol and tobacco use, Table 3.1 also shows that at $\mathrm{T} 1$, both among girls and boys the largest group consisted of those adolescents who had not smoked and had not used alcohol. A higher percentage of girls than boys were not engaged in none of the two health-risk behaviours. Among girls, there were more subjects who have smoked without using alcohol than those who used alcohol without smoking; among boys a reversed pattern was found. A group comprising of $9.4 \%$ of the girls and $27 \%$ of the boys engaged in both behaviours; the occurrence of both behaviours was significantly more frequent among boys than among girls.

At the second measurement, the percentage of youngsters who had not smoked and had not use alcohol decreased from $68 \%$ to $61.7 \%$ among girls and from $41.6 \%$ to $29.2 \%$ among boys (see Table 3.2). Similar with the first measurement, among girls smoking without using alcohol was more frequent than alcohol use without smoking; again for boys a reversed pattern was found. The percentage of girls engaged in both behaviours increased significantly from $\mathrm{T} 1$ to $\mathrm{T} 2(\mathrm{p}<0.05)$, but the largest group was still composed by those who were not involved in none of the two risk behaviours. Among boys, the occurrence of both behaviours also increased at $\mathrm{T} 2$ comparing with $\mathrm{T} 1$; the increase did not reach significance ( $p>0.05$ ), but it led to the fact that at $T 2$ among boys the largest group was consisting of those engaged in both behaviours.

\section{Prediction of alcohol and tobacco use at $\mathbf{T} 2$}

Table 3.3 shows the results of the logistic regression analyses, which assessed the longitudinal relationship between smoking and alcohol use. For the total sample, tobacco use at $\mathrm{T} 1$ predicted the initiation of alcohol use at $\mathrm{T} 2(\mathrm{OR}=3.4)$ and vice versa $(\mathrm{OR}=2.3)$. However the pattern varied across genders. Among girls smoking behaviour at $\mathrm{T} 1$ predicted the initiation of alcohol use at $\mathrm{T} 2$, while alcohol use at $\mathrm{Tl}$ did not predict smoking initiation at T2. Among boys, an opposite effect was found; alcohol use at T1 predicted the onset of smoking at $\mathrm{T} 2$, while smoking at $\mathrm{T} 1$ did not predict the onset of alcohol use at $\mathrm{T} 2$. 
Table 3.3 Prediction of initiation of $\mathrm{T} 2$ tobacco use among non-smokers at $\mathrm{T} 1$ ( $\mathrm{N}=297$; 206 girls and 91 boys) from $\mathrm{T} 1$ alcohol use and initiation of $\mathrm{T} 2$ alcohol use among nonusers of alcohol at $\mathrm{T} 1$ ( $\mathrm{N}=282 ; 216$ girls and 66 boys) from $\mathrm{T} 1$ tobacco use

\begin{tabular}{|c|c|c|c|c|c|}
\hline \multirow{7}{*}{$\begin{array}{l}\text { Tl tobacco use } \\
\text { Tl alcohol use } \\
\text { Tl tobacco use } \\
\text { Tl alcohol use } \\
\text { T1 tobacco use } \\
\text { T1 alcohol use }\end{array}$} & \multirow[b]{3}{*}{ Total } & \multicolumn{2}{|c|}{$\begin{array}{l}\text { Initiation of } \mathrm{T} 2 \\
\text { tobacco use }\end{array}$} & \multicolumn{2}{|c|}{$\begin{array}{c}\text { Initiation of T2 alcohol } \\
\text { use }\end{array}$} \\
\hline & & OR & $95 \% \mathrm{CI}$ & OR & $95 \% \mathrm{Cl}$ \\
\hline & & $2.3^{\mathrm{c}}$ & $1.1-4.7$ & $3.4^{\mathrm{d}}$ & $1.7-6.8$ \\
\hline & Girls & & & $4.9^{d}$ & $2.2-10.8$ \\
\hline & & 1.3 & $0.4-4.3$ & & \\
\hline & Boys & & & 1.9 & $0.4-8.2$ \\
\hline & & $3.5^{\mathrm{c}}$ & $1.1-10.8$ & & \\
\hline
\end{tabular}

\section{Discussion}

The present study shows that among Romanian adolescent aged 15 to 17 alcohol and cigarette use are linked reciprocally. For the whole sample, tobacco use at the first wave predicted the initiation of alcohol use one year later and analogously smoking onset at the second wave was predicted by baseline alcohol use. Our results correspond with those of earlier studies, mainly from North America and Western Europe, which have also demonstrated a strong connection between adolescent cigarette and alcohol use (Dierker et al., 2006; Johnson et al., 2000; Ellickson et al., 1992; Jackson et al., 2002).

Furthermore, the results show that the interrelationship alcohol-tobacco use is subject of gender differences. At both waves, among girls smoking without use of alcohol was more frequent than alcohol use without smoking, while among boys it was the other way around. At the same time, the results of the logistic regression analyses confirm that among Romanian girls smoking predicts alcohol use better than the converse, while for the boys it is the other way around.

A large, prospective, Western European six-country study on the alcohol-tobacco relationship showed that among younger adolescents aged 13 to 14 overall tobacco use predicted subsequent alcohol use better than the converse. However, among Dutch girls, alcohol use predicted subsequent smoking behaviour better than the converse (Wetzels et al., 2003).

The gender differences found among Romanian young people could be the result of cultural differences and different parenting practices. Romanian parents may be permissive with alcohol use with their sons, but not with their daughters. A study performed among Romanian secondary school students (aged 11 to 14 years) also showed that significantly more boys than girls from urban areas $(14.1 \%$ vs $8.8 \%)$ drank alcohol in their houses at a young age (Lotrean et al., unpublished data). More research is needed in Romania to better understand this difference and to tailor public health messages accordingly to boys and girls as well as to their parents.

Our study shows that by the age of 15 almost one third of the girls and half of the boys are engaged in at least one of the two risk behaviours. These figures clearly suggest the 
importance for early preventive interventions concerning smoking and alcohol. Alcohol prevention could contribute also to smoking prevention, especially among boys. At the same time smoking prevention could have benefits for alcohol use prevention, especially among girls. Moreover, as other studies also suggested (Wetzels et al., 2003; Weitzman and Chen 2005; Vitoria et al., 2006) a dual focus in the prevention activities, could have benefits over more single focus efforts. However, the advantages and disadvantages of combined programmes are not clear at this time (Neumark-Sztainer et al., 1997; Wetzels et al., 2003; Flay et al., 2004, Werch et al., 2005). In order to draw any conclusions regarding how prevention of alcohol and tobacco use should best be addressed, intervention studies are necessary in which different approaches are compared.

This study is subject to limitations. First, only first year senior high school students from Cluj-Napoca were included. This is one of the main cities of Romania, but it is inevitably a limit to the generalization of the study findings beyond this sample. Moreover, despite the fact that the schools offered diverse curricula, which should attract both girls and boys, the percentage of girls in each class was generally higher. This meant our sample unexpectedly consisted of more girls. Future research should analyse whether similar patterns are to be found among groups of adolescents with different ages and from different urban and rural areas.

Second, similar with another study (Ritchey et al., 2001), our analyses distinguished alcohol and tobacco users on the basis of monthly use. Some studies have however used other definitions of alcohol and tobacco use, such as weekly use (Ellickson, 1992) or daily use (Fleming, 1989). Several studies suggest that the use of substances on monthly bases is a better indicator of initiation phase, while the use on weekly or daily bases is already an indicator of regular use (Flay et al., 1998; Kremers et al., 2004c). The present study aimed to investigate the relationship between alcohol and tobacco use initiation; hence both behaviours were classified into two categories, that of adolescents who used the substance at least once per month and that of those who did not use the substance or used it less than monthly. Other studies coded alcohol and tobacco users on the bases of never users vs those who used the substance at least once during lifetime (Andrews et al., 1991; Wetzels et al., 2003). However, due to the age of our students and the sample size, our analyses could not be performed based on this definition, because our sample included few students who never used alcohol.

Third, the results of the study are based on adolescents' self-reports on smoking and alcohol use behaviour. Several studies have found high correlations between self-reports and biochemical assessments of adolescent smoking behaviour (Dolcini et al., 1996). Besides, assuring strict confidentiality of responses will expectedly have optimised measuring conditions. Finally, studies should also focus on psychosocial correlates of alcohol and tobacco use in order to better understands the interrelationships among these health-risk behaviours as well as the risk and protective factors for them.

Despite these limitations, this study indicates that alcohol use and smoking are linked reciprocally among Romanian adolescents, which has important implications on future health promotion activities. It suggests that prevention of alcohol use may be more successful if it is linked closely to the prevention of cigarette use, and vice versa.

The differences between boys and girls regarding alcohol-tobacco use interrelationship show that it is important for future studies of adolescent substance use to investigate systematically the role of gender differences. 


\section{Part 2}

Smoking prevention 


\section{Chapter 4}

Tobacco use among Romanian youth

A slightly different version was published as: Lotrean, L.M., Ionut, C., De Vries, H. (2006). Tobacco use among Romanian youth. Salud Publica de Mexico, 48 suppl 1, 107-112. 


\begin{abstract}
This paper reviewed data published between 1990 and 2007, regarding smoking prevalence, as well as individual and contextual influences on the smoking behaviour among Romanian young people aged 11 to 24 years. Highlights included a consideration of multiple levels of influence, from intra-individual factors, such as demographic and cognitive factors, to social influences, such as families and peers, to the more macro, societal/cultural levels of influence, including advertising and tobacco-related policies. The source of data was represented by national and regional reports, legislation, statistics, articles and short information published in scientific journals, conference abstract books and electronic format as well as unpublished data received from Romanian tobacco control experts. Based on these data, recommendations for future actions of smoking preventions and reduction for Romanian youth are taken.
\end{abstract}




\section{Introduction}

It is estimated that each year in Europe tobacco use is responsible for more than 1.2 million deaths, 700000 of which occur in the countries of Central and Eastern Europe (World Health Organization, 2002a). In Romania, smoking is responsible for more than 32,000 deaths annually (Shafey et al., 2003). Particular concern is caused by the increasing trends in smoking prevalence among Romanian young people, which call for comprehensive actions of smoking prevention and reduction among this group (Romanian Ministry of Health, 2004).

The argument for smoking prevention among adolescents is based on the observation that, if smoking does not start during adolescence, it is unlikely to ever occur and on data indicating that the probability of cessation among adults is inversely related to age at initiation. Even infrequent experimental smoking in adolescence significantly increases the risk of adult smoking, as well as the risk of diseases and death (Tyas and Pederson, 1998).

In order to develop a comprehensive strategy regarding smoking prevention and reduction among Romanian youth, it is very important to make a clear diagnosis of the situation, to identify the factors, which led to this situation and the mechanisms, which could help in tobacco control actions. Hence, the objective of this paper is to review data regarding smoking prevalence as well as individual and contextual influences on the smoking behaviour among Romanian young people. Based on these data, weaknesses and strengths of tobacco control targeting young people in Romania will be revealed and recommendations for future actions of smoking preventions and reduction for Romanian youth will be made.

\section{Methods}

A search was conducted for documents published between 1990 and 2007, regarding smoking behaviour among 11-24 year-old Romanian young people. The source of data was represented by national and regional reports, legislation, statistics, articles and short information published in scientific journals, conference abstract books and electronic format as well as unpublished data received from Romanian tobacco control experts. Each document was reviewed to allow the collection of data regarding prevalence of smoking among Romanian young people as well as several levels of influence on their smoking behaviour, from intra-individual factors, such as demographic and cognitive factors, to social influences, such as families and peers, to the more macro, societal/cultural levels of influence, including advertising and tobacco-related policies. In order to assess the prevalence of smoking among Romanian youth only studies based on national representative samples of adolescents were included. With regard to influences on smoking behaviour of Romanian adolescents all documents touching these issues were considered. 


\section{Results}

\section{Smoking prevalence among Romanian young people}

For many years, there were few published data in Romania regarding smoking prevalence among Romanian young people, based on national representative surveys. A study performed among 18-19 year-old school students as part of a national surveillance programme regarding the lifestyle of Romanian school students showed that between 1993 and 1999 , smoking prevalence rose from $9 \%$ to $24 \%$ among girls and from $20 \%$ to $38 \%$ among boys; unfortunately, no clear definition of smoking used by this study is available (Bucur, 1999).

Several studies have recently documented the prevalence of smoking among Romanian young people. According to The National Survey on Tobacco, Alcohol and Drugs, which was part of The European School Survey Project on Alcohol and other Drugs (ESPAD) carried out in 2003, 64\% of 16 year-old Romanian school students reported smoking at least once during their lifetime, being noticed an increase of $11 \%$, compared with the year 1999 (Romanian Ministry of Health, 2004).

Global youth Tobacco Survey (GYTS) carried out for the first time in Romania in the year 2003, showed that $56.7 \%$ of 13-17 year-old school students had ever smoked cigarettes and $23.2 \%$ currently smoked cigarettes (smoked cigarettes at least once in the last month) (National Center for Chronic Disease Prevention and Health Promotion, 2004a). These data are similar with those found in other former communist countries, such as Slovakia, Slovenia, and Hungary (National Center for Chronic Disease Prevention and Health Promotion, 2004b).

A general population-based study from 2003 pointed out that $40.6 \%$ of the Romanian young people aged 14-24 years smoked at least 100 cigarettes during lifetime (Centre for Health Policies and Services, 2004). According to another study from 2004 smoking prevalence among general population aged $15-24$ years was $61.8 \%$ during lifetime and $32.9 \%$ within the past month previous to the survey (Abraham, 2005).

\section{Individual factors which influence smoking behaviour}

\section{Socio-demographics}

Although historically the prevalence of smoking was higher among young men than young women, data from different Western European countries have revealed that the rates of current smoking and initiation to smoking are approximately equal for the two groups (Tyas and Pederson, 1998). This pattern started to be found in some Central and Eastern European countries, such as Hungary and Serbia (National Center for Chronic Disease Prevention and Health Promotion, 2004b). In Romania smoking is still more frequent among boys than girls. Global Youth Tobacco Survey showed that $49.1 \%$ of $13-17$ year-old girls smoked at least once during lifetime and $19.7 \%$ smoked in the past, while smoking prevalence among 13-17 year-old boys was $65.1 \%$ during lifetime, respectively $27.1 \%$ in the past month (National Center for Chronic Disease Prevention and Health Promotion, 2004a). A general populationbased study presented that $29.8 \%$ of 14-24 year-old Romanian girls smoked at least 100 cigarettes during lifetime, while the figure was $50.6 \%$ for the Romanian boys from the same age group (Center for Health Policies and Services, 2004). 
Several studies from other countries showed that smoking behaviour of young people could also vary according to ethnicity, residence (rural/urban) and socio-economical status (Conrad et al., 1992; Tyas and Pederson, 1998). Unfortunately, in Romania there is no available information regarding these issues.

\section{Cognitive factors}

Different cognitive factors have consistently found to be predictors of smoking onset in many studies from North America or Western European countries (Conrad et al., 1992; US Department of Health and Human Services, 1994a; Tyas and Pederson, 1998), but few data are available from Eastern European countries, including Romania.

Similar to their counterparts from other countries, Romanian adolescents often concentrate on the short-term benefits of tobacco use, neglecting its harmful effects (Laza and Lotrean, 2003; Lotrean et al., 2005). One out of three Romanian young people 15-24 years of age believes that smoking less than 10 cigarettes /day can not be dangerous to health (Abraham, 2005). Smoking is mainly a social activity for adolescents and a way of controlling their emotions, such as stress and nervousness (Laza and Lotrean, 2003; Lotrean et al., 2005). Many of them were not taught refusal skills, since the smoking prevention programme in Romania were generally concentrated only on offering information on health effects of smoking (Laza and Lotrean, 2003; Lotrean et al., 2005).

\section{Social influences}

In Romania smoking has a high social acceptance and Romanian young people often see teenagers and adults smoking. The prevalence of daily smoking among general population older than 15 years is $31.3 \%$, while $62.1 \%$ of them smoked at least once during their lifetime (Abraham, 2005).

Parents' and siblings' behaviour and attitudes regarding smoking have been proved to be important factors in influencing smoking behaviour of young people (Engels et al., 1997; Wang et al., 1999; De Vries et al., 2003a, De Vries et al., 2006a). In Romania, almost two thirds of 13-17 year-old school students have at least one smoking parent (National Center for Chronic Disease Prevention and Health Promotion, 2004a). Moreover, 9 out of 10 school students declared that they were exposed to passive smoking in their house in the past week (National Center for Chronic Disease Prevention and Health Promotion, 2004a). This is not surprising, since another Romanian study shows that $54.6 \%$ of smokers aged $14-60$ years smoke at home in the presence of other non-smokers members of their family (Center for Health Policies and Services, 2004).

Many studies from different countries proved that peer influence is an important factor associated with smoking behaviour among teenagers (Tyas and Pederson, 1998; Conrad et al., 1992). Since the prevalence of smoking among youth is high in Romania, many adolescents have friends and classmates who smoke and thus they are probably often confronted with cigarette offers and pressure to smoke from their peers. Actually, a study carried out among 15-17 year-old school students from Cluj-Napoca, a big city of Romania, showed that having friends who smoke was an important factor associated with smoking among Romanian teenagers (Lotrean et al., 2005). 


\section{Societal/cultural influences}

\section{Tobacco advertising and promotion}

After the fall of the communist regime in 1989, all Eastern European countries, including Romania, have suffered the invasion of transnational tobacco companies (TTC), which discovered new important markets in this part of the world.

As Philip Morris documents show (Bates No: 2500120503-0537), their strategy was to work very closely with the high level officials and to impose the policy they wanted (Radu Loghin, 2003):

"PM's strategy has been to work via top-level political contacts in Eastern European markets, notably in the Finance Ministries. PM is also making use of US diplomatic missions in the Eastern Countries to convey our point of view. This effort is being done in coordination with our Washington office, while our monitoring and lobbying capabilities in EE are being beefed up."

One example that shows that this strategy adopted by all TTC is an effective one is the position of the USA ambassador Alfred Moses addressed in 1994 to the audience at the grand opening of a new American cigarette factory near Bucharest, the capital of Romania: "I am sure that Camel and the other splendid products of the RJ Reynolds Tobacco Co. will prosper in Romania."

At the same time, the transnational tobacco companies have started an aggressive campaign of promotion in Romania, including ample advertisement targeted to young people as well as sponsorship of different social and cultural events for youth. Figure 4. la presents a picture from a concert in a club from Bucharest, the capital of Romania, sponsored by the tobacco industry, where one of the singers was a girl from the audience. Selling packages of cigarettes with less than 20 cigarettes (see figure $4.1 \mathrm{~b}$ ), offering objects with a cigarette brand logo as well as cigarette free samples were other tactics used by tobacco companies in Romania in the past 17 years. GYTS showed that $22.2 \%$ of Romanian school students aged 13-17 years had an object with a cigarette brand logo and $11.6 \%$ were offered free cigarettes by a tobacco company representative (National Center for Chronic Disease Prevention and Health Promotion, 2004a).

The tobacco companies have tried all the time to associate the image of smoking with the idea of freedom, success, wellness and a Western value system whose allure has been hard to resist for adolescents during their search for identity. In spite of this, the tobacco companies denied that they promoted their products to young people and even organized socalled smoking prevention programmes. Phillip Morris Romania and British American Tobacco Romania launched in 2000 and 2001 the smoking prevention programme "The decision is mine"(see figure 4.1c). The main message of the programme was that smoking is a decision of adults, provoking in this way the young people, who want to be considered mature, to smoke. The programme had the support of the Ministry of National Education, Ministry of Youth and Sports and the Ministry of Health of that time.

\section{Tobacco control in Romania}

\section{Legislation regarding tobacco advertising}

After political changes from 1989, cigarettes were present practically in all mass media - on TV, radio, outdoor billboards, magazines, etc - with attractive spots, banners and articles. Since 2000 , advertisement was regulated partially, being accepted some forms of indirect advertisement: outdoor, sponsorship for cultural events, advertisement inside journals, magazines and books (The Official Gazette of Romania no. 359, 2000; The Official Gazette 
of Romania no. 534, 2002). Starting with January 2007 the advertisement for tobacco products on outdoor billboards, in mass media or the presence of the logo of the companies on other products than cigarette packages is also prohibited in Romania (The Official Gazette of Romania no. 1067, 2004). As a consequence, the tobacco companies started to advertise their products by sending advertisement messages on mobile phones.

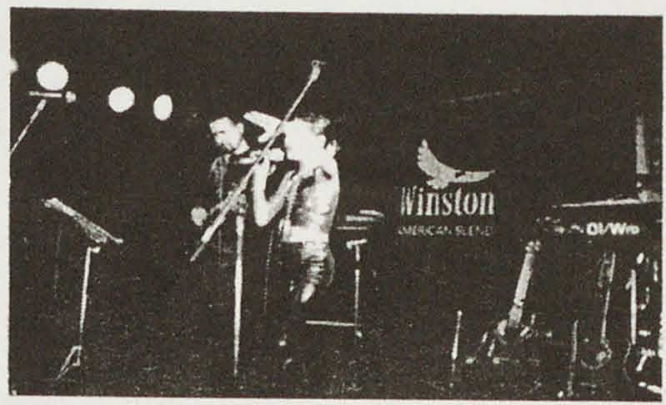

Figure 4.1a A tobacco industry sponsored concert from Bucharest, Romania in 2002

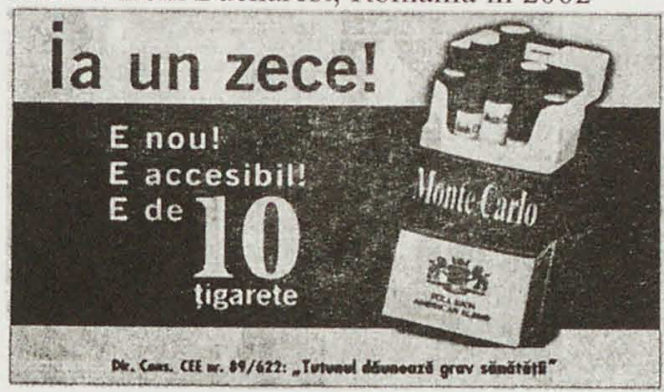

Figure 4.1b An advertisement for a ten cigarettes package with the slogan TAKE A TEN

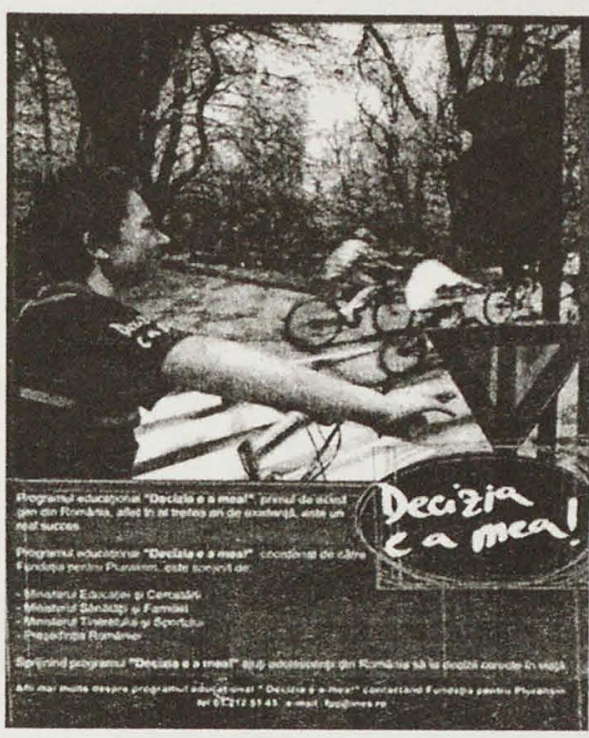

Figure 4.1c. The poster of the educational programme "Decision is mine" developed by tobacco industry in Romania in 2000 and 2001

Figure 4.1 Examples of tobacco industry promotion activities in Romania

\section{Cigarette availability for teenagers}

In Romania there is a complete ban for sale of single or unpacked cigarettes and for selling of tobacco products to minors (below age of 18) (The Official Gazette of Romania no. 165, 1999).

Nevertheless, the law is very poor enforced. GYTS showed that $62.9 \%$ of teenagers who smoked bought cigarettes in a store (National Center for Chronic Disease Prevention and Health Promotion, 2004a). Besides, the price of cigarettes was quite low in the past 17 years in Romania (Radu Loghin, 2003).

\section{Smoke-free areas in public places}

In Romania smoking in public places (except pubs and restaurants), workplaces, health care buildings and public transportation is banned (The Official Gazette of Romania no. 435, 2002), but the law is not very well enforced (Radu Loghin, 2003; Trofor and Radu Loghin, 
2004). GYTS showed that 8 out of 10 Romanian teenagers were exposed to smoke in public places in the past week previous to the survey (National Center for Chronic Disease Prevention and Health Promotion, 2004a).

\section{Tobacco control actions and programmes}

During the past 17 years, education of children, adolescents and young people from Romania regarding tobacco use prevention had and still has weaknesses. Not enough informational and educational programmes were implemented. Often the programmes were implemented just occasionally and for a short period of time, evidencing the lack of long-term strategies as well as the lack of evaluation of the programmes.

On the other hand, health professionals were not offering frequent smoking cessation counselling for their patients, whatever their age. The primary impediment to their accepting responsibility for tobacco control lies in their failure to recognize that their professional responsibility extends beyond the treatment and cure of tobacco-caused diseases and includes the prevention and cessation of tobacco use. This lack of recognition was reinforced by a medical compensation system that did not pay for counselling and smoking cessation services.

In the past few years, different governmental institutions such as the Ministry of Health and the National Agency against Drugs, as well as non-governmental organizations were starting to get more actively involved in tobacco control actions. Several campaigns have been organized, as well as programmes on smoking prevention and cessation, based upon previous similar international campaigns and funded by international, national and local organizations. These have included: World and National No Tobacco Days, campaign of information and education regarding passive smoking, smoking prevention and cessation programmes for teenagers such as Quit and Win, Smoke Free Class Competition, I do not smoke, Adolescent smoking cessation and Protego. Table 4.1 describes the target group and content of these programmes.

As a signatory to the Framework Convention on Tobacco Control since the end of 2005, Romania is in the process of further strengthening its tobacco control legislation and activities.

\section{Discussion}

After the changing of the political regime in 1989, Romania was confronted with an aggressive campaign of promotion developed by the transnational tobacco companies as well as with lack of sustainability in the field of tobacco control. Under these circumstances, it is not surprising that the social acceptance and prevalence of smoking increased among Romanian young people. From this point of view, Romania is a good example of how effective the tobacco industry strategies can be in penetrating a new market, including influencing political factors. A similar situation was encountered in other Eastern European countries (Radu Loghin, 2003; Gilmore and McKee, 2004; Szilágyi and Chapman, 2003).

Hence, a comprehensive tobacco control strategy needs to be adopted and applied in Romania. One focus must be on educational smoking prevention programmes, which should help Romanian young people to develop skills in order to cope with pressure to smoke and with challenging situations. Programmes that motivate and help smoking adolescents to quit smoking must be also implemented for Romanian young people, since many of them are already regular smokers. 
As several studies from different countries showed (Wakefield and Chaloupka, 2000; Lantz et al., 2000) a ban on tobacco advertising and tobacco industry promotional activities, restrictions of smoking in public places, enforcing of smoke-free schools policy, increase of cigarette price could have important benefits in preventing and decreasing smoking among Romanian adolescents. Mass media could be also a useful ally in attempts of promoting a non-smoking culture among Romanian young people. Regular surveys should also be conducted to monitor the situation and the effectiveness of tobacco control programmes, campaigns and actions.

On the way to integration into the European Union, the Romanian legislation has to be harmonised with the European one and at this moment, different governmental as well as non-governmental organizations should actively advocate and help to speed-up the application of the Framework Convention on Tobacco Control in Romania.

Table 4.1 Smoking prevention and reduction programmes for Romanian young people

\begin{tabular}{|c|c|c|c|c|}
\hline $\begin{array}{c}\text { Action / } \\
\text { programme }\end{array}$ & $\begin{array}{c}\text { Year of } \\
\text { implementation }\end{array}$ & Main organizers & $\begin{array}{l}\text { Target } \\
\text { group }\end{array}$ & Activities \\
\hline $\begin{array}{l}\text { World No } \\
\text { Tobacco Day }\end{array}$ & $\begin{array}{l}\text { Annually on } 31 \\
\text { of May }\end{array}$ & $\begin{array}{l}\text { Ministry of Health, } \\
\text { National Agency } \\
\text { against Drugs, Non- } \\
\text { governmental } \\
\text { organizations }\end{array}$ & $\begin{array}{l}\text { General } \\
\text { population }\end{array}$ & $\begin{array}{l}\text { Campaigns of } \\
\text { information and } \\
\text { increasing of } \\
\text { awareness } \\
\text { regarding } \\
\text { dangerous of } \\
\text { smoking }\end{array}$ \\
\hline $\begin{array}{l}\text { National No } \\
\text { Tobacco Day }\end{array}$ & $\begin{array}{l}\text { Annually, on } 18 \\
\text { of November } \\
\text { since } 2002\end{array}$ & $\begin{array}{l}\text { Ministry of Health, } \\
\text { National Agency } \\
\text { against Drugs, Non- } \\
\text { governmental } \\
\text { organizations }\end{array}$ & $\begin{array}{l}\text { General } \\
\text { population }\end{array}$ & $\begin{array}{l}\text { Campaigns of } \\
\text { information and } \\
\text { increasing of } \\
\text { awareness } \\
\text { regarding } \\
\text { dangerous of } \\
\text { smoking }\end{array}$ \\
\hline $\begin{array}{l}\text { Mass media } \\
\text { campaign } \\
\text { regarding } \\
\text { passive } \\
\text { smoking }\end{array}$ & 2004 & $\begin{array}{l}\text { Centre for Health } \\
\text { Policy and Services }\end{array}$ & $\begin{array}{l}\text { General } \\
\text { population }\end{array}$ & $\begin{array}{l}\text { Campaign on } \\
\text { information on } \\
\text { TV and } \\
\text { billboards } \\
\text { regarding } \\
\text { passive smoking }\end{array}$ \\
\hline $\begin{array}{l}\text { Smoke Free } \\
\text { Class } \\
\text { Competition }\end{array}$ & $\begin{array}{l}2005 \\
2006 \\
2007\end{array}$ & $\begin{array}{l}\text { Non-governmental } \\
\text { Organization Pure } \\
\text { Air, Romania; } \\
\text { National Agency } \\
\text { Against Drugs; } \\
\text { Ministry of } \\
\text { Education and } \\
\text { Research }\end{array}$ & $\begin{array}{l}\text { School } \\
\text { teenagers } \\
\text { aged } 11- \\
15 \text { years }\end{array}$ & $\begin{array}{l}\text { A few month } \\
\text { competition, } \\
\text { where the classes } \\
\text { of pupils who did } \\
\text { not smoke during } \\
\text { the competition } \\
\text { and performed } \\
\text { different anti- } \\
\text { smoking activities } \\
\text { could win } \\
\text { different prizes }\end{array}$ \\
\hline
\end{tabular}




\begin{tabular}{|c|c|c|c|c|}
\hline $\begin{array}{c}\text { Action / } \\
\text { programme }\end{array}$ & $\begin{array}{c}\text { Year of } \\
\text { implementation } \\
\end{array}$ & Main organizers & $\begin{array}{l}\text { Target } \\
\text { group }\end{array}$ & Activities \\
\hline $\begin{array}{l}\text { Adolescent } \\
\text { smoking } \\
\text { cessation }\end{array}$ & 2005 & $\begin{array}{l}\text { Non-governmental } \\
\text { Organization Pure } \\
\text { Air, Romania; } \\
\text { National Agency } \\
\text { Against Drugs . } \\
\text { Ministry of } \\
\text { Education and } \\
\text { Research }\end{array}$ & $\begin{array}{l}\text { School } \\
\text { teenagers } \\
\text { aged } 15- \\
19 \text { years }\end{array}$ & $\begin{array}{l}\text { Courses and } \\
\text { group } \\
\text { counselling for } \\
\text { smoking } \\
\text { cessation }\end{array}$ \\
\hline Quit and Win & 2005 & $\begin{array}{l}\text { Non-governmental } \\
\text { Organization Pure } \\
\text { Air, Romania; } \\
\text { National Agency } \\
\text { Against Drugs, } \\
\text { Ministry of } \\
\text { Education and } \\
\text { Research }\end{array}$ & $\begin{array}{l}\text { School } \\
\text { teenagers } \\
\text { aged 15- } \\
19 \text { years }\end{array}$ & $\begin{array}{l}\text { A few months } \\
\text { competition, } \\
\text { where the } \\
\text { teenagers who } \\
\text { remained non- } \\
\text { smokers or } \\
\text { quitted smoking } \\
\text { could win } \\
\text { different prizes }\end{array}$ \\
\hline $\begin{array}{l}\text { I do not } \\
\text { smoke }\end{array}$ & 2006 & $\begin{array}{l}\text { Non-governmental } \\
\text { Organization Pure } \\
\text { Air, Romania; } \\
\text { National Agency } \\
\text { Against Drugs, } \\
\text { University of } \\
\text { Medicine and } \\
\text { Pharmacy from Cluj } \\
\text { Napoca; Ministry of } \\
\text { Education and } \\
\text { Research }\end{array}$ & $\begin{array}{l}\text { School } \\
\text { teenagers } \\
\text { aged 13- } \\
14 \text { years }\end{array}$ & $\begin{array}{l}\text { Peer-led } \\
\text { smoking } \\
\text { prevention } \\
\text { programme on } \\
\text { video }\end{array}$ \\
\hline Protego & 2006 & $\begin{array}{l}\text { National Agency } \\
\text { Against Drugs; } \\
\text { Ministry of } \\
\text { Education and } \\
\text { Research }\end{array}$ & $\begin{array}{l}\text { Teenagers } \\
\text { 'parents } \\
\text { from } \\
\text { several } \\
\text { big towns } \\
\text { of } \\
\text { Romania }\end{array}$ & $\begin{array}{l}\text { Counselling of } \\
\text { parents about } \\
\text { how to talk with } \\
\text { their children } \\
\text { about substance } \\
\text { use and abuse }\end{array}$ \\
\hline $\begin{array}{l}\text { Health } \\
\text { education in } \\
\text { schools }\end{array}$ & Since 2002 & $\begin{array}{l}\text { Ministry of } \\
\text { Education and } \\
\text { Research }\end{array}$ & $\begin{array}{l}\text { School } \\
\text { students } \\
\text { aged } 11- \\
19 \text { years }\end{array}$ & $\begin{array}{l}\text { Lessons of health } \\
\text { education } \\
\text { regarding } \\
\text { different issues, } \\
\text { including } \\
\text { smoking } \\
\end{array}$ \\
\hline
\end{tabular}




\section{Chapter 5}

Predictability of smoking onset among Romanian adolescents

Manuscript submitted as: Lotrean, L.M., Mesters, I., Ionut, C., De Vries, H. Predictability of smoking onset among Romanian adolescents 


\begin{abstract}
The objective of this study was to assess the cognitive and socio-demographic factors associated with smoking onset among Romanian teenagers, using both cross-sectional and longitudinal data. The data were obtained from a two-wave, one-year longitudinal study carried out among 316 senior high school non-smokers from Cluj-Napoca, Romania. Questionnaires assessed smoking behaviour, attitudes, social influence, self-efficacy and intention regarding smoking (motivational variables), as well as different socio-demographic features. The cross-sectional analyses showed that socio-demographics and motivational variables were strongly associated with smoking behaviour; the explained variance was $76 \%$. The longitudinal analyses revealed that four variables explained $33 \%$ of the variance in change of status from non-smoking to regular smoking over a period of one year. Regular smoking onset after one year was predicted by baseline low self-efficacy in refraining from smoking in different situations, having more smoking friends and playing truant from school. Having a brother was a protective factor. The results suggest that smoking prevention programmes in Romania should strengthen self-efficacy beliefs and resistance against peer modelling and help Romanian young people to develop skills and action plans to cope with pressure to smoke and challenging situations.
\end{abstract}




\section{Introduction}

In South-East Europe, smoking is an important public health problem (World Health Organization, 2007). Studies investigating smoking behaviour among adolescents from South-Eastern European countries, such as Romania, are sparse. Research identifying reliable and region-specific predictors of smoking is needed. This information can be used to develop effective, country-specific adolescent smoking prevention programmes.

The European School Project on alcohol, tobacco and drug use (ESPAD) carried out in 30 European countries showed that in $2003,64 \%$ of participating 16 year-old Romanian school students reported smoking at least once during their lifetime. This represented an increase of $11 \%$ from 1999 (Romanian Ministry of Health, 2004). The lifetime smoking prevalence in Romania was close to the ESPAD average (66\%), while the prevalence of smoking in the last month (29\%) was below average (35\%) (Hibell et al., 2004). Another study (the Global Youth Tobacco Survey) showed that in 2003, 23.2\% of 13 to 17 year-old Romanian school students currently smoked cigarettes (smoked at least once in the past month)(National Center for Chronic Disease Prevention and Health Promotion, 2004a). This prevalence was higher than that in other South-Eastern European countries such as Greece (14.3\%), Serbia (16.5\%), Croatia (16.6\%), Bosnia-Herzegovina (13.8\%), but lower than in Bulgaria (37.4\%). It was similar to or even lower when compared with Central-Eastern European countries such as Poland (23.3\%), Slovakia (24.3\%), the Czech Republic (29.5\%) and Hungary $(33.5 \%)$ (National Center for Chronic Disease Prevention and Health Promotion, 2004b). Neither of these studies, however, investigated the behavioural determinants of smoking onset among Romanian adolescents.

The present study aims to identify the socio-demographics and motivational factors that predict smoking onset in Romanian adolescents aged 15 to 17 . Both cross-sectional and longitudinal outcomes are presented. The data will be used for the development of future Romanian smoking prevention programmes.

Current smoking prevention programmes are characterized by the use of comprehensive theories (Bartholomew et al., 1998; Ausems, 2003), such as the Integrated Model of Change (the I-Change Model) (De Vries et al., 2003c). This model as well as its predecessor (Attitude-Social Influences-Self Efficacy Model) has proven to be a useful tool in assessing the determinants of smoking as well as developing and evaluating smoking prevention programmes in several European countries (De Vries et al., 1995; Dijkstra et al., 1999; Holm et al., 2003; De Vries et al., 2003b; De Vries et al., 2006b; Vitoria et al., 2006). Based on these positive European experiences, we adopted the model to guide our Romanian study.

The I-Change Model, like other social-cognitive health behaviour models (Fishbein and Ajzen, 1975; Bandura, 1986; Prochaska and DiClemente, 1983), assumes that an important determinant of behaviour is behavioural intention, which is in turn influenced by three proximal factors: individuals' overall evaluations of the behaviour (attitude), their beliefs about the beliefs and behaviours of significant others (social influence), and the control that they perceive themselves to have over performing a behaviour (self-efficacy). Distal factors such as demographics (e.g. age, gender) and psychological factors (e.g. selfesteem) are assumed to influence behaviour via these proximal factors (De Vries et al., 2003c).

Several previous I-Change studies from different European countries pinpointed the following factors as predictors of smoking onset among adolescents aged 12 to 14: lower perception of the disadvantages of smoking, stronger influences from the social environment 
to smoke, lower self-efficacy to refuse smoking in several situations and lower intention not to smoke in the future (Nebot et al., 2004; Hoving et al., 2007; Ausems, 2003; De Vries et al., 1995). Other international studies also found these variables to be predictors of smoking onset among older adolescents aged 14 to 18 (Chang et al., 2006; Engels et al., 1999; Tucker et al., 2003; Sperber et al., 2001; Forrester et al., 2007).

Our present study has the following objectives. First, we aim to cross-sectionally and prospectively assess the importance of socio-demographic factors as well as attitudinal, social, self-efficacy and intentional beliefs in predicting smoking onset among Romanian adolescents. Based on the assumptions from the I-Change Model and findings from previous studies (Conrad et al., 1992; Tyas and Pederson, 1998; US Department of Health and Human Services, 1994a), we expect that more favourable attitudes to smoking, more social influences in favour of smoking from peers and family, lower self-efficacy beliefs in refraining from smoking in different situations and stronger intention to smoke in the future will predict smoking onset. Second, we compare the outcomes and amount of variance explained when using a cross-sectional compared to a longitudinal design.

\section{Methods}

\section{Sample and procedure}

In spring 2004, five senior high schools from Cluj-Napoca, a city in north-west Romania with approximately 330,000 inhabitants and 39 high schools, were randomly chosen and approached to participate in a survey about adolescent smoking behaviour. Time and financial constraints limited the inclusion of more schools in the study. The principals of the five schools were informed about the survey during individual meetings with the research team; all principals agreed to participate, and all first-year classes from the five schools were involved in the survey. Consent was obtained from the school administration only, in line with standard procedure in Romania.

Data were gathered in two waves. A baseline measurement was conducted in MayJune 2004 ( $\mathrm{Tl}$ ) among students from 19 first-year senior high school classes (aged 15 to 17), and a follow-up measurement was performed 12 months later (T2).

The students were not informed in advance about the date on which the assessment would take place. The research team administered the questionnaires to each class; classroom completion of the questionnaire took approximately 50 minutes.

Students were asked to read an introductory letter. They were assured that the researchers would treat their questionnaires confidentially and that they could refuse to participate by leaving the questionnaire blank. They put their completed questionnaires in an envelope, sealed it, and wrote their names on the envelope and the researchers collected the envelopes. No refusals were recorded; non-participation was exclusively due to absence of students on the day of assessment. The questionnaires were filled in by 473 students at $\mathrm{Tl}$ and 482 students at T2. A total of 416 students participated in both measurements; $66.5 \%$ of these were girls.

: :

\section{Questionnaire}

An existing questionnaire based on the I-Change Model (De Vries et al., 2003c) was translated from the version used for OCTOPUS, a European three-country study (Ausems et al., 2002), and for the European Smoking Prevention Framework Approach (ESFA), a 
collaboration of six European countries (De Vries et al., 2003b). It was designed to be sensitive to changes in smoking levels in primary and high school settings, and has shown satisfactory scale reliability and item homogeneity (Ausems, 2003; De Vries et al., 2003c). It assessed smoking behaviour, motivational factors regarding smoking (attitudes, social influences, self-efficacy expectations, intention) and several socio-demographic items, which are described in more detail below.

In a pilot test, the instrument was given to 30 Romanian first-year senior high school students to evaluate item clarity. The students' comments revealed no lack of clarity in the wording of the items about motivational factors and showed completeness of most relevant items. Adaptations were needed of only a few items on socio-demographic characteristics such as ethnicity, religion, and pocket money spent per month.

Smoking behaviour was assessed by a combination of five questions. First, students were asked to choose a statement that best described their smoking behaviour (e.g. 'I smoke less than weekly'; 'I smoke at least once a week'). The responses were cross-validated using an algorithm of concepts measuring current smoking (smoking in the last month, the last week and the last 24 hours) and lifetime smoking (number of cigarettes smoked during lifetime). The adolescents were then categorised into two groups: regular smokers and nonsmokers. Regular smokers were defined in line with the definition of the Center for Disease Control and Prevention's (CDC) Behavioral Risk Factor Surveillance System (National Center for Disease Control and Prevention, 2002) and other international studies (De Vries et al., 2003c) as smoking at least one cigarette per week or smoking less than weekly, but having smoked more than 100 cigarettes during their lifetime. The remaining respondents were classified as non-smokers, in line with another European study (De Vries et al., 2003c).

Attitudes were measured on a seven-point scale using 12 items. The answer categories ranged from 'I totally disagree $(=-3)$ to 'I totally agree' $(=+3)$. A factor analysis on the attitudes was conducted using oblimin rotation and two scales were created: pros (six items referring to the expected positive outcomes of smoking such as 'It helps to calm my nerves'; Cronbach's $\alpha=.75$ at $\mathrm{T} 1 ; \alpha=.77$ at T2) and cons of smoking (six items referring to the perceived negative outcomes such as 'It's bad for my health'; Cronbach's $\alpha=.62$ at T1; $\alpha=.69$ at $\mathrm{T} 2$ ).

To assess social influences, we measured perceived social norms, perceived social pressure and perceived smoking behaviour. Social norms were measured by a 7-point scale assessing adolescents' perceptions of whether their parents $(\alpha=.64$ at $\mathrm{Tl} ; \alpha=.67$ at T2), siblings (sister and brother; $\alpha=.45$ at $\mathrm{T} 1 ; \alpha=.49$ at T2) and peers (best friend, other friends and people in the same school year; $\alpha=.60$ at $\mathrm{T} 1 ; \alpha=.72$ at $\mathrm{T} 2$ ) thought they should smoke or not (e.g. 'My best friend thinks I definitely should smoke' $(+3)$ to 'should not smoke' $(-$ 3). Social pressure was assessed using items with five answer categories on perceived pressure from parents (mother and father; $\alpha=.82$ at $\mathrm{T} 1 ; \alpha=.78$ at $\mathrm{T} 2$ ), siblings (sister and brother; $\alpha=.40$ at T1; $\alpha=.60$ at T2) and peers (best friend, other friends, people in the same school year; $\alpha=.77$ at $\mathrm{T} 1 ; \alpha=.78$ at $\mathrm{T} 2$ (e.g. 'Have you ever felt pressure from your mother to smoke?' where never $=0$ and very often $=4$ ). For both social norms and social pressure, the three scales regarding parents', siblings' and peers' influences were created based on the results of the factor analysis using oblimin rotation.

Perceived behaviour was measured by asking whether those in their social circles (mother, father, sister(s), brother(s) and best friend) smoked (no $=0$, yes $=1$ ), as well as how many friends and people in the same school year smoked, with five answer possibilities (nobody $=0$; everybody $=4$ ). Because these items are not assumed to be one-dimensional, perceived behaviour was analysed separately for each measured person in the social environment.

Self-efficacy expectations to avoid smoking were measured by 12 items on a 7 point scale. The items measured the adolescents' perception of their ability to refrain from 
smoking when pressured by others (e.g. when with friends who smoke), when under emotional strain (e.g. when feeling upset), or when undertaking daily routines (e.g. when watching TV). Answer categories ranged from 'I'm sure I will smoke $(=-3)$ to 'I'm sure I won't smoke' $(=+3)$. Factor analysis revealed one factor for self-efficacy; consequently one scale was created ( $\alpha=.95$ at $\mathrm{T} 1 ; \alpha=.97$ at T2).

Intention was measured by one question on a 7-point scale, and evaluated adolescents' intention to smoke in the next year $(+3=$ definitely yes; $-3=$ definitely not $)$.

For each motivational concept, we calculated the mean of the scale items.

The assessed demographic variables included: age, gender, religious background, ethnic background and family structure. The literature had indicated that the following risk factors influence smoking behaviour: spending pocket money, school performance, choice of leisure time location, involvement in several health-risk behaviours (Nebot et al., 2004; Hoving et al., 2007; Tyas and Pederson, 1998; Forrester et al., 2007; De Vries et al., 2007). Pocket money spent per month by adolescents was measured using eight response categories ranging from nothing per month to the equivalent of more than $€ 25 /$ month; the response categories were created based on the medium salary of $€ 250 /$ month from Romania in the year 2004 (National Institute of Statistics, 2004). Previous studies showed that smoking was statistically significantly more frequent among Romanian adolescents who spent more than E15 per month than among those who spent less money (Lotrean et al., 2005). Analyses were carried out using a dichotomous variable: spending less than $€ 15 /$ month $(0)$ and at least $€ 15 /$ month (1); the $€ 15$ represents around twice the monthly governmental scholarship received by each Romanian high school student. Perceived school performance in the previous year was assessed as follows: $0=$ in the bottom third of their class, $1=$ in the middle third, $2=$ in the top third. Each student also had to choose three places where they frequently spent their leisure time (home, friends' houses, street, shops, bars/discos/parties, sport clubs, youth clubs, and work) (De Vries et al., 2007). Involvement in other risk behaviours (using alcohol, marijuana and other drugs, gambling, playing truant from school, physically fighting with other people, stealing, destroying things) was measured with eight items on a 5-point scale ranging from never $(=0)$ to at least once a week $(=4)$.

An identification code was used in the data file for each questionnaire for data connection; researchers replaced the names of students before the data were entered.

\section{Analyses}

A logistic regression analysis was used to compare participating and non-participating subjects in the second measurement, with data from the first measurement as predictors of dropout.

The sample consisted of students who participated at both measurements and were non-smokers at $\mathrm{T} 1(\mathrm{~N}=316)$. Due to the limited sample size, the analyses were performed for the whole sample and not for boys and girls separately.

The prevalence of different socio-demographic characteristics and risk behaviours was assessed for the non-smokers at $\mathrm{Tl}$ at baseline and at follow-up; $\mathrm{chi}^{2}$ tests were used to compare the results from the two waves.

Mean scores and standard deviations were calculated for the motivational concepts. Bivariate correlation was used to assess both cross-sectional and longitudinal association between smoking onset at $\mathrm{T} 2$ and motivational factors measured at $\mathrm{T} 2$ and $\mathrm{T} 1$, respectively.

Differences between the new regular smokers $(n=44)$ and those who remained non-smokers $(n=272)$ at $T 2$ were tested using cross-sectional logistic regression analyses. The independent variables as measured at the second wave were entered in four blocks. 
Demographic variables were included in block 1: gender, family structure and pocket money spent per month. Several risk behaviours (school achievement, use of alcohol on a monthly basis, playing truant from school at least once a month, frequently spending free time in bars/discos/parties) were added in block 2 . Attitudes, social influence and self-efficacy items were included in block 3, while intention to smoke in the future was added in block 4. Forward method was used within the first three blocks, and enter method applied in the last block.

To gain deeper insight into the process of transition from non-smoking to smoking between the two waves, multiple logistic regression analyses were also conducted for the longitudinal data, with the aim of assessing the association between smoking onset at $\mathrm{T} 2$ and explanatory variables measured at $\mathrm{T} 1$. The logistic regression analyses used the same procedure as described above.

Data analysis was performed with the SPSS-12 statistics programme. Significant results are reported at $\mathrm{p}<0.05$.

\section{Results}

\section{Characteristics of the sample}

A total of 416 students participated in both measurements. The dropouts $(N=57)$ did not differ significantly from the rest of the sample in terms of. gender, smoking behaviour or other risk behaviours such as alcohol use or frequently spending their free time in bars or discos.

Among the 416 students who participated in both measurements, regular smoking at $\mathrm{T} 1$ was $24 \%(N=100)$. The non-smokers in the first wave $(N=316)$ represented the base for this study. The mean age of the non-smokers was $15.9(\mathrm{SD}=0.3$; range $15-17$ years $)$ at $\mathrm{T} 1$; $69.9 \%$ were female. Table 5.1 presents the socio-demographic characteristics as well as several health-risk behaviours of the non-smokers at $\mathrm{T} 1$. It reveals that all risk behaviours increased from $\mathrm{Tl}$ to $\mathrm{T} 2$. A percentage of $13.9 \%$ of the non-smokers at $\mathrm{T} 1$ became regular smokers at $\mathrm{T} 2(\mathrm{~N}=44)$.

Table 5.2 indicates the mean scores of the motivational concepts measured at both $\mathrm{T} 1$ and $\mathrm{T} 2$.

\section{Cross-sectional correlates of regular smoking}

Table 5.2 shows the cross-sectional bivariate correlations of cognitive variables measured at $\mathrm{T} 2$ with smoking behaviour at the second wave (smoking onset $\mathrm{N}=44$; non-smokers $\mathrm{N}=272$ ). All variables except the perceived behaviour of father and brother were significantly correlated with regular smoking. Low self-efficacy and high intention to smoke in the future correlated most strongly with smoking behaviour.

Table 5.3 presents the results of the cross-sectional regression analyses. Adolescents with lower self-efficacy and stronger intention to smoke in the next year were more likely to smoke. So, too, were those who frequently spent their free time in bars/discos, and who had less strong attitudes against smoking and a higher proportion of smoking friends. The model variables explained $76 \%$ of the variance in smoking behaviour at the second wave. 
Table 5.1 Socio-demographic characteristics and risk behaviours of the sample

\begin{tabular}{|c|c|c|}
\hline Variables & $\begin{array}{c}\mathrm{T1} \\
\% \\
\mathrm{~N}=316\end{array}$ & $\begin{array}{c}\mathrm{T} 2 \\
\% \\
\mathrm{~N}=316\end{array}$ \\
\hline $\begin{array}{l}\text { Family structure } \\
\text { Living with the mother } \\
\text { Living with the father } \\
\text { Living with the brother(s) } \\
\text { Living with the sister(s) }\end{array}$ & $\begin{array}{l}90.5 \\
80.1 \\
33.5 \\
32.1\end{array}$ & $\begin{array}{l}89.9 \\
79.4 \\
34.2 \\
29.4\end{array}$ \\
\hline Spending $\geq 15$ Euros/month & $4.1^{a}$ & 9.3 \\
\hline $\begin{array}{l}\text { Risk behaviours } \\
\text { Playing truant from school at least } \\
\text { once/month } \\
\text { Bad school achievements last year } \\
\text { Using alcohol at least once/month } \\
\text { Spending time in bars/discos/parties }\end{array}$ & $\begin{array}{c}20.1 \\
1.9^{\mathrm{a}} \\
19.9^{\mathrm{a}} \\
16.6^{\mathrm{a}}\end{array}$ & $\begin{array}{c}25.6 \\
5.4 \\
29.8 \\
22.9 \\
\end{array}$ \\
\hline
\end{tabular}

a- Statistically significant difference between $T 1$ and $T 2$ variables at chi ${ }^{2}$ test $(p<0.05)$ 
Table 5.2 Mean scores of cognitive variables/scales at $\mathrm{T} 1$ and $\mathrm{T} 2$ and their bivariate correlations with smoking onset at $\mathrm{T} 2$

\begin{tabular}{|c|c|c|c|c|}
\hline Variables/Scales & $\begin{array}{l}\text { Mean (SD) } \\
\text { of T1 } \\
\text { variables }\end{array}$ & $\begin{array}{l}\text { Mean (SD) } \\
\text { of T2 } \\
\text { variables }\end{array}$ & $\begin{array}{c}\text { Associations } \\
\text { between } \\
\text { smoking onset } \\
\text { at } T 2 \text { and } T 1 \\
\text { variables } \\
\end{array}$ & $\begin{array}{c}\text { Associations } \\
\text { between } \\
\text { smoking onset } \\
\text { at } T 2 \text { and } T 2 \\
\text { variables }\end{array}$ \\
\hline $\begin{array}{l}\text { Pro smoking attitude }(-3 \\
\text { to }+3)^{b}\end{array}$ & $0.37(0.56)$ & $0.36(0.55)$ & NS & 0.31 \\
\hline $\begin{array}{l}\text { Con smoking attitude (-3 } \\
\text { to }+3)^{b}\end{array}$ & $2.02(0.75)$ & $1.81(0.85)$ & -0.25 & -0.45 \\
\hline $\begin{array}{l}\text { Social norms parents }(-3 \\
\text { to }+3)^{c}\end{array}$ & $-2.49(0.81)$ & $-2.42(0.86)$ & 0.20 & 0.27 \\
\hline $\begin{array}{l}\text { Social norms siblings (-3 } \\
\text { to }+3)^{c}\end{array}$ & $-0.99(1.07)$ & $-1.00(1.08)$ & 0.13 & 0.21 \\
\hline $\begin{array}{l}\text { Peer social norms }(-3 \text { to } \\
+3)^{c}\end{array}$ & $-1.32(0.97)$ & $-1.30(1.13)$ & 0.11 & 0.31 \\
\hline Mother smokes ( 0 to 1$)^{d}$ & $0.37(0.48)$ & $0.36(0.48)$ & 0.10 & 0.12 \\
\hline Father smokes $(0 \text { to } 1)^{d}$ & $0.44(0.49)$ & $0.43(0.49)$ & NS & NS \\
\hline Brother smokes ( 0 to 1$)^{d}$ & $0.15(0.35)$ & $0.18(0.39)$ & NS & NS \\
\hline Sister smokes $(0 \text { to } 1)^{d}$ & $0.08(0.27)$ & $0.09(0.29)$ & NS & 0.15 \\
\hline Friends smoke (0 to 4$)^{e}$ & $1.48(1.31)$ & $1.65(1.36)$ & 0.20 & 0.29 \\
\hline $\begin{array}{l}\text { Best friend smoke (0 to } \\
\text { l) }^{d}\end{array}$ & $0.18(0.38)$ & $0.24(0.43)$ & NS & 0.25 \\
\hline $\begin{array}{l}\text { People in the same } \\
\text { school year smoke ( } 0 \text { to } \\
\text { 4) }\end{array}$ & $1.47(1.22)$ & $1.89(1.27)$ & 0.15 & 0.11 \\
\hline Parents pressure $(0 \text { to } 4)^{f}$ & $0.05(0.33)$ & $0.06(0.34)$ & NS & 0.10 \\
\hline Siblings pressure $(0$ to 4$)$ & $0.10(0.38)$ & $0.09(0.37)$ & NS & 0.11 \\
\hline Peer pressure $(0 \text { to } 4)^{f}$ & $0.59(0.66)$ & $0.62(0.67)$ & 0.12 & 0.12 \\
\hline Self-efficacy $(-3 \text { to }+3)^{\mathrm{B}}$ & $2.47(0.77)$ & $2.20(1.17)$ & -0.33 & -0.71 \\
\hline $\begin{array}{l}\text { Intention to smoke in the } \\
\text { next year }(-3 \text { to }+3)^{h}\end{array}$ & $-2.20(1.83)$ & $-1.83(1.65)$ & 0.23 & 0.64 \\
\hline \multicolumn{5}{|c|}{$\begin{array}{l}\mathrm{b}-(-3)=\mathrm{I} \text { totally disagree to }(+3)=\mathrm{I} \text { totally agree } \\
\mathrm{c}-(-3)=\mathrm{I} \text { definitely should not smoke to }(+3)=\mathrm{I} \text { definitely should smoke } \\
\mathrm{d}-0=\text { no; } 1=\text { yes } \\
\mathrm{e}-0=\text { nobody; } 4=\text { everybody } \\
\mathrm{f}-0=\text { never; } 4=\text { very often } \\
\mathrm{g}-(-3)=\mathrm{I} \text { am sure } \mathrm{I} \text { will smoke to }(+3)=\mathrm{I} \text { am sure I won't smoke } \\
\text { h- }(-3)=\mathrm{I} \text { am sure I will not smoke to }(+3)=\mathrm{I} \text { am sure I will smoke } \\
\mathrm{i}-\mathrm{All} \text { correlations with depicted correlation coefficient are significant: } \mathrm{P}<0.05 \\
\text { NS=Non-significant }\end{array}$} \\
\hline
\end{tabular}




\section{Longitudinal predictors of regular smoking onset}

Table 5.2 also presents the results of the longitudinal bivariate correlation analysis. It shows that the variables measured at $\mathrm{T} 1$ associated with smoking onset at $\mathrm{T} 2$ were less distinct attitudes against smoking, lower social nonms against smoking, more perceived behaviour of the mother, friends and colleagues, more perceived peer pressure towards smoking, lower self-efficacy and higher intention to smoke in the next year. The associations of the baseline factors with behaviour one year later were generally lower when longitudinal associations were evaluated than when cross-sectional associations were assessed. Baseline self-efficacy and baseline cons of smoking correlated most strongly with smoking onset one year later.

Table 5.4 shows the results of the longitudinal regression analysis. Sociodemographic and health-risk behaviours predicted $15 \%$ of the variance in regular smoking onset. When the cognitive variables were also included, self-efficacy explained $13 \%$ of the variance of adolescents' smoking behaviour, while the smoking behaviour of their friends added $5 \%$ of explained variance. The inclusion of intention in the model made no significant contribution. The final model shows that the transition to regular smoking over a period of one year was predicted by low self-efficacy in refraining from smoking in different situations, having more smoking friends at first measurement and playing truant from school. Having a brother was a protective factor.

Table 5.3 Results of $\mathrm{T} 2$ independent variables in the cross-sectional logistic regression model for those who remained non-smokers at $\mathrm{T} 2$ and those who became smokers at $\mathrm{T} 2$ $\left(\mathrm{N}=299^{\text {a }}\right)$

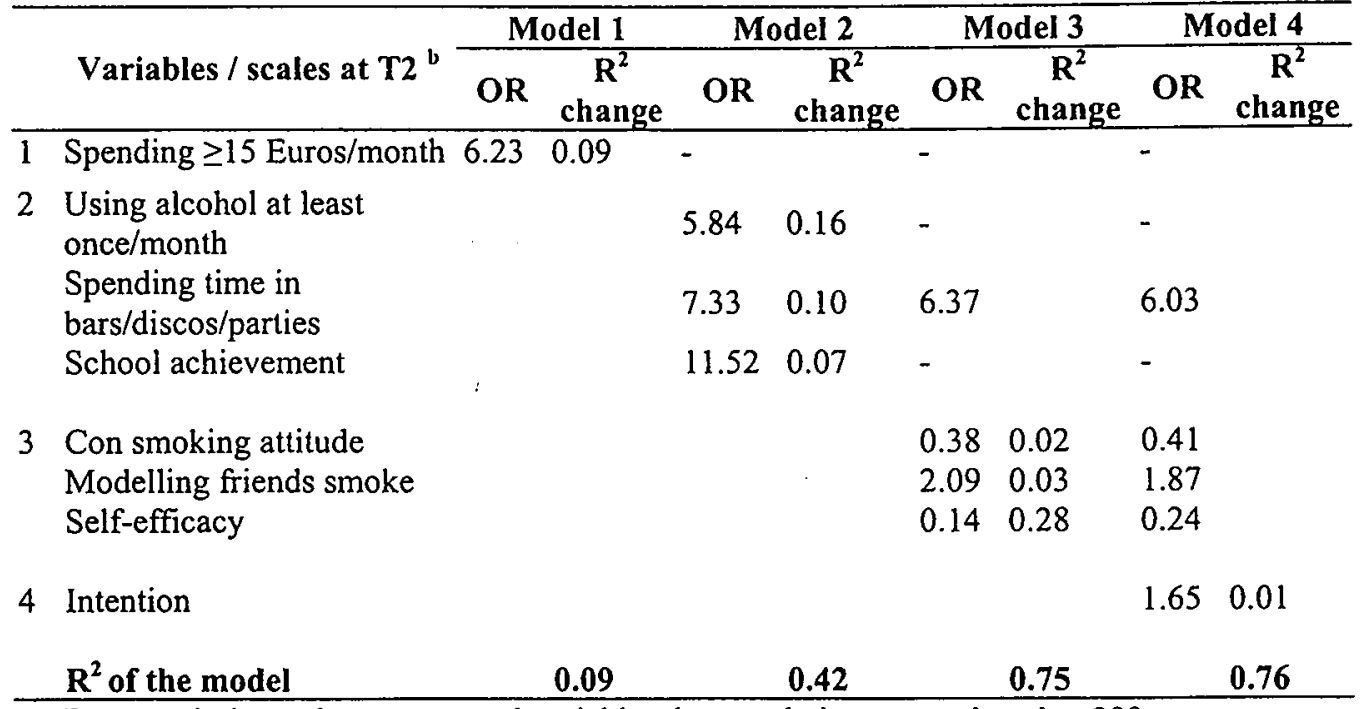

a - Due to missing values on several variables the population was reduced to 299

$\mathrm{b}$ - All variables/scales with depicted $O R$ are significant: $P<0.05$ 
Table 5.4 Results of the $\mathrm{T} 1$ independent variables in the longitudinal logistic regression model for those who remained non-smokers at $\mathrm{T} 2$ and those who became smokers at $\mathrm{T} 2$ $\left(\mathrm{N}=298^{\mathrm{a}}\right)$

\begin{tabular}{llccccccc}
\hline \multirow{2}{*}{ Variables / scales at T1 } & \multicolumn{2}{c}{ Model 1 } & Model 2 & Model 3 & \multicolumn{2}{c}{ Model 4 } \\
\cline { 2 - 8 } & OR & $\begin{array}{c}\mathbf{R}^{2} \\
\text { change }\end{array}$ & OR & $\begin{array}{c}\mathbf{R}^{2} \\
\text { change }\end{array}$ & OR & $\begin{array}{c}\mathbf{R}^{2} \\
\text { change }\end{array}$ & OR $\begin{array}{c}\mathbf{R}^{2} \\
\text { change }\end{array}$ \\
\hline 1 Living with the father & 0.43 & 0.03 & 0.44 & - & - \\
Living with the brother & 0.36 & 0.04 & 0.27 & 0.16 & 0.16
\end{tabular}

2 Spending time in

bars/discos / parties

Playing truant from school

at least once/month

3 Modelling friends smoke

Self-efficacy

\section{$3.00 \quad 0.05$}

$\begin{array}{lll}2.53 & 0.03 & 3.64\end{array}$

3.64

4 Intention

$\mathbf{R}^{2}$ of the model

0.07

0.15

0.33

0.33

$\mathrm{a}$ - Due to missing values on several variables the population was reduced to 298 b- All variables/scales with depicted $O R$ are significant: $P<0.05$

\section{Discussion}

Several findings from this study provide important information on the process of smoking initiation among Romanian adolescents. As in other studies (White et al., 2007), playing truant from school predicted regular smoking onset. This underlines the fact that preventing truancy among Romanian adolescents may also have important benefits on smoking prevention.

Regular smoking onset was also predicted by baseline low self-efficacy expectations to avoid smoking. Other studies also found this to be an important predictor of smoking initiation (Nebot et al., 2004; Chang et al., 2006; De Vries et al., 1995).

As regards social influences, the longitudinal results confirmed the strong influence of smoking friends on adolescents' smoking behaviour. The results of other international studies also showed important influences of friends in explaining smoking uptake (Tyas and Pederson, 1998; Conrad et al., 1992; US Department of Health and Human Services, 1994a).

Having a brother was a protective factor. Other studies have also found some support for family bonding in influencing smoking behaviour (Tyas and Pederson, 1998; Conrad et al., 1992; Van Den Bree et al., 2004). Since no information was recorded on the 
age of the brother or bonding between the siblings, no further interpretation of this finding is possible. Yet, why the study did not find a similar impact of having a sister remains unclear. Although one interpretation may be that brothers may serve as a more important role model or bonding factor, more in-depth research is needed to further explain this result.

The influence of smoking parents on the smoking behaviour of Romanian adolescents aged 15 to 17 was not confirmed by our results. Several studies from other countries also showed that when controlling for peer influence, the effect of parental smoking behaviour has non-significant results (Tyas and Pederson, 1998; US Department of Health and Human Services, 1994a). According to other studies (Piperakis et al., 2008; Engels et al., 1997; Wang et al., 1999; De Vries et al., 2003a; De Vries et al., 2006a) parental smoking can also be a strong predictor of the transition to regular smoking. Our study population had recently transitioned to senior high school; this may have prompted feelings of increasing maturity among the students, which caused them to turn away from parental influence and towards the influence of their friends' smoking behaviour.

Contrary to our hypothesis, attitudes to smoking did not predict smoking initiation after one year. Several studies showed that more positive attitudes toward smoking were associated with an increased likelihood of smoking among adolescents. However, other studies have found that such attitudes did not predict smoking uptake in the presence of other socio-demographic, environmental, and behavioural factors (Tyas and Pederson, 1998). It is conceivable that teenagers alter their attitudes and intention and start smoking over a short period of time, and longitudinal studies with several months between the waves do not capture this process (Engels et al., 1999). As other studies also suggested (Engels et al., 1999; Kremers et al., 2004b), another explanation is, however, that for adolescents at this age smoking related attitudes follow behaviour instead of predicting it; our finding that the cons of smoking were cross-sectionally associated with smoking behaviour may support this.

While some studies found intention to smoke in the future to be an important predictor of smoking onset (Van De Ven et al., 2007; Wakefield et al., 2004), others did not (Milton et al., 2004). In our study, intention did not predict smoking initiation among Romanian adolescents. It is not quite clear why we did not find a predictive role of intention, as one would have expected according to the notions of the Theory of Planned Behaviour (Ajzen, 1991). It is, however, conceivable that intention for Romanian adolescents at this age is quite unstable and, hence, do not predict behaviour but, as with attitudes, follow behaviour.

Several studies have argued that smoking initiation among adolescents is unplanned behaviour (Kremers et al., 2004b). Romanian young people were widely exposed to tobacco product advertisement and promotional activities (Centre for Health Policies and Services, 2004; National Center for Chronic Disease Prevention and Health Promotion, 2004a; Trofor and Loghin, 2004) before 2007, when these activities were banned in Romania (The Official Gazette of Romania, 2004). They also frequently see many adolescents and adults smoking and are exposed to passive smoking in public places or even in the home, as the smoking prevalence in Romania is high and the law prohibiting smoking in public places is poorly enforced (Center for Health Policies and Services, 2004; National Center for Chronic Disease Prevention and Health Promotion, 2004a; Trofor and Loghin, 2004). Under these circumstances, it is not unexpected that some Romanian young people start to feel unable to refrain from smoking in different situations and at certain moments start smoking regularly, even if this was not their intention.

As in other studies (Engels et al., 1999; De Vries et al., 1995) the cross-sectional findings showed that much of the variance in smoking behaviour could be explained by demographic and cognitive variables. Nevertheless, these variables could explain only $33 \%$ of the variance between becoming regular smokers and remaining non-smokers in the longitudinal logistic regression analysis; this may be explained in terms of the long interval 
(one year) between the two waves. The explained variance found by other prospective studies over a period of one year was similar (De Vries et al., 1995; Engels et al., 1999; Pederson and Lefcoe, 1987) and decreased when the interval between the measurements increased (De Vries et al., 1995). Many studies have demonstrated that social cognitive models explained behaviour in cross-sectional studies well, but that the explained variance of these models to predict behaviour might be more limited (Godin and Kok, 1996; Armitage and Conner, 2001). Nevertheiess, even small effect sizes can have theoretical and practical utility (Rosenthal, 1990). Thus, although the explained variance of our longitudinal study implies that much remains unknown about why Romanian youngsters start smoking, it still offers some tools for prevention efforts.

The most important finding of this study is that in a society with high social acceptability of smoking such as Romania, even if intention might not predict smoking onset, self-efficacy beliefs play an important role in smoking initiation. The results imply that smoking prevention programmes should strengthen self-efficacy beliefs and resistance against peer influences and help Romanian young people develop skills as well as action plans to cope with pressure to smoke and with challenging situations; these findings are similar to those from other international studies (Tyas and Pederson, 1998; Conrad et al., 1992; Van Den Bree et al., 2004; Nebot et al., 2004; Chang et al., 2006; De Vries et al., 1995).

This study is subject to certain limitations. First, we included only first-year high school students from Cluj-Napoca. Moreover, despite the fact that the schools offered diverse curricula, which should attract girls and boys, the percentage of girls in each class was generally higher. This meant our sample unexpectedly consisted of more girls. Second, the sample size limited the performing of analyses separately for boys and girls. Future Romanian studies should include a nationally representative sample of adolescents, and analyse subpopulations based on age and gender.

Third, this study adopted a questionnaire developed by other countries. The questionnaire had been tested in several European countries, however, and reliability analyses showed that alpha per each scale created for motivational factors varied between 0.63 and 0.96 (Vitoria et al., 2006; Ausems et al., 2002; De Vries et al., 2003c); similar results were obtained in our study.

Fourth, like other studies (De Vries et al., 2003c; Engels et al., 1999), we classified smoking behaviours in just two categories: non-smokers and regular smokers. The results from another European study have identified five stages of smoking initiation (Kremers et al., 2004a); future Romanian studies should also use more categories. Information on siblings' age and smoking behaviour as well as the bond between siblings could be also useful in further explaining smoking onset.

Fifth, the results are based on adolescents' self-reports of smoking behaviour. Several studies, however, have found high correlations between self-reports and biochemical assessments of adolescent smoking behaviour when confidentiality of responses is assured (Murray and Perry, 1987; Hansen et al., 1985; Dolcini et al., 1996) (as it was in our study).

In short, this study presents similar patterns of smoking onset among Romanian adolescents as other European and intemational studies (Tyas and Pederson, 1998; Conrad et al., 1992; Van Den Bree et al., 2004; Nebot et al., 2004; Chang et al., 2006; De Vries et al., 1995), showing that the smoking prevention programmes to be developed in Romania can benefit from the extensive experience in this field from other countries. 


\section{Chapter 6}

Evaluation of a peer-led smoking prevention programme on video for Romanian adolescents

Manuscript submitted as: Lotrean, L.M., Dijk, F., Mesters, I., Ionut, C., De Vries, H. Evaluation of a peer led smoking prevention programme on video for Romanian adolescents 


\begin{abstract}
The goal of this study was to assess the effects of a peer-led smoking prevention programme on video among Romanian junior high school students aged 13 to 14 . The programme used the social influence approach and concentrated on enhancing self-efficacy and the acquisition of cigarette refusal skills. Twenty schools were randomly assigned to the control and experimental condition, resulting in 55 participating classes from the $7^{\text {th }}$ grade $(28$ in the control group and 27 in the experimental group). Pre-test and 9 months follow-up data on weekly smoking initiation and data on psychosocial variables were collected from 1071 students. Multilevel logistic regression analyses demonstrated a significant effect of the programme on adolescents' smoking behaviour after nine months. At post-test, smoking onset was $4.5 \%$ in the experimental group versus $9.5 \%$ in the control group. Furthermore, significant effects of the programme on smoking-related beliefs were observed. In the experimental group, this resulted in a more negative attitude towards smoking, increased social self-efficacy levels and a more negative intention towards smoking. The findings of the study show that short-term effects of smoking prevention programme can be realized in Romania. More studies are needed to analyse how to maintain these effects over time.
\end{abstract}




\section{Introduction}

Smoking among Romanian young people represents an important public health problem (Centre for Health Policies and Services, 2004; Romanian Ministry of Health, 2004). The Global Youth Tobacco Survey (GYTS) showed that, in 2003, 56.7\% of 13-17 year-old school students had smoked cigarettes at least once during their lifetime and $23.2 \%$ had smoked cigarettes at least once in the past month (National Center for Chronic Disease Prevention and Health Promotion, 2004a). A recent study showed that around two thirds of Romanian adolescents in the first-year of high school (aged 15-17 years) had already experimented with smoking and one quarter of the students were regular smokers (smoke at least once a week) (Lotrean et al., 2005). This implies that prevention activities should start at younger ages, when adolescents are tempted to start smoking, but they are not yet smokers.

During the past 19 years, smoking prevention education programmes for children, adolescents and young adults in Romania contained many weaknesses: 1 . Most programmes were focused only on knowledge transfer regarding the dangers of smoking; 2. Most programmes were implemented irregularly and for a short period of time; 3. Programme evaluations are absent (Lotrean et al., 2006). These findings imply the need for effective smoking prevention programmes for Romanian adolescents.

In many countries, over the last three decades, smoking prevention aimed at youngsters has often been embedded in school settings. There are various advantages to the use of school settings for smoking prevention: they can reach wide audience, health education is part of the curriculum in many countries, there are opportunities for interpersonal communications and lastly, the school setting is optimal for evaluation studies. (US Department of Health and Human Services, 1994; Ausems et al., 2002). Consequently, a school based peer-led smoking prevention programme on video was adapted and implemented in 2006 among Romanian junior high school students aged 13-14 years.

The goal of this programme was the prevention of regular smoking, defined as smoking at least one cigarette a week. Previous research showed that low self-efficacy in refraining from smoking in different social situations and peer influences are important predictors of smoking onset among Romanian adolescents (Lotrean et al., submitted). Hence, the programme focused on the development of social skills to resist social influences that encourage smoking and on the increase of self-efficacy to be able to refuse offers to smoke. Similar approaches have shown promising results in several smoking prevention programmes in Europe (De Vries et al., 1994; Reid et al., 1995; Rooney and Murray, 1996; Josendal et al., 1998; Dijkstra et al., 1999; De Vries et al., 2006b) and worldwide (US Department of Health and Human Services, 2000; Lantz et al., 2000; Tobler et al., 2000), although long-term effects are less often observed (Sowden et al., 2003), but can be realized as well (Vartiainen et al., 1986; Biglan et al., 2000; Perry et al., 1992).

The content of the programme was based on an integration of social cognitive models, the Integrated Model of Change (I-Change Model) (De Vries et al., 2003c) and a Dutch programme that had shown significant effects on smoking prevention (De Vries et al., 1992; 1994). Consequently, the programme addressed attitudes towards smoking and nonsmoking, social norms, social modelling, social support, self-efficacy and intentions towards non-smoking. This programme used peers to explain the content of the programme on video. Moreover, students had peer leaders who came from the same class and chaired the various school-based and out-of-school based activities that the adolescents had to undertake. 
The aim of this study is to present the effect and process evaluation of the programme. First, the effects of the project on adolescents' attitudes, self-efficacy expectations and intentions to smoke will be described. Second, differences at post-test between the experimental and control conditions with respect to smoking behaviour will be outlined. Third, students' opinions regarding the programme, its content and structure will be depicted.

\section{Methods}

\section{Design and sample}

Approval for the implementation of the programme in schools was received from the Romanian Ministry of Education. In the autumn of 2005, schools from Cluj-Napoca, a city with approximately 330,000 inhabitants situated in the northwest Romania, were approached with the help of the Romanian National Agency against Drugs (an authority governmental agency involved in smoking prevention activities) regarding participation in the project.

Twenty-five school principals were informed about the programme during one of their administrative meetings, where the local school inspectorate, which pertains to the Romanian Ministry of Education, convoked their participation. They received information about the content of the programme, its method and the study design implying that participation would involve random allocation to either the experimental or the control group. In Romania, the principals of the schools are entitled to decide whether or not their students would participate in educational programmes.

Twenty out of the twenty-five school principals agreed to participate with their schools in the project and provided the number of the $7^{\text {th }}$ grade classes that could participate. The research team randomly assigned ten schools to the experimental condition and ten to the control condition. The experimental group consisted of $277^{\text {th }}$ grade classes. The control group comprised of $287^{\text {th }}$ grade classes.

Power calculations were run, applying a significance level of 0.05 and power of 0.95 and hypothesizing differences between the probabilities of success in preventing smoking onset in both conditions of $10 \%$. (expected smoking onset of $10 \%$ in the control condition and of $20 \%$ in the experimental condition). Power calculations indicated a recommended sample size of at least $2 \times 348$ non-smokers. Based on the estimation of the regular smoking prevalence among the adolescents aged 13-14 years of $15 \%$ and an estimated dropout rate of $15 \%$, the chosen sample size resulted in the selection of a baseline sample of at least $2 \times 483$ $=966$ students

\section{Procedure}

The pre-test was in January-February 2006, programme implementation took place during March and April and the follow-up was conducted nine months after the pre-test in OctoberNovember 2006.

The research team administered the pre-test and post-test questionnaires. Classroom completion of the questionnaire took approximately 50 minutes. Teachers were present in the classroom during data collection, but they stayed in the front of the class and were not involved in questionnaire collection, in order to assure confidentiality. Consent to participate was obtained from the school principal, which is the standard procedure in Romania. Next, before the administration of the pre-test questionnaires, students were asked to participate 
and read an introductory letter. They were assured that the researchers would treat their questionnaires confidentially and that they could refuse to participate by leaving the questionnaire blank. They put their completed questionnaires in an envelope, sealed it, and wrote their name on the envelope and the researchers collected the envelopes. No refusals were recorded; non-participation was exclusively due to absence of students on the day of assessment.

In May 2006, at the end of the programme, students in the experimental conditions completed a process evaluation questionnaire, which was included in the manual of the programme and was collected by the research team.

\section{Questionnaires}

\section{Outcome measurement for students}

The pre-test and post-test questionnaire was based on previous versions used for OCTOPUS, a European three-country study (Ausems et al., 2002), and for the European Smoking Prevention Framework Approach (ESFA), a collaboration of six European countries (De Vries et al., 2003b).

The primary outcome measured by the questionnaire concerned the students' smoking behaviour, which was assessed by a combination of five questions that were crossvalidated. Adolescents were categorized as non-smokers (never having smoked, having experimented with smoking but had quit experimenting, experimenting with smoking, but not smoking weekly and those who had quit) or as regular smokers (smoking at least once a week). Self-reports were cross-validated by the adolescents' responses to questions about current smoking and lifetime smoking. In the case of incongruent answers, the adolescent was allocated the most unfavourable response. For instance, if an adolescent reported being an experimental smoker on the first question, but indicated having smoked more than 100 cigarettes in his life, the respondent was classified as a regular smoker (National Center for Disease Control and Prevention, 2002; De Vries et al., 2003b; US Department of Health and Human Services, 1994a).

Secondary outcomes in the study were attitudes regarding smoking, social influences, self-efficacy in refraining from smoking in several situations and intention to smoke in the next year. Attitudes were measured on a seven-point scale using 12 items assessing the pros of smoking ( 6 items, $\alpha=0.67$ ) and cons of smoking ( 6 items, $\alpha=0.61$ ). The pros of smoking referred to expected positive outcomes of smoking (e.g. 'It helps to calm my nerves'; 'It will make me feel relaxed'). The cons of smoking refer to negative outcomes of smoking (e.g. 'It is bad for my health', 'It tastes horrible'). Answering categories ranged from 'I totally disagree $(=-3)$ to I totally agree' $(=+3)$. Two scales were created for the attitudes with respect to the pros, respectively cons of smoking using the mean of the scale items.

At the same time, three components of social influence were also assessed with regard to parental influence, siblings' influence and peer influence: perceived social norm, perceived social pressure, and perceived smoking behaviour (social modelling). Social norms were measured by a 7-point scale assessing adolescents' perceptions of whether their parents (father and mother; $\alpha=81$ ), siblings (sister and brother; $\alpha=67$ ) and peers (best friend, friends in general and people in the same school year; $\alpha=.72$ ) think they should smoke or not (e.g.: My best friend thinks I definitely should smoke $(+3)$ to definitely should not smoke (3)). Social pressure was assessed using items with five answering categories on perceived pressure from the same persons: parents (father and mother; $\alpha=.74$ ), siblings (sister and brother; $\alpha=.75$ ) and peers (best friend, friends, people in the same school year; $\alpha=77$ ) (e.g. 
have you ever felt pressure from your mother to smoke?; never $=0$ to very often=4). For each scale of the social influences we calculated the mean of the scale items. Perceived behaviour was measured by asking whether mother, father, sister(s), bother(s) and best friend smoked or not as well as how many friends and people in the same school year smoked, with 5 possibilities of answer ranging from everybody to nobody. Because these behaviours are not assumed to be one-dimensional, this concept was not treated as a scale; perceived behaviour was analysed separately for each measured person in the social environment.

Self-efficacy was measured by 12 questions on a seven-point scale. Four items assessed beliefs with regard to refraining from cigarettes in social situations such as when friends smoke, when friends offer them a cigarette (social self-efficacy; $\alpha=0.93$ ). Other four questions measured the adolescents' perception of their ability to refrain from smoking when under emotional strains (e.g. when they feel upset) (emotional/stress self-efficacy, $\alpha=0.92$ ). The last questions referred to the adolescents' perception of their ability to refrain from smoking in different routine situations, such as when they are shopping, when they are watching TV (situational self-efficacy; $\alpha=0.90$ ). Answering categories ranged from 'I am sure I will smoke' $(=-3)$ to 'I am sure I won't smoke' $(=+3)$. The three scales for selfefficacy were created using the mean of the scale items.

Intention was measured by one question on a seven-point scale and measured adolescents' intention to smoke in the next year $(+3=$ definitely yes; $-3=$ definitely not $)$.

Other questions assessed age, gender, family structure (living with mother, father, brother(s) and sister(s)), alcohol use and playing truancy from school (0-never, 1-sometime, 2-less than once a month, 3-not weekly, but at least once/month, 4-at least once/week), perceived school performance in the previous year ( 0 -in the bottom third of their class, 1 -in the middle third of their class, 2 -in the top third of their class) and pocket money spent/month by students. Previous studies showed that smoking was statistically significant more frequent among Romanian adolescents spending more than $€ 15 /$ month than among those who spent less money (Lotrean et al, 2005). Analyses were carried out using a dichotomous variable: spending less than $€ 15 /$ month (0) and using at least $€ 15 /$ month (1). We furthermore assessed places where adolescents spend more frequently their leisure time (home, friends' houses, street, shops, bars/discos/parties, sport clubs, youth clubs, working place; each student had to choose three places where they spent more frequently their leisure time) (De Vries et al., 2007). In order to be able to conduct multilevel analyses, information regarding the respondents' class and school was also recorded.

\section{Programme evaluation}

Students were asked to evaluate the programme on a five-point scale ( -2 negative evaluation; +2 positive evaluation), using 10 questions to assess overall evaluation, the lessons on videos, watching videos, the home activities, the activities during the lessons, the manual, working in groups, having a peer leader, assistance by the peer leader and assistance by the teacher (De Vries et al, 1992).

\section{Intervention}

The programme consisted of five weekly sessions of forty-five minutes each and was translated from an effective Dutch programme (De Vries, 1989; De Vries et al., 1992; De Vries et al., 1994). This programme used a video-peer-led strategy and was adapted to the Romanian situation and culture by using different cartoons and recording scenes for the 
video that matched the Romanian context of 13-14 year-old adolescents. All items were piloted and revised when needed.

With regard to the attitude, the programme focused on reasons why people do or do not smoke and why people quit smoking, primary short-term effects of smoking and some long-term effects of smoking, passive smoking, addiction and alternatives to smoking. Regarding social influences, the programme discussed differences between direct and indirect pressure to smoke, direct pressure to smoke from peers, indirect pressure to smoke from adults and advertisements. Self-efficacy was incorporated by demonstrating resistance skills to students and by their practice in various challenging situations.

The structure and content of each session, presented by adolescents on video, can be summarized as follows: a. introduction of the theme in a class on video, $b$. activities in small groups, peer-led, c. return to one group and continuation of the lesson on video, d. activities in small groups, peer-led, e. (sometimes) home activities.

The video consisted of an introduction by three adolescents, real life situations played by adolescents, interviews with adolescents and an introduction to the activities by a young person. The activities, focusing on the theme of the lessons, were realized in groups of four or five students and were led by a peer leader. The peer leaders were students from the same class as the students. Teachers could use various methods to form groups and to choose peer leaders. Two weeks before the programme started, the teacher told the class that they would work on a smoking prevention programme for the next weeks and that they would have to work in small groups. Mostly, teachers formed the groups and then the students in the group chose their own peer leader who had to be a non-smoker. If necessary, teachers could select a peer leader, as well. The peer leaders did not present information about the programme, but served as chairmen of the small activity groups. They summarized the activities, stimulated the group to work and presented the outcomes of group work.

The teachers coordinated the lessons, assisted the peer leaders and stimulated the students to participate. Both teachers and peer leaders received one-hour training before the beginning of the programme. For the training of peer leaders and teachers a special training video was developed which explained their task. Students, peer leaders and teachers had their own manuals, summarizing content of the video by cartoons, as well as the activities and instructions for the achievement of the activities.

Each lesson had a different theme. The first lesson gave a general introduction, shortly discussing the consequences of smoking as well as direct and indirect pressure to smoke. The second lesson focused mainly on the effects of active and passive smoking, which were also shown on video. The third lesson discussed peer pressure and the activities were aimed at recognizing and handling direct pressure. Several methods of skills training were modelled on video and were practiced afterwards during activities by role-plays in small groups in order to enhance self-efficacy and the acquisition of refusal skills. The fourth lesson analysed indirect pressure from advertisements and adults. The last lesson provided a summary; the activities centred on skills training and decision making. To increase commitment, students were asked to make a non-smoking contract and to write their name on a non-smoking poster that could be clearly seen in the class. Table 6.1 summarizes the main themes and activities of the programme. 
Table 6.1 Description of the programme

\begin{tabular}{|c|c|c|c|}
\hline Lesson & $\begin{array}{c}\text { Items presented on } \\
\text { video }\end{array}$ & Activities & Home assignment \\
\hline Lesson 1 & $\begin{array}{l}\text { General introduction } \\
\text { Reasons why people } \\
\text { do or do not smoke } \\
\text { General introduction } \\
\text { to direct and indirect } \\
\text { pressure to smoke }\end{array}$ & $\begin{array}{l}\text { Discussing in groups about } \\
\text { reasons of young people for } \\
\text { starting or not starting to } \\
\text { smoke as well as about } \\
\text { pressure to smoke and ways } \\
\text { of refusing a cigarette }\end{array}$ & $\begin{array}{l}\text { Questionnaire to } \\
\text { assess smoking } \\
\text { related attitudes and } \\
\text { behaviours of one or } \\
\text { more family members } \\
\text { (preferably parents) }\end{array}$ \\
\hline Lesson 2 & $\begin{array}{l}\text { Short-term and long- } \\
\text { term effects of } \\
\text { smoking } \\
\text { Dangers of } \\
\text { experimentation with } \\
\text { smoking }\end{array}$ & $\begin{array}{l}\text { Discussions in groups about } \\
\text { the effects of active and } \\
\text { passive smoking } \\
\text { Discussions about how to } \\
\text { react when bothered by } \\
\text { smoking }\end{array}$ & $\begin{array}{l}\text { Questionnaire to } \\
\text { assess family } \\
\text { members' opinions } \\
\text { regarding the effects } \\
\text { of smoking on health }\end{array}$ \\
\hline & $\begin{array}{l}\text { Passive smoking } \\
\text { Addiction }\end{array}$ & $\begin{array}{l}\text { Discussion of home } \\
\text { assignment from lesson } 1\end{array}$ & \\
\hline Lesson 3 & $\begin{array}{l}\text { Peer pressure and } \\
\text { acquiring skills to } \\
\text { resist it }\end{array}$ & $\begin{array}{l}\text { Role-play in small groups in } \\
\text { order to enhance self- } \\
\text { efficacy and the acquisition } \\
\text { of cigarette refusal skills }\end{array}$ & \\
\hline Lesson 4 & $\begin{array}{l}\text { Indirect pressure from } \\
\text { advertisements and } \\
\text { adults }\end{array}$ & $\begin{array}{l}\text { Discussion of home } \\
\text { assignment from lesson } 2 \\
\text { Discussions about indirect } \\
\text { pressure to smoke, how to } \\
\text { identify and resist it }\end{array}$ & \\
\hline Lesson 5 & $\begin{array}{l}\text { Summary of all the } \\
\text { relevant issues } \\
\text { presented during the } \\
\text { previous lessons }\end{array}$ & $\begin{array}{l}\text { Discussions in small groups } \\
\text { about alternatives to } \\
\text { smoking } \\
\text { Role-play and discussions } \\
\text { centred on cigarette refusal } \\
\text { skills and decision-making } \\
\text { To increase commitment, } \\
\text { students were asked to make } \\
\text { a non-smoking contract and } \\
\text { to write their name on a } \\
\text { non-smoking poster that } \\
\text { could be clearly seen in the } \\
\text { classroom }\end{array}$ & \\
\hline
\end{tabular}


A logistic regression analysis was used to compare participating subjects and dropouts (those not participating in the second measurement) with data of the first measurement as predictors of dropout.

Data analysis included basic descriptive statistics of the respondents with regard to socio-demographics and health-risk behaviours at $\mathrm{Tl}$; chi square test was used in order to compare treatment conditions. Mean age was also calculated for the sample and independent sample T-test was used in order to compare treatment conditions.

Differences at post-test between the conditions on attitudes, self-efficacy and intention were analysed using covariance analysis. The covariates included were the relevant cognitive factors as measured at $\mathrm{T} 1$ and the gender. Similar to other studies (De Vries et al., 2003b; De Vries et al., 2006b), social influences were excluded from the analysis because the outcomes are not assumed to change as a result of the intervention.

Differences in regular smoking onset at T2 between the control and experimental groups were analysed using logistic regression; the analysis included only students who were non-smokers at T1. The covariates included in the analysis were age, gender, family structure, spending more than $€ 15 /$ month, health-risk behaviours (school achievements, alcohol use and playing truant from school on monthly bases, spending frequent their free time in bars/discos), adolescents' attitudes, social norms, social modelling and pressure as well as self-efficacy and intention scores at $\mathrm{T} 1$. The inclusion of covariates occurred to correct for potential baseline differences, to increase power; previous research showed the (potential) relationship of these covariates with smoking and the treatment condition (De Vries et al., 1994; US Department of Health and Human Services, 1994a; Dijkstra et al., 1999; Ausems et al., 2002). Non-significant predictors were deleted backwise.

The final models were re-run using a multilevel analysis to test the intervention effect on cognition and smoking behaviour (Rasbash et al., 2000), since subjects were nested within classes and schools.

Mean and standard deviation were calculated for the variables regarding students' opinions on the programme. Independent sample T-tests were used in order to compare boys and girls, respectively smokers and non-smokers with regard to these variables.

Data analysis was performed with the SPSS-12 statistics programme. Significant results were reported at $p<0.05$. The multilevel analysis was performed by using MLWIN programme (Rasbash et al., 2000).

\section{Results}

\section{Response}

At $\mathrm{T} 1$ the sample consisted of 1196 students and at $\mathrm{T} 2$ the number of respondents was 1187 . The final sample consisted of 1071 students (523 in the experimental group and 548 in the control group) who participated in both measurements. The dropout rates were similar ( $>0.05$ ) in both conditions ( $11 \%$ in the experimental group and $9.8 \%$ in the control group). The results of the logistic regression analyses show that the dropouts did not differ from the remaining sample with regard to gender or smoking behaviours or other risk behaviours such as alcohol use or playing truant from school on monthly bases. 


\section{Sample description}

The mean age of the sample was $13.7(\mathrm{SD}=0.3)$ years and did not differ significantly between the experimental and control group. The conditions also did not differ significantly regarding their gender distribution (50.9\% girls in the experimental group vs. $51.5 \%$ in the control group). No significant differences were found between the experimental and control group with respect to the prevalence of health-risk behaviours, such as playing truant from school at least once/month $(7.2 \%$ vs. $5.6 \%)$, using alcohol on monthly bases $(12.4 \%$ vs. $11.9 \%$ ), spending frequently time in bars/discos $(5.9 \%$ vs. $7.4 \%)$ or bad school achievements in the previous year $(6.1 \%$ vs. $8.4 \%)$. In both conditions similar percentages of students (8.9\% in the experimental group and $8.3 \%$ in the control group) declared that they spend more than $€ 15$ /month.

At baseline, $7.7 \%$ of the students were already weekly smokers. The prevalence of weekly smoking was similar in the experimental (7.5\%) and control group (8.0\%).

\section{Cognitive effects}

Table 6.2 shows the results of the covariance analyses which present differences at post-test found between both conditions regarding the cognitive variables controlling for baseline scores. At post-test, students in the experimental group were significantly less convinced of the advantages of smoking than students from the control group. Adolescents in the experimental group also reported significantly higher levels of social self-efficacy and more negative intentions to smoke than those from the control group. The effect sizes for these differences were small, ranging from 0.01 to 0.18 . No significant effects were found between the conditions with regard to perceived disadvantages of smoking, emotional and situational self-efficacy.

The data were reanalysed using multilevel linear regression analyses using MLWIN, since pupils were nested in classes and schools. The multilevel analyses confirmed the effects described above. These analyses furthermore showed that the effects were independent of school or class level of the students (intraclass correlation coefficient varied between 0.00 and 0.05 ).

Table 6.2 Adjusted means ${ }^{2}$ for attitudes, self-efficacy and intention scores at T2 (corrected for $\mathrm{T} 1$ scores)

\begin{tabular}{lcccc}
\hline \multirow{2}{*}{ Items } & \multicolumn{2}{c}{ Mean } & & \multicolumn{2}{c}{\begin{tabular}{c} 
Effect \\
sizes \\
\cline { 2 - 5 }
\end{tabular}} & Experimental group & Control group & Palue & (ES) \\
\hline Pros of smoking & -0.09 & 0.08 & $<0.01$ & -0.18 \\
Cons of smoking & -0.01 & 0.01 & NS & -0.01 \\
Self-efficacy social & 0.07 & -0.07 & $<0.05$ & 0.07 \\
Self-efficacy emotional & 0.06 & -0.05 & NS & 0.05 \\
Self-efficacy situational & 0.05 & -0.05 & NS & 0.05 \\
Intention to smoke & -0.06 & 0.06 & $<0.05$ & -0.06 \\
\hline
\end{tabular}

a -Means were calculated using $\mathrm{z}$ scores

b-Effect size (ES) interpretations are based on Lipsey (Lipsey, 1990) defining ES $<0.32$ as small, ES $=0.32-0.55$ as medium and $\mathrm{ES}>0.55$ as large.

NS-non significant 


\section{Regular smoking onset}

The programme resulted in significant preventive effects on smoking behaviour. At T2 there were $4.5 \%$ new regular smokers in the experimental group, whereas $9.5 \%$ of the nonsmokers at $\mathrm{T} 1$ become regular smokers at $\mathrm{T} 2$ in the control group. These figures represent a $5 \%$ higher increase of regular smoking in the control group.

The results of the logistic regression analysis (see Table 6.3) show that the risks of non-smokers from the control group to become regular smokers were twice as high as those from the experimental condition. Other predictors of regular smoking onset were low social self-efficacy and high intention to smoke in the future. For all the predictors the effect size was small, ranging from 0.01 to 0.14 .

The logistic regression model was reanalysed using multilevel analyses using MLWIN, since pupils were nested in classes and schools. This analysis confirmed the effects described above; again the effects were independent of students' school or class level (intraclass correlation coefficient for class and school level was 0.05 , respectively 0.00 )

Table 6.3 Predictors of regular smoking onset at $\mathrm{T} 2$; results of the logistic regression model $\left(\mathrm{N}=959^{\mathrm{a}}\right)$

\begin{tabular}{lcccc}
\hline \multicolumn{1}{c}{ Item } & OR & $\mathbf{9 5 \%} \mathbf{C l}$ & $\mathbf{p}$ & Effect sizes (f 2) $^{\mathbf{b}}$ \\
\hline Condition & 2.23 & $1.29-3.85$ & $<0.01$ & 0.02 \\
Intention & 1.56 & $1.31-1.86$ & $<0.001$ & 0.14 \\
Social self-efficacy & 0.73 & $0.50-0.92$ & $<0.01$ & 0.01 \\
\hline
\end{tabular}

a-Due to the missing values on some variables the population decreased to 959

b-Effect sizes over 0.02 were considered small, over 0.15 medium and over 0.35 large (Cohen, 1988, 1992)

\section{Process evaluation}

The process evaluation questionnaire was returned by 532 students; the response rate was $83 \%$. Table 6.4 shows that students rated the programme positively, as well as its activities and materials, such as the video and the manual with cartoons. Working in groups was also positively evaluated. The peer-led approach and the assistance received from their group leader, as well as the help received from the teachers got positive scores from the students.

Girls evaluated the programme more positively than the boys did, in particular the activities, working in groups and having a peer leader. No significant differences were found with regard to the other items.

Pre-test smokers evaluated the programme less positively than non-smokers. They were less positive about the evaluation of the manual, about having a peer leader and appreciated less the assistance received from the peer leader and the teacher. The two groups did not differ significantly in their evaluation of the other issues. 
Table 6.4 Mean and standard deviation of the items regarding students' opinions on the programme $^{2}$

\begin{tabular}{|c|c|c|c|c|c|}
\hline \multirow[b]{2}{*}{ Item } & $\begin{array}{c}\text { Total } \\
\text { sample }\end{array}$ & Girls & Boys & Non-smokers & Smokers \\
\hline & $\begin{array}{c}\mathrm{N}=532 \\
\text { Mean (SD) }\end{array}$ & $\begin{array}{c}N=280 \\
\text { Mean (SD) }\end{array}$ & $\begin{array}{c}N=252 \\
\text { Mean (SD) }\end{array}$ & $\begin{array}{c}N=446^{b} \\
\text { Mean (SD) }\end{array}$ & $\begin{array}{c}\mathrm{N}=35 \\
\operatorname{Mean}(\mathrm{SD})\end{array}$ \\
\hline $\begin{array}{l}\text { Programme } \\
(-2 \text { to }+2)^{c}\end{array}$ & $1.10(0.91)$ & $1.21(0.81)^{* *}$ & $0.98(0.99)$ & $1.15(0.89)^{9}$ & $0.85(0.94)$ \\
\hline $\begin{array}{l}\text { Watching the } \\
\text { videos } \\
(-2 \text { to }+2)^{c}\end{array}$ & $1.36(0.94)$ & $1.39(0.94)$ & $1.34(0.93)$ & $1.41(0.88)$ & $1.25(1.17)$ \\
\hline $\begin{array}{l}\text { Lessons on } \\
\text { video }\end{array}$ & $1.15(1.00)$ & $1.17(1.00)$ & $1.13(1.01)$ & $1.19(0.97)$ & $0.94(1.3)$ \\
\hline $\begin{array}{l}\text { Manual } \\
(-2 \text { to }+2)^{c}\end{array}$ & $1.23(0.94)$ & $1.26(0.89)$ & $1.19(1.00)$ & $1.27(0.90)^{*}$ & $0.88(1.15)$ \\
\hline $\begin{array}{l}\text { Activities } \\
\text { during lessons }\end{array}$ & $1.24(0.90)$ & $1.31(0.82)^{*}$ & $1.16(0.97)$ & $1.29(0.85)$ & $1.00(1.25)$ \\
\hline $\begin{array}{l}\text { Home activities } \\
(-2 \text { to }+2)^{c}\end{array}$ & $1.03(1.10)$ & $1.09(1.06)$ & $0.95(1.14)$ & $1.08(1.07)$ & $0.88(1.25)$ \\
\hline $\begin{array}{l}\text { Working in } \\
\text { groups } \\
(-2 \text { to }+2)\end{array}$ & $1.39(0.89)$ & $1.43(0.79)^{8}$ & $1.34(0.99)$ & $1.41(0.87)$ & $1.20(1.13)$ \\
\hline $\begin{array}{l}\text { Having a peer } \\
\text { leader } \\
(-2 \text { to }+2)^{c}\end{array}$ & $1.33(1.00)$ & $1.51(0.82)^{* * *}$ & $1.15(1.13)$ & $1.40(0.91)^{*}$ & $0.77(1.43)$ \\
\hline $\begin{array}{l}\text { Assistance by } \\
\text { peer leader }\end{array}$ & $1.29(1.03)$ & $1.37(0.94)$ & $1.20(1.12)$ & $1.33(1.00)^{*}$ & $0.85(1.37)$ \\
\hline $\begin{array}{l}\text { Assistance by } \\
\text { teacher } \\
(-2 \text { to }+2)^{c}\end{array}$ & $1.35(0.91)$ & $1.35(1.04)$ & $1.35(1.03)$ & $1.42(0.93)^{* * *}$ & $0.48(1.59)$ \\
\hline \multicolumn{6}{|c|}{$\begin{array}{l}\text { a-Comparisons are made between boys and girls, respectively between non-smokers and } \\
\text { smokers } \\
\text { b-Information about smoking behaviour at } \mathrm{Tl} \text { was available only for } 481 \text { students of those } \\
\text { who filled in the process evaluation questionnaire } \\
\text { c }-(-2) \text { negative evaluation to }(+2) \text { positive evaluation } \\
\text { - }-p<0.1 \\
* \mathrm{p}-<0.05 \\
* *-p<0.01 \\
* * *-p<0.001\end{array}$} \\
\hline
\end{tabular}




\section{Discussion}

The goal of this study was to assess the effects that a peer-led smoking prevention programme on video exerts on regular smoking (smoking at least one cigarette/week) among Romanian junior high school students.

With regard to behavioural effects, the results showed that, 9 months after the initiation of the study, the programme resulted in a significant effect, in that $4.5 \%$ of the $\mathrm{Tl}$ non-smokers from the experimental group had become regular smokers compared to $9.5 \%$ in the control group. This figure represents a $5 \%$ lower increase in smoking in the experimental group. Students from our control condition had a two times higher risk of becoming new regular smokers at $\mathrm{T} 2$ as compared with students from the experimental group. Additional predictors of non-smoking were represented by a negative intention toward smoking and high self-efficacy in refraining from smoking in several social situations.

The previously tested programme from the Netherlands found slightly better results regarding the prevention of regular smoking among students aged 13-14 years from vocational schools (they prepare students for special vocations); regular smoking increased by $7.1 \%$ in the experimental group, as compared with $14.1 \%$ in the control group (De Vries et al., 1994).

Furthermore, significant cognitive effects of the programme were also observed. In the experimental group, this resulted in a more negative attitude towards smoking, increased social self-efficacy levels and a more negative intention towards smoking. Our results can be interpreted in two ways, either as support for the assumption that realizing shifts in attitude, self-efficacy and intention may help adolescents to refrain from smoking, or as that remaining a non-smoker may strengthen a person's attitude, self-efficacy and intention not to smoke. Ideally, one needs three measurements and a cross-lagged design (Burkholder and Harlow, 2003) in order to be able to better analyse causal patterns.

In all cases, the effect sizes were small. The effects of public health interventions mostly show small and medium effect sizes (Kroeze and Brug, 2006; Lipsey, 1990). However, small effects may have great implications in a practical context (Abelson, 1985; Yeaton and Sechrest, 1981). When implemented on a larger scale, the public impact (effect $\mathrm{X}$ reach) of interventions with small effect size can be significant (De Vries and Brug, 1999; Green and Kreuter, 1990; Willey et al., 1996).

The programme evaluated by this study used the social influence approach and focused on the enhancement of self-efficacy and the acquisition of refusal skills. This represents quite a new approach in Romania, which traditionally used knowledge-based prevention programmes. Similar effects of programmes based on the social influence approach are also documented by several other reviews (Hansen, 1992; Thomas and Perera, 2006; Tobler et al, 2000; Telch et al., 1990, Lantz et al., 2000). In order to enhance the effects of school based programmes, it is recommended to embed them into a larger integral or community-based approach. Several programmes showed that these procedures could result in effects over time (Vartiainen et al., 1986; Perry et al., 1992; De Vries et al., 2006b), although community programmes do not necessarily guarantee success because of their complex nature (Hyland et al., 2006; Sowden et al., 2003; Wandersman and Florin, 2003). Moreover, recent studies suggest that social influences exerted by modelling may not be the sole predictor of smoking onset, implying more elaborate approaches, as well (De Vries et al., 2006a), in particular for slightly older adolescents (Hoving et al., 2007). Additionally, a long-term strategy starting with primary school and continuing to older adolescents is 
needed. It should target adolescents in and out of school, as well as their parents and even their schools (De Vries et al, 2006a; De Vries et al., 2007).

This programme was also the first peer-led smoking prevention programme in Romania. Romanian students liked this peer-led approach, the content and the structure of the programme. Girls were more positive about the programme and they liked more the peerled approach. Smokers evaluated the programme and some of its components more negatively than non-smokers. This was expected, since the programme favours non-smoking norms and behaviours. Different studies suggest that peer-led use may be important for the enhancement of programme effects (Telch et al., 1990; Klepp et al., 1993; Black et al., 1998; Erhard, 1999), although the results are still inconclusive (Mellanby et al., 2000).

This study is subject to limitations. First, self-reports on smoking could not be biologically validated because of logistical and financial constraints. The validity of selfreported smoking by adolescents has been shown to be good and in high concordance with biological indicators when measurements are carried out under optimal conditions assuring confidentiality (Murray et al., 1987; Hansen, 1992; Dolcini et al., 1996)(as it was in our study). However, the under-reporting of smoking cannot be excluded. Second, the results discussed in this study are based on short-term assessment. Smoking prevention programmes using the social influence approach can be effective. However, effects have been shown to diminish over time (US Department of Health and Human Services, 1994a; Peterson et al., 2000). On the other hand, there were programmes, which did not show any short-term effects, but long-terms effects appeared (De Vries et al., 2006b). Therefore, future research should include also a long-term evaluation of the programme to see whether the results persist, decrease or increase over time.

Recommendations for the purpose of realizing long-term effects suggest the use of comprehensive programmes that address multiple determinants of the smoking onset process at the micro-, meso- and macro-levels, thus including the broader social and cultural environment of adolescents (US Department of Health and Human Services, 1994a; Tones and Tilford, 2001). Furthermore, different studies showed that the use of booster sessions might prolong effectiveness (Dijkstra et al., 1999, Ausems et al., 2002). Hence, future studies should analyse the extent to which the inclusion into the programme of elements such as booster sessions, actions targeting teachers' behaviour and school policy regarding tobacco use could influence the smoking behaviour of Romanian adolescents. Furthermore, recent studies also demonstrated the importance of other predictors, such as social selection processes and the role of parents (Engels et al., 1997; Wang et al., 1999; De Vries et al., 2003a; De Vries et al., 2006a). Therefore, future programmes should also address the factors that determine the selection of smokers as friends, the parenting roles and how parents can stimulate the non-smoking behaviour among their children.

In conclusion, this first effect evaluation of a Romanian smoking prevention programme shows that smoking prevention programmes using the social influence approach and peer education can have beneficial short-term effects on smoking among Romanian young people. 
Chapter 7

General discussion 
This thesis describes several health-related behaviours of Romanian young people and zooms in on preventing one particular behaviour: smoking. The last chapter summarizes and discusses the main findings in order to identify what we have learned and which items need further exploration. The limitations of the study design will be also addressed. Lastly, implications for future research as well as recommendations for tobacco control and health education in Romania will be discussed.

\section{What were the important health-risk behaviours for Romanian youngsters and were they interrelated?}

Chapter 2 has presented data on health-risk behaviours among Romanian young people. This study has three main strengths. First, the sample of the study has comprised junior high school students, senior high school students, as well as university students, thus allowing a broad overview and comparison of different adolescent groups. Second, the study has covered a wide range of health-related behaviours, while other studies from Romania had restricted investigations to a more narrow range of problem behaviours. Third, to the best of our knowledge, it has been the first Romanian study, which has assessed the accumulation and relationship between health-risk behaviours among Romanian young people. What were the main findings?

Tobacco use

The results have showed that half of the Romanian young people aged 11-25 years from junior high school, senior high school and university have tried smoking at least once during their lifetime and one quarter declared having smoked at least once in the previous month.

Consistent with previous research from other countries (Ellickson et al., 2001; Paavola et al., 2004; Brener and Collins, 1998), the likelihood of involvement in risk-taking behaviours, such as tobacco use, increased with age, but no significant difference was found between senior high school students and university students with regard to lifetime smoking. These figures suggest the idea that most Romanian young people begin using tobacco before the age of 18 years and if effective prevention programmes are implemented before this age, the risk that they will start smoking will be lower. Moreover, another national representative study has underlined the increasing trend of experimenting with smoking among Romanian first-year senior high school students; it showed that in $200364 \%$ of the 16 year-old Romanian school students reported smoking at least once during their lifetime, which represents an increase of $11 \%$ compared with the year 1999 (Romanian Ministry of Health, 2004). These findings underline the necessity of developing smoking prevention programmes for Romanian adolescents starting with junior high school and continuing through senior high school, since many of them are tempted to smoke or experiment with smoking; these programmes are thus needed in order to prevent them from becoming regular smokers. Moreover, because of the high prevalence of smoking among senior high school and university students, innovative smoking cessation programmes should be developed for this target group. 
One out of two students has reported using alcohol at least once/month and half of the students has reported alcohol intoxication at least once in their life; both behaviours increased also with age. Prevalence of alcohol intoxication in the previous month was around $5 \%$ among the study sample; no increase has been found from senior high school students to university students regarding alcohol intoxication in the previous month, which proves that several alcohol use-related habits are already well established among senior high school students. These figures show the importance of developing programmes for preventing alcohol abuse starting with junior high school and continuing through senior high school and university.

\section{Illicit drug use}

A percentage of $7.4 \%$ of the senior high school and university students has declared the use of illicit drug at least once during their lifetime and this health-risk behaviour has been more frequent among university students. Other Romanian studies have also found quite low prevalence of illicit drug use (Abraham, 2005; Lotrean et al., 2001; Hibell et al., 2004), which shows that the problem of illicit drug use seems still lower in Romania compared with other European countries (Hibell et al., 2004; Currie, 2004). Nevertheless, other Romanian studies have also underlined that the use of drugs among Romanian adolescents has had an increasing trend during the last years (Hibell et al., 2004; Hibell et al., 2000). These findings call for comprehensive programmes of illicit drug use prevention for Romanian adolescents from both senior high school and university students in order to maintain this low prevalence.

\section{Delinquency and violence}

The delinquent-related behaviour - stealing or destroying somebody's things - has been encountered among one sixth of the study subjects and it increased steadily with age. On the other hand, one fifth of the total sample recognized the involvement in a physical fight in the previous month, and this problem was more evident among junior and senior high school students. It shows that some risks, particularly those that are physical fighting-related, are associated with particular developmental phases and that these risks tend to be replaced rather than compounded over time; this has been reported in other studies from other countries also (Brener and Collins, 1998; Curie et al., 2004). The results of our study show that violence and delinquent behaviour prevention is an important issue, which must be addressed especially to junior and senior high school students. Our study has investigated only one violence-related behaviour, namely fighting in the previous month and one delinquent-related behaviour - stealing or destroying somebody's things. Future studies should focus in more detail on different types of violence and delinquent behaviour in order to give a better image of the magnitude of the problem and to obtain information, which can help future violence prevention and health promotion activities.

\section{Sexual behaviour}

Adolescents have been recognized as an important population group in the area of reproductive health (UNAIDS, 2006; Currie, 2004). Our results have showed that one third of the Romanian adolescents had had their first sexual intercourse by the age of 18 and no significant differences were found between junior. high school students and university students with regard to this issue. Hence, similar to studies from other countries (Hibell et al., 2004; Lazcano et al., 2004), our results underline the importance of educating Romanian adolescents with respect to the adoption of safe sexual practices before they reach the age of 18. 
Similar to other studies in the world (Fetro et al., 2001; Takakura et al., 2001b; Everett et al., 2000), in our study we have found that many health-risk behaviours were interrelated rather than being a collection of independent activities. Almost one third of the junior high school students and around $60 \%$ of the senior high school as well as university students were involved in more than one risk behaviour. The mean number of risk behaviours has been statistically significant higher among senior high school students than among junior high school students, while no significant difference has been found between senior high school and university students with respect to the mean number of multiple risk behaviours. This shows that engagement in multiple risk behaviours starts in junior high school and it increases with age, being already well established in senior high school. These data provide further evidence that health-risk behaviours warrant early intervention because the patterns of unhealthy behaviour are formed in many cases in early adolescence.

The strongest correlations found in our study have been between smoking and alcohol-related behaviours among junior high school students and between smoking, alcohol and sex-related behaviours among senior high school and university students. This type of interrelationship has also been documented by studies from other countries (Anteghini et al., 2001; Shrier et al., 1996; Takakura et al., 2001b). There was also a correlation between different other health-compromising behaviours (e.g. between illicit drug use and violence and delinquency-related behaviours or between illicit drug use, smoking and alcohol abuse), but the correlation was weaker.

Several studies have also used factor analyses in order to assess the combinations of health-risk behaviours which young people are engaged in. Jessor (1991) has pointed out that a single common factor accounted for the positive correlations among a number of adolescent problem behaviours, including problem drinking, marijuana use, delinquent-type behaviour and precocious sexual intercourse, because different risk behaviours help meet similar psychosocial developmental needs and have the same causal factors. On the other hand, other studies have found that health behaviours are multidimensional, but the examined behaviours, as well as the precise number of dimensions involved and their behavioural content, varied between studies (Vickers et al., 1990, Ebin et al., 2001; Kulbok and Cox, 2002). Moreover, several studies have showed that the correlations between several health-risk behaviours vary across age groups (Kulbok and Cox, 2002; Guilamo-Ramos et al., 2005).

The results of the factor analyses from our study have revealed an interesting finding among Romanian adolescents, showing a distinction between early and later adolescence. Among junior high school students, all investigated health-compromising behaviours - smoking, alcohol-related behaviours, as well as violence and delinquency loaded on one factor. Knowing whether a young adolescent experiments one of the healthcompromising behaviours is an important marker for possible other subsequent or already experimented risk behaviours, which shows that there is a need to address the other problems too. Hence, for junior high school students who are engaged in one risk behaviour, such as smoking or alcohol use, there is an increased risk to be also involved in violence or delinquent-related behaviours.

Behaviours that are considered risky at the age of 12 years, such as tobacco or alcohol use, may be common by the age of 18 years. Among senior high school students and university students the risky behaviours split in two factor loadings. Factor 1 comprised of smoking, use of alcohol and alcohol intoxication as well as precocious sexual intercourse, while factor 2 included illicit drug use, violence and delinquency-related behaviours. Similarly to other studies (Ebin et al., 2001), we interpret this as a distinction between the behaviours which have been most frequently encountered and which are possibly part of the normal experimentation period that often characterizes adolescent behaviour at this age and 
the behaviours, which have been uncommon and may have more severe consequences regardless of developmental stage.

These findings regarding the relationship between several health-related behaviours among Romanian adolescents raise the question whether to address the promotion of healthy lifestyles among youth in one overall programme or to deal with them as separate topics and whether the same approach has to be taken for younger and older adolescents. In order to draw any conclusions regarding how these behaviours should be best addressed, intervention studies, in which different approaches should be compared (ex. generic programmes vs. programmes which are focused on one behaviour only), are necessary. This will assist the makers of health, education and social policy to develop appropriate programmes of health promotion among Romanian youth.

In conclusion, our findings from chapter 2 support the need for health promotion activities among Romanian adolescents for a wide array of behaviours discussed in this study. Nevertheless, evidence-based health promotion activities were missing in Romania at the beginning of this thesis. Because of the high prevalence of smoking among Romanian adolescents as well as of the impact of smoking on health, we have decided to start with smoking the first systematic and planned prevention intervention addressing health-risk behaviours in Romania.

\section{Gender differences regarding health-risk behaviours among Romanian young people}

Chapter 2 has also presented the gender differences regarding health-related behaviours of Romanian young people. Several studies have showed that gender differences with regard to health-related behaviour vary within the countries and regions (Currie, 2004; Hibell et al., 2004). Traditionally, young boys are more often engaged in risky behaviours than girls, but in some countries these differences are dissipating (Hibell et al., 2004; The Global Youth Tobacco Survey Collaborative Group, 2002).

Our results presented in chapter 2 have showed that in Romania the prevalence of health-risk behaviours was generally higher among boys than girls. Moreover, the accumulation of health-risk behaviours was higher among boys than among girls. The mean number of health-risk behaviours was significantly higher among boys than girls in junior high school, senior high school, as well as in university. Studies from other countries have also showed that boys had generally a higher number of concurrent risk behaviours (Brener and Collins, 1998).

Even if the prevalence of the investigated health-related behaviours was lower among girls than boys in our study, the patterns of correlations between these behaviours were similar for boys and girls. However, because of the limitations associated with crosssectional studies, future longitudinal studies are needed in order to better assess potential gender differences with regard to the relationship between several health-risk behaviours in order to develop appropriate health promotion programmes. 


\section{Is smoking preceding alcohol, and is this pattern the same for boys and girls?}

Chapter 3 has focused in more depth on relationship between alcohol and tobacco use among Romanian adolescents aged 15-17 years. Four types of pathways have been proposed to account for the co-occurrence of alcohol and tobacco use (1) alcohol use causes tobacco use; (2) tobacco use causes alcohol use; (3) alcohol use and tobacco use influence each other reciprocally; and (4) alcohol and tobacco use are a function of common third variables (Jackson et al., 2002). A consistent finding of the studies is that alcohol and tobacco use are linked reciprocally. Yet the conclusions about the pathways suggested are inconsistent. While some prospective studies have suggested that alcohol use predicts cigarette use more strongly than the converse (Kandel and Faust 1975; Andrews et al., 1991; Ellickson et al., 1992; Jackson et al., 2002), other longitudinal studies have identified that cigarette use was particularly important for subsequent involvement in alcohol use (Fleming et al., 1989; Duncan et al., 1998; Lewinsohn et al., 1999; Field et al., 2002; Wetzels et al., 2003). Moreover, some of the studies, which have focused on gender differences, have concluded that there are no clear differences between boys and girls regarding the relationship between alcohol and tobacco use (Kandel and Faust, 1975), while others have suggested that these differences might exist (Weitzman et al., 2005; Wetzels et al., 2003; Hoffman et al., 2001).

The longitudinal results presented in chapter 3 have showed that among Romanian adolescents aged 15 to 17 , alcohol and cigarette use were reciprocally linked. Tobacco use at least once per month at one moment (T1) predicted the initiation of alcohol use on a monthly base one-year later (T2) and analogously the onset of monthly smoking at T2 was predicted by alcohol use at $\mathrm{T} 1$.

Interestingly, our results suggest that the interrelationship alcohol-tobacco use may be different for the two genders. At both waves, among girls, smoking without use of alcohol was more frequent than alcohol use without smoking, while among boys it was the other way around. Additionally, the longitudinal results have confirmed this pattern suggesting that among Romanian girls smoking predicts alcohol use better than the converse, while for the boys it was the other way around.

The results of the present study do not necessarily prove causality between smoking and alcohol use, because even longitudinal methods do not provide proof of causation (Conrad et al., 1992). Cigarette use among girls at a particular moment needs to be interpreted as a predictor of alcohol use on regular bases at a later moment, rather than as a cause. At the same time, the results do not imply that all boys using alcohol frequently will necessarily end up smoking as well.

What have we learned from these findings? First, they underline that alcohol prevention may need to precede smoking prevention for boys. Further research is needed to determine whether this also results in lower smoking uptake. At the same time, smoking prevention needs to precede alcohol prevention for girls. Research is also needed to analyse whether this will later impact alcohol uptake among girls. As other studies have also suggested (Wetzels et al., 2003; Weitzman and Chen, 2005; Vitoria et al., 2006), school health education curricula may provide smoking and alcohol prevention programmes within the same school year, since a dual focus in the prevention activities may have benefits over more single focus efforts, especially if they target common factors such as self-efficacy to cope with peer pressure (California Department of Health, 2002). However, when the health education messages for alcohol use (moderation) and smoking (abstinence) are different, research is needed on whether it is feasible and effective to combine the two approaches within one programme. 
Second, the gender differences observed among Romanian young people could be the result of cultural differences and different parenting practices. Romanian parents may be permissive with alcohol use by their sons, but not by their daughters. A study performed among Romanian secondary school students (aged 11-14 years) has also showed that, statistically significant, in urban areas, more boys than girls (14.1\% vs. $8.8 \%)$ drank alcohol in their houses at a young age (Lotrean, unpublished data). Hence, the prevention efforts must contain educative programmes for adolescents, but they must be also directed towards the improvement of parenting practices regarding alcohol use.

Third, because of the relationship between alcohol and tobacco use found among Romanian adolescents, some tobacco control measures, such as an increase in cigarette price, could have benefits not only on decreasing smoking, but also on alcohol use, especially among Romanian girls. Promising results in this matter have been found in other countries with regard to the use of cigarettes and marijuana (Chaloupka et al. 1999; Farrelly et al. 1999).

In conclusion, despite of the fact that chapter 2 has depicted no clear gender differences in the cross-sectional relationship between several health-risk behaviours, chapter 3 did identify some gender differences in the prospective associations between cigarette smoking and alcohol use. More research is needed in Romania to better understand this difference and to tailor public health messages accordingly, for boys and girls, as well as for their parents. Future studies should also focus on psychosocial correlates of alcohol and tobacco use in order to better understand the interrelationships among these health-risk behaviours as well as their risk and protective factors.

\section{Tobacco use among Romanian youth}

Chapter 2 has showed that in Romania several health-related behaviours are relevant. From this chapter it has become clear that choices needed to be made. Since smoking among Romanian young people represents an important public health problem, which calls for comprehensive actions, chapters 4, 5 and 6 have focused on smoking prevention and covered a broad area of research from factors associated with smoking to the development and the evaluation of a smoking prevention programme for Romanian adolescents.

Chapter 4 has addressed a review of the data on Romanian adolescents' smoking behaviour, published between 1990-2007, in order to reveal the weaknesses and the strengths of tobacco control targeting young people in Romania. The chapter has revealed that after the change of the political regime in 1989, Romania was confronted with an aggressive promotion campaign developed by the transnational tobacco companies including a lot of adyertisement targeted towards young people, sponsorship of different social and cultural events for youth, offering free samples of cigarettes and even organizing so-called smoking prevention programmes for young people. In fact, Romania is a good example of how effective the tobacco industry strategies can be for penetrating a new market, including influencing political factors. This is not an isolated finding, since after the fall of the communist regime in 1989, all Eastern European countries have suffered the invasion of transnational tobacco companies, which discovered new important markets in this part of the world and used similar techniques in order to promote their products and to impose the policy they wanted (National Center for Disease Control and Prevention, 2004b; Radu Loghin, 2003; Gilmore and McKee, 2004; Szilágyi and Chapman, 2003).

The lack of effective tobacco control in Romania also becomes obvious as it can be noted from the poor enforcement of laws banning smoking in public places or sales of cigarettes to young people under the age of 18 . Few programmes of smoking prevention and 
cessation have been implemented for Romanian adolescents; they mostly addressed knowledge, occurred infrequently and without a long-term strategy as well as without any effect evaluation of the programmes. Under these circumstances, it is not surprising that the social acceptance and prevalence of smoking have increased among Romanian young people.

In order to solve this important public health problem, over the last few years, different governmental institutions, as well as non-governmental organisations, have started to become more actively involved in tobacco control actions. Several studies have recently documented the prevalence of smoking among Romanian young people (Centre for Health Policies and Services, 2004; Romanian Ministry of Health, 2004; National Center for Disease Control and Prevention, 2004a). However, no study regarding psychosocial factors associated with smoking behaviour among Romanian adolescents had been available at the time of the beginning of the thesis. The lack of information on these factors seriously limits the development of tailored smoking prevention programmes.

Understanding the psychosocial determinants is one of the first crucial analyses that should be undertaken in order to understand which specific beliefs should be addressed in intervention programmes. Hence, the study presented in the next chapter has focused on the assessment of the cognitive and socio-demographic factors associated with smoking among Romanian teenagers, using both cross-sectional and longitudinal dala.

\section{Factors associated with smoking among Romanian young people}

Even though theory-based programmes are the sine qua non of health promotion programmes, the application of theories in contexts other than the ones they were developed for, remains to be answered. Culture is one of the factors that may determine the fit between theories and health-related behaviours. Pasik (1997) has defined culture as a unique shared set of values, beliefs and practices that are directly associated with a health-related behaviour, that are indirectly associated with a health-related behaviour or that influence acceptance and adoption of the health education message. Researchers are advised to test the applicability of existing theories in the cultural contexts in which they are used (Pasick, 1997).

Chapter 5 has investigated the cognitive factors cross-sectionally and longitudinally associated with the smoking behaviour of Romanian young people aged 15 to 17 , using the framework of the Integrated Model for explaining the motivational and behavioural change (I-Change Model). No theory-based studies on smoking prevention have been yet done in Romania.

The I-Change model was used to assess attitudes (pros and cons) of smoking, social influences (perceived social norms, perceived smoking behaviour of others and direct social pressure) and self-efficacy as proximal factors that are related to intention and smoking behaviour, while socio-economic characteristics and several risk behaviours were investigated as predisposing factors of smoking onset.

The data were gathered in two waves among Romanian students aged 15 to 17 (mean age 15.9 years) from five senior high schools of Cluj-Napoca city; the baseline measurement was conducted in May/June 2004 (T1) and a follow-up measurement was performed 12 months later (T2). The study sample consisted of non-smokers at T1.

The cross-sectional results concerning the post-test data have showed that students with lower self-efficacy and stronger intention to smoke in the next year were more likely to smoke. Having low attitudes against smoking and more smokers among the group of friends were also positively associated with current smoking at the second wave. Some socio- 
demographic and health-risk behaviour variables, such as frequently spending their free time in bars and discos, were also cross-sectionally associated with smoking behaviour.

The model variables explained $76 \%$ of the variance in smoking behaviour at the second wave. Studies from other countries have also found similar explained variance (De Vries et al., 1995; Engels et al., 1999; Vitoria et al., 2006).

The longitudinal results have showed that the transition to regular smoking over a period of one year was predicted by a low self-efficacy in refraining from smoking in different situations and more smoking friends at first measurement. In addition, playing truant from school at least once per month predicted smoking onset, while having a brother was a protective factor. The results pointed out that $33 \%$ of the variance in change of the smoking status from non-smoking to regular smoking over a period of 1 year could be explained by cognitive and socio-demographic factors. The explained variance found by other prospective studies over a period of one year has been similar (De Vries et al., 1995; Engels et al., 1999; Pederson and Lefcoe, 1987) and decreased when the interval between the measurements increased (De Vries et al., 1995).

In sum, the significance of self-efficacy expectations regarding its association with smoking behaviour is stressed by both cross-sectional and longitudinal results. Other studies have also found low self-efficacy as an important predictor of smoking onset (Conrad et al., 1992; De Vries et al., 1995; Nebot et al., 2004; Kim, 2005; Chang et al., 2006). Hence, this implies the inclusion in smoking prevention approaches of self-efficacy as a crucial factor.

As regards the social influences on smoking, both cross-sectional and longitudinal results confirm the strong influence of smoking friends on adolescents' smoking behaviour. Results of other international studies have also showed that influence coming from friends is very important (Tyas and Pederson, 1998; Conrad et al., 1992; US Department of Health and Human Services, 1994a). This underlines the necessity of helping Romanian adolescents to develop skills to resist the influences to smoke coming from their peers.

We have not found support for significant influences of smoking parents in the cross-sectional study or in the longitudinal study. Several studies from other countries have also showed that when controlling for peer influence, the effect of parental smoking behaviour results non-significant (Tyas and Pederson, 1998). On the other hand, according to other studies (Engels et al., 1997; Wang et al., 1999; De Vries et al., 2003a; De Vries et al., 2006a), parental smoking can also be a strong predictor of the transition to regular smoking. The study reported in chapter 5 has not supported the influence of smoking parents on the smoking behaviour of Romanian adolescents aged 15-17 years. However, the special circumstances of our studied population who was in the period after school transition to senior high school may have caused feelings of maturity among the students, which might have reduced the impact of parental influence.

Comparing the findings of our cross-sectional and longitudinal studies of smoking determinants reveals some differences. In going from cross-sectional associations to longitudinal predictors, several significant associations declined or disappeared, which is not an isolated finding. Both attitudes regarding smoking, as well as the intention to smoke in the future, were associated with smoking behaviour of Romanian adolescents in the crosssectional study. Despite this, the attitudes were not predictors of smoking in the longitudinal study. Moreover, in spite of their negative intention towards smoking, adolescents still started to smoke, easily putting aside their negative intention towards smoking. This might indicate the formation of the attitude and intention after a behavioural transition is made in the smoking uptake process (Kremers et al., 2004). Crucial events in which smoking suddenly becomes an important topic (e.g. someone offers a cigarette) may put an individual in a position to decide without having the motivation or the opportunity to deliberate. Another explanation is that initiation takes place during adolescence, which is characterized by a quick succession of personal and social changes, so teenagers may alter their attitudes 
and intention and start to smoke over a short period of time; these two events might be so close together that longitudinal studies with more than a few months between the waves cannot capture this process (Engels et al., 1999).

The findings from the present study show that the application of the social cognitive approach is feasible within the Romanian context and can provide a platform for programme development among Romanian young people. Overall, the study has presented patterns regarding smoking onset similar to those found in other European and international studies, showing that the smoking prevention programmes that need to be developed in Romania can benefit from the extensive experience in this field from other countries.

Our results imply that smoking prevention programmes should strengthen selfefficacy beliefs and resistance against peer influences and help Romanian young people to develop skills in order to cope with pressure to smoke and with challenging situations.

Nevertheless, some questions have still remained open with regard to predictors of smoking among Romanian young people. These include assessing action plans and goal settings, since different studies have showed these factors as contributing to the promotion of various health-related behaviours (Armitage, 2004; Milne et al, 2002), including smoking cessation (van Osch et al., 2008). On the other hand, studies from other European countries have showed that a friend selection process results in a smoking behaviour: youngsters who have a positive attitude towards smoking and associate smoking with various advantages look for peers with similar values (De Vries et al., 2006a). Hence, the selection influence issue also warrants research attention in Romania. Future Romanian studies should also gather information on the potential impact of parenting practices since several international studies have showed that they are related to several adolescents' smoking-related cognition and behaviours (Ennett et al., 2001; Engels et al., 2005; Huver et al., 2007). From a macro perspective, future Romanian studies should also pay attention to the effects of tobacco control policies such as price policies and smoke-free environments.

\section{Effects of a peer-led smoking prevention programme}

\section{Effect evaluation}

As a first step in the smoking prevention among Romanian adolescents, a school-based peerled smoking prevention programme on video was implemented in 2006 among junior high school students aged 13-14 years. The goal of the programme was the prevention of regular smoking, defined as smoking at léast one cigarette a week.

Because of the time and funding constrains, the determinants of smoking onset among this age group could not be assessed before the beginning of the programme. Hence, the development of the programme was based on empirical findings from the literature and on the results of the previous studies performed among a little older Romanian adolescent from senior high school, which were presented in chapter 5 of the thesis. These studies have showed that low self-efficacy in refraining from smoking in different social situations and the peer influences are important predictors of smoking onset among Romanian young people (Lotrean et al, submitted c). Hence, the programme focused on the development of social skills to resist social influences that encourage smoking and on the increase of selfefficacy in order to be able to refuse offers to smoke. Similar approaches have shown promising results in several smoking prevention programmes in Europe (De Vries et al., 1994; Reid et al., 1995; Rooney and Murray, 1996; Jøsendal et al., 1998; Dijkstra et al., 1999; De Vries et al, 2006b) and worldwide (US Department of Health and Human Services, 2000; Lantz et al., 2000; Tobler et al., 2000). Nevertheless, a programme, which embraces a "social 
influence" model, represents quite a new approach in Romania, where information-based prevention programmes have been generally used.

Using the school as a place of intervention increases the chance of exposure, but in order to prevent implementation failure, the programme has to be easy-to-apply and should have a clear structure without requiring special time-consuming training sessions. Moreover, to enhance message reception, it is important that the message should be attractive, easy to understand and easy to implement. As a result of the above-described reasons, an effective school-based peer-led programme on video was translated from a Dutch version that had been previously tested (De Vries et al., 1992, De Vries et al., 1994) and adapted to the Romanian situation and culture. This programme contained several advantages. First, the teachers needed to follow only a short training, as their main task consisted of coordinating the lessons, assisting the students and stimulating their participation. The teachers did not have to spend much time in discovering how to use and prepare the lessons. Second, by using adolescents, who introduced the lessons on video, the video was meant to be attractive for students and to improve their comprehension since they paid more attention to the message. Third, students were involved in performing activities in small groups, which improved their active participation. Instead of providing information, students were encouraged to discover information (active learning). Thus, students may discover gaps in their knowledge, which will make them more receptive to new information (Flay et al, 1983).

The results have showed that the programme had significant effects on smoking behaviour. At the post-test there were $4.5 \%$ new regular smokers in the experimental group, while $9.5 \%$ of the non-smokers at the pre-test become regular smokers at the follow-up in the control group. These figures present a 5\% higher increase of regular smoking in the control group. These results were similar to those found by the previously tested programme from the Netherlands among Dutch students aged 13-14 years from vocational schools (De Vries et al., 1994).

The non-smokers at the first wave, who did not participate in the smoking prevention programme, had a two times higher risk of becoming regular smokers 9 months later as compared with those from the experimental conditions. Furthermore, significant effects of the programme on cognition were observed. In the experimental group, this resulted in a more negative attitude towards smoking, increased social self-efficacy levels and a more negative intention towards smoking. In view of the relationship between attitudeintention-behaviour and the positive effects of self-efficacy on behaviour, the attitude, intention and self-efficacy shifts found in the present study might help students to refrain from smoking also in the future when smoking behaviour will become even more frequent in their peer environment.

Short-term effects of programmes that are based on the social influence approach are also documented by several other studies (Hansen, 1992; Thomas and Perera, 2006; Tobler et al., 2000; Telch et al., 1990, Lantz et al., 2000; De Vries et al., 2003b). Although long-term effects have been found to be more difficult to realize (Sowden et al., 2003), intermediate effects (De Vries et al, 2006b; Josendal et al., 2005; Vartiainen et al., 2006; Ariza et al., 2008) and long-term effects (Vartiainen et al., 1986; Biglan et al., 2000; Perry et al., 1992) have been realized as well. Smoking prevention projects differ widely in their application of social influence elements such as length of the programme, number of training sessions provided, type of skill training technique used, characteristics of providers and age of the target group, being unclear which of these elements result in the effectiveness of such programmes (De Vries et al., 2006b). Programme "boosters" or subsequent interventions appear to enhance the staying power of the intervention effects (Dijkstra et al., 1999, Ausems et al., 2002; Lantz et al., 2000) although the most appropriate content of and timing for these booster sessions is not known (Peterson et al., 2000). Peer-led teaching methods appear promising; they benefit from increased attractiveness and comprehensibility and the peer 
leaders may be most effective when used as models for social skills. However, results regarding the effectiveness of peer-led programmes are, as yet, inconclusive (Mellanby et al., 2000). Because school-based programmes only may not always be effective (Thomas and P.erera, 2006), it is recommended to embed them in a larger integral or community-based approach. When both school and community channels are used for influencing smoking behaviour of young people, better preventive effects can be achieved. Moreover, an asset of community interventions is the possibility to reach young people who drop out the school. This approach has shown to increase the long-term effects of smoking prevention programmes (Vartiainen et al., 1986; Perry et al., 1992), but Sowden and colleagues (2003) have concluded in their review that while there is support for the effectiveness of community interventions, the support is still limited.

In conclusion, our study has been the first effect evaluation of a Romanian health promotion programme. It shows that smoking prevention programmes using the social influence approach and peer education can have beneficial short-term effects among Romanian young people. Future studies from Romania should focus on identifying combinations of methods which could prolong the short-term effects achieved by the programme, in order to provide evidence-based recommendations to put into practice and to be able to further develop effective smoking prevention approaches for Romanian young people.

\section{Process evaluation}

The process evaluation has showed that the students rated the programme positively. They had positive evaluations concerning the activities of the programme and its materials: the video and the manual with cartoons. Working in groups was also positively rated. This method of using peer leaders was quite new for Romania, but students liked it; the peer-led approach and the assistance received by their group leader as well as the help received from the teachers got positive scores from the students.

Girls were more positive about the programme than the boys and they liked more the peer-led approach. Pre-test smokers evaluated the programme and some of its components more negatively than non-smokers. This was expected, since the programme favours non-smoking norms and behaviours.

In conclusion, the new peer-led approach, although not used before in Romania, was well accepted by students. Moreover, the structure and the materials of the programme have been proven to be attractive for Romanian students. These findings may facilitate adoption of the programme in the future.

Our study has not assessed the acceptance of the programme by teachers. Future studies should also asses the teachers' opinions regarding the content and materials of the programme in order to better understand the factors which will help the adoption of the programme and the improvements which could be appropriate. Future research is also necessary to determine the level of implementation of the programme and the factors, which influence this process when the programme is diffused on a larger scale without a concurrent effectiveness study.

\section{Methodological issues}

Representativeness The studies reported on this thesis had some limitations. Due to funding and logistical restrictions, the studies did not include a national representative sample, involved only school youth and did not include out-of-school adolescents. This is 
inevitably a limit to the generalization of the findings of the present studies beyond their sample.

Time and financial constraints Time and financial constraints disabled the assessment of the determinants of smoking among Romanian junior high school students prior to the implementation and evaluation of the peer-led smoking prevention programme. Hence, the development of the programme was based on findings from international literature and on results of the studies evaluating factors associated with smoking among somewhat older Romanian adolescents from senior high school. Nevertheless, the analyses of the predictors of smoking among the junior high school students from the control group of the smoking prevention programme showed similar results with those found among the senior high school students. They underline the importance of peer influence and the role of social self-efficacy in predicting smoking behaviour among Romanian junior high school students. These findings together with the results of the smoking prevention programme in preventing smoking onset confirm that the social influences approach of the programme is appropriate for Romanian junior high school students.

Smoking validation Self-reported smoking and nicotine dependence were not biologically validated due to logistical and financial restrictions. However, when anonymity is assured, self-reports of smoking have been shown to be reliable and in agreement with biochemical markers (Murray and Perry, 1987; Hansen et al., 1985; Dolcini et al., 1996). Moreover, several methods were adopted to ensure the confidentiality during survey administration. Students were informed that their answers were kept confidential and were asked not to write their names on questionnaires, but on the envelope. The questionnaire was administered by the research team simulating examination-like conditions to prevent peers from viewing their answers and the teachers were not involved in the collection of questionnaires.

Adolescent's reports on smoking behaviour of others The reports on parents, siblings and friends smoking were based on the adolescents' own perception. However, studies in which independent reports were obtained have shown that adolescents appear to be well aware of their parents and friends risk behaviour (Wilks et al., 1989).

Attrition The study that evaluated the smoking prevention programme encountered the problem of attrition, which is common for smoking prevention programmes. Attrition can be a threat to internal validity if it is differential across conditions. Fortunately, this was not the case in our study. Moreover, the attrition was similar to or even less than in another international studies (De Vries et al, 2006b; Josendal et al., 2005; Vartiainen et al., 2006; Ariza et al., 2008). However, external validity, the extent of generalization of the results is always threatened, being unclear, for instance, whether the programme worked or will work for dropouts.

Small effect sizes Effect sizes were assessed indicating the magnitude of the effect of smoking prevention programme on adolescents' cognition and behaviour regarding smoking. In all cases, the effect sizes were small. However, small effects may have great implications in a practical context (Abelson, 1985; Yeaton and Sechrest, 1981). The effects of public health interventions mostly show small and medium effect sizes (Kroeze et al., 2006; Lipsey, 1990). Nevertheless, when implemented on a larger scale, the public impact (effect X reach) can be significant (De Vries and Brug, 1999; Green and Kreuter, 1990; Willey et al., 1996). 


\section{Implications}

The results of the studies presented in this thesis have several implications for future research and the health promotion practice. Some of them were already addressed above. The next section will provide an overview of the most important implications for research and for practice. The recommendations for future research relate to issues that remained unclear after the present studies. The implications for practice focus on the possible application of the results of the thesis on smoking prevention and health promotion among adolescents from Romania.

\section{Implication for future research}

Lifestyle The results of the thesis indicate the interrelationship between different health-related behaviours and suggest that programmes addressing multiple risk behaviours could be appropriate for Romanian young people, but more work is needed in examining patterns of lifestyle among youth. Surveys should incorporate more detailed measures on a wide range of health-compromising and health-promoting behaviours, as well as on psychosocial correlates of individual behaviours in order to better understand the interrelationships among behaviours, as well as the risk and protective factors.

With respect to the measurement of multiple types of behaviour it is important to identify how multiple types of behaviour and their determinants can be best measured. Kremers and colleagues (2005) argue that it is important to try to keep questionnaires down to acceptable sizes, in order to avoid annoying participants with long questionnaires, which may lead to low response rates of answer and invalid data. Hence, finding a balance between the number of questions in a questionnaire about several health-risk behaviours and a reliable questionnaire remains a challenge.

History of substance use Further research is also needed on the influence of the level of alcohol and tobacco use, as well as the age of initiation on the use of substances and other health-risk behaviours. Several researches have found that these characteristics are important predictors of progression for the use of other drugs (Henningfield et al., 1990; Johnson and Jennison, 1992; Duncan et al., 1998; Lewinsohn et al., 1999) as well as of other health-compromising behaviours, such as sexual risk behaviour (Rosenbaum and Kandel, 1990; Durant et al., 1999) or injury-related behaviour (Bonnie and O'Connel, 2004), but they were not included in the present study.

Extended models Since the prediction of smoking among Romanian adolescents was modest, future studies should continue to investigate if smoking initiation can be predicted by several other factors, such as action plans and goals setting. Moreover, considering the importance of the social environment in smoking behaviour, an understanding of the influences, such as parenting styles and practices at the meso-level as well, as tobacco control policies at the macro-level, which were essentially beyond the scope of this thesis, would provide a more comprehensive picture. Shorter intervals between the studies are also needed in order to detect rapid changes in cognitions and/or behaviour.

Relevance of stage algorithm The present thesis used the classification of the smoking behaviour in two categories: smokers and non-smokers. One option to improve knowledge regarding the factors affecting smoking initiation could be the classification of smoking behaviour in more categories, such as the classification proposed by Kremers and colleagues (2004a): never smokers (never smoked, not even one puff), triers (trying smoking once in a while, but not monthly), experimenters (smoking at least once a month, but not weekly), regular smokers (currently smoking cigarettes weekly), non-smoking deciders (tried 
smoking less than once a week, but not smoking anymore) and quitters (quit smoking after having smoked at least once a week).

Gender differences Due to sample limitations, this thesis did not assess gender differences regarding factors associated with smoking among Romanian adolescents. Further research should investigate the differences that may exist between boys and girls from Romania with regard to predictors of smoking. This information is needed in order to draw conclusions regarding the necessity of developing gender sensitive smoking prevention activities and the content of tailored messages for boys and girls included in the sessions/programmes.

Access Point Analysis should become the definitive objective of health promotion planning models among Romanian young people. Adolescents have distinct preferences for the channels through which they can be accessed for tobacco control programmes; internetbased approaches, for instance, are increasing in popularity. Hence, more information is needed on adolescent channel preferences and an understanding of how to best use a preferred channel for Romanian young people is therefore required. Moreover, key elements, which influence the fidelity of the implementation of programmes for the prevention of substance use, include, besides programme characteristics, provider training, provider characteristics and organizational characteristics (Dusenbury et al., 2003). Hence, in order to avoid a bad implementation of successful smoking prevention programmes and thus to prevent a type III error, an analysis for the identification of the best providers should also be performed.

Improving the smoking prevention programme Further research is necessary to identify how to maintain the initial smoking prevention effects accomplished by the Romanian peer-led smoking prevention programme on video, since many studies have found this to be difficult. Future studies should also focus on the impact of the inclusion into the programme of action plans and goals setting, booster interventions, as well as other strategies such as parental involvement, school policies on smoking and wider community programmes.

Smoking cessation Since smoking cessation is also very important, a topic for further research concerns the methods smoking cessation programmes must use. At the same time, it is important to assess if they should be incorporated within smoking prevention interventions as well as if they should stay separate or if they should also focus on the inclusion of social networks such as developing cessation interventions for smoking parents as well.

Developmental appropriateness of health education programmes As adolescents grow, the likelihood of involvement in some risk taking behaviours.increases, while other decreases. Given the age-related changes seen in health-risk behaviours, additional research is needed to better identify issues that are particularly important to some age groups and prioritise developmentally appropriate risk reduction strategies.

Combining programmes Future studies should also investigate which behaviour types could be best combined in order to implement effective programmes of health education among Romanian young people. Moreover, since the advantages and disadvantages of more generic programmes as compared to programmes that focus on specific behaviours are not clear at this time (Neumark-Sztainer et al., 1997; Wetzels et al., 2003; Flay et al., 2004, Werch et al., 2005) intervention studies, where different types of approaches are compared, are necessary. 


\section{Implication for practice}

Many of the concerns related to health in young adulthood are linked to personal lifestyle choices. However, all of these "choices" are linked to the capacity of the home, school, community, workplaces and governments to make "the healthy choices" the "easy choices for young people" (Bonnie and O'Connel, 2004). The results of the thesis underline several recommendations for the diffusion of the smoking: prevention programme as well as for tobacco control in Romania.

\section{Recommendations for diffusion of the peer-led smoking prevention programme}

Use of the linkage approach The impact of a health education programme is determined not only by the effectiveness of the interventions, but also by the quality of programme implementation and the proportion of intended participants exposed to the programme (Parcel, 1995). Several studies showed that smoking prevention programmes could be effective in preventing or delaying smoking onset (Lantz et al., 2000; De Vries et al., 1994; Dijkstra et al., 1999, Ausems et al., 2002; Josendal et al., 2005; Vartiainen et al., 2006; Ariza et al., 2008). However, the impact of these programmes will remain limited if they are not diffused and adopted by schools. Hence, one important implication of this thesis is the necessity for the diffusion of the peer-led smoking prevention programme.

As other studies from other countries showed, one approach that helps to improve diffusion is the linkage approach to innovation development and diffusion planning (Orlandi, 1990; Dijkstra et al., 1993). This approach suggests cooperation between several systems, which forms the linkage system (also sometimes referred to as a project team): the resource system, the research system, the implementation system, the target group system and the finance system (De Vries, 1991). The resource system consists of those involved with the production of materials and products. The research system involves those responsible for the programme and effect evaluation. The implementation system includes those who are responsible for the actual implementation in practice and are well aware of the barriers and limits (e.g. health educators, teachers). The finance system consists of those who are responsible for the financial resources for the innovation (De Vries, 1991).

In order to disseminate the Romanian smoking prevention programme, three main groups may be relevant to be included in the project team: governmental agencies, nongovernmental organizations and schools.

Involvement of governmental agencies With regard to the governmental organizations, it is very important to put the smoking prevention programme on their agenda. The Romanian Ministry of Health is funding the implementation of the peer-led smoking prevention programme in 2009 . The programme will be implemented by Public Health Directorates from all over the country, pertaining to the Ministry of Health, in cooperation with non-governmental organizations and schools. This underlines the importance of training and motivating the people involved in this process in order to assure a good implementation of the programme. Moreover, it is important to encourage them to provide their feedback on barriers and enabling factors that improve programme diffusion to schools.

Nevertheless, the funding will make possible the implementation of programme in 300 classes in 2009 , but the funding of the smoking prevention programme in the future remains uncertain. Hence, it is important to obtain the commitment from the Ministry of Health for providing financial resources to enhance the diffusion of the programme on a larger scale also in the future, as part of a long-term smoking prevention strategy for Romanian adolescents. 
Involvement of non-governmental organizations Several non-governmental organizations from Romania were actively involved in the field of tobacco control and health education in the last 10 years. Many times they have been responsible for the development and implementation of the main innovative programmes for smoking prevention and reduction in Romania, including the smoking prevention programme evaluated by this thesis. As a result of their limited financial resources, one of their greatest problems may be the acquisition of funding in order to disseminate the programme at a national level. Nevertheless, their experience and social network made them important partners in the process of diffusion of the smoking prevention programme.

Involvement of schools Health education for junior high schools is not mandatory in Romania. Nevertheless, more and more schools are interested in offering healthy lifestyle education for their students and some of them have already asked for smoking prevention programmes. However, due to the lack of financial resources of the schools, the implementation of the programme depends on the possibility of receiving funding from other organizations in order to print the materials needed.

There are also schools that do not pay attention to smoking prevention or do not have knowledge about the existence of the programme. Different governmental and nongovernmental organizations should support and motivate these schools to pay more attention to the smoking prevention programme. Moreover, schools that have already adopted the programme could provide an important modelling role for later adopters. It is also very important to prevent implementation failure of the programme, by offering training to the school teachers involved in the programme as well as by providing guidance and supervision during the implementation of the programme.

In conclusion, a wider collaboration between governmental institutions, nongovernmental organizations and schools made possible the dissemination of the programme in 2009 at a national scale and has the potential to assure the financial and scientific tools needed for continuing the dissemination of the programme in the future, too.

\section{Recommendations for tobacco control in Romania}

Content of the smoking prevention programmes Smoking prevention activities should reinforce adolescent attitudes about the advantages of non-smoking, demonstrating the inaccuracies of some perceived advantages of smoking and indicating that these advantages of smoking can also be achieved by other activities. At the same time, they must help adolescents to develop skills to resist the influences of smoking peers, to cope with pressure to smoke and to increase their self-efficacy to resist smoking in stressful, social and routine situations.

Use of the social influence approach School based smoking prevention programmes that use the social influence approach must be implemented for Romanian adolescents. They must be sustained by school smoking policies and out-of-school activities held over weekends and vacations.

Development of smoking cessation programmes for Romanian adolescents Due to the fact that a considerable numbers of Romanian youngsters do start and maintain smoking, it is necessary to develop and implement smoking cessation programmes for smoking adolescents, too.

Implementation of interactive educational programmes The educational programmes must be highly interactive and should not rely on unidirectional-presented messages, but should use teaching techniques that encourage participants to actively engage in the process of forming social norms. A peer-led approach can be used as an important tool for smoking prevention. 
Comprehensive tobacco control actions School based tobacco control programmes must be supported by interventions at the meso-(community) and macro-level (policy). At the meso-level, they may include programmes to help teachers and parents to stop smoking. At the macro-level, this may involve enforcement of the laws that decrease accessibility to tobacco products by youngsters, such as price policies and tobacco-free environments.

Active role of the Romanian government It is recommended that the Romanian government take an active role in enhancing smoking prevention and health promotion. Suggested means are for instance: the inclusion of health education and smoking prevention in the curriculum of junior and senior high school students, funding the development and evaluation of smoking prevention programmes as well as the dissemination of tested effective programmes at national level, the promotion of community programmes, enforcement of legislative means and the enhancement of a health promotion approach.

Broad cooperation Although governmental institutions at all levels have an indispensable role to play in creating this boundary and in supporting actions to reduce smoking among adolescents, voluntary initiatives assumed by individuals and nongovernmental institutions are also of great importance. Long-term strategies must be implemented based on the cooperation between governmental institutions, academic areas, non-governmental organizations and mass media. 
Appendix 1. The program matrix applied to the adaptation of the smoking prevention program

\begin{tabular}{|c|c|c|c|}
\hline Determinant & Learning objectives & $\begin{array}{l}\text { Theoretical } \\
\text { methods }\end{array}$ & Practical strategies \\
\hline 䍘 & $\begin{array}{l}\text { - Increase the level of } \\
\text { knowledge about short-term } \\
\text { disadvantages of smoking on } \\
\text { the body/health } \\
\text { - Increase the level of } \\
\text { knowledge on the long- term } \\
\text { effects of smoking on the } \\
\text { body/health } \\
\text {-Increase the level of } \\
\text { knowledge about the } \\
\text { economic consequences of } \\
\text { smoking (e.g. the amount of } \\
\text { money spent by s smoker on } \\
\text { tobacco each month and what } \\
\text { other things could be bought } \\
\text { with money spent on } \\
\text { smoking) } \\
\text {-Increase the level of } \\
\text { knowledge about smoking as } \\
\text { an addiction and the dangers } \\
\text { of experimentation with } \\
\text { smoking } \\
\text {-Realize that non- smoking is } \\
\text { the only way to escape from } \\
\text { the risk of smoking } \\
\text {-Increase knowledge about } \\
\text { short-term advantages of non- } \\
\text { smoking and that non- } \\
\text { smoking is the behaviour of } \\
\text { the majority } \\
\text {-Increase awareness about } \\
\text { consequences for health of } \\
\text { passive smoking and the right } \\
\text { of non-smokers } \\
\text {-Enhance knowledge about } \\
\text { positive alternatives to } \\
\text { smoking (e.g. more healthy to manage weight or } \\
\text { stress) }\end{array}$ & $\begin{array}{l}\text { Arguments } \\
\text { Information } \\
\text { about personal } \\
\text { risk } \\
\text { Persuasive } \\
\text { communication } \\
\text { Active learning } \\
\text { Discussion } \\
\text { Modelling } \\
\text { Advance } \\
\text { organizers } \\
\text { Repeated } \\
\text { exposure }\end{array}$ & $\begin{array}{l}\text {-Adult expert which } \\
\text { demonstrated on } \\
\text { video several } \\
\text { physical effects of } \\
\text { smoking } \\
\text { - Adolescents on } \\
\text { video who introduced } \\
\text { the lessons, explained } \\
\text { the activities, played } \\
\text { real life situations } \\
\text { and conducted } \\
\text { interviews } \\
\text {-Formulating clear } \\
\text { conclusions on video } \\
\text { presentations } \\
\text {-Activities in small } \\
\text { groups peer-led to } \\
\text { stimulate awareness } \\
\text { of risks and } \\
\text { alternatives to } \\
\text { smoking } \\
\text {-Use of peer leaders } \\
\text { who coordinated the } \\
\text { group activities and } \\
\text { presented the results } \\
\text { in front of the class } \\
\text {-Manual with } \\
\text { cartoons who } \\
\text { summarized the main } \\
\text { issues presented on } \\
\text { video and contained } \\
\text { information about the } \\
\text { group activity } \\
\text {-Repetition of the } \\
\text { most important issues } \\
\text { during several } \\
\text { lessons }\end{array}$ \\
\hline
\end{tabular}




\begin{tabular}{|c|c|c|c|}
\hline Determinant & Learning objectives & $\begin{array}{l}\text { Theoretical } \\
\text { methods }\end{array}$ & Practical strategies \\
\hline 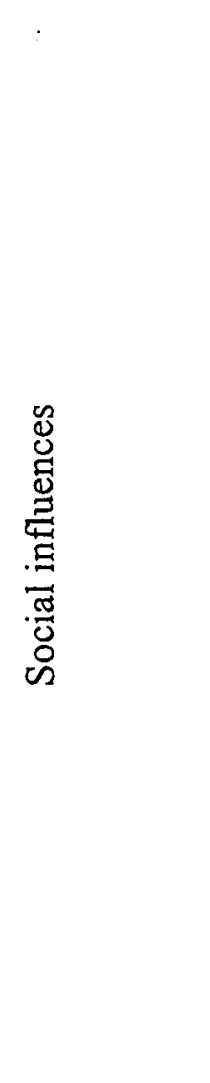 & $\begin{array}{l}\text {-Identify direct and indirect } \\
\text { pressure to smoke } \\
\text {-Distinguish between light } \\
\text { pressure and great pressure to } \\
\text { smoke } \\
\text {-Increase the level of } \\
\text { knowledge about the impact } \\
\text { of peer influence on smoking } \\
\text { behaviour of adolescents } \\
\text {-Recognize the influence of } \\
\text { advertisement for tobacco } \\
\text { products } \\
\text {-Increase the level of } \\
\text { awareness about the theme } \\
\text { that advertisement use to } \\
\text { pressure young people to } \\
\text { become smokers (e.g. } \\
\text { adventure, making friends, } \\
\text { looking good) } \\
\text {-Understand attitudes and } \\
\text { behaviour of family members } \\
\text { with regard to smoking }\end{array}$ & $\begin{array}{l}\text { Arguments } \\
\text { Persuasive } \\
\text { communication } \\
\text { Active learning } \\
\text { Discussion } \\
\text { Advance } \\
\text { organizers } \\
\text { Modelling } \\
\text { Visible } \\
\text { expectations }\end{array}$ & $\begin{array}{l}\text {-Demonstrations on } \\
\text { video } \\
\text {-Test questions for } \\
\text { students with } \\
\text { feedback presented } \\
\text { on video } \\
\text {-Activities in small } \\
\text { groups who stimulate } \\
\text { the awareness of } \\
\text { students about } \\
\text { several forms of } \\
\text { direct and indirect } \\
\text { pressure to smoke } \\
\text { - Manual with } \\
\text { cartoons } \\
\text {-Interviews with } \\
\text { family members } \\
\text { about their smoking } \\
\text { related attitudes and } \\
\text { behaviour }\end{array}$ \\
\hline
\end{tabular}




\begin{tabular}{|c|c|c|c|}
\hline Determinant & Learning objectives & $\begin{array}{l}\text { Theoretical } \\
\text { methods }\end{array}$ & Practical strategies ${ }^{1}$ \\
\hline 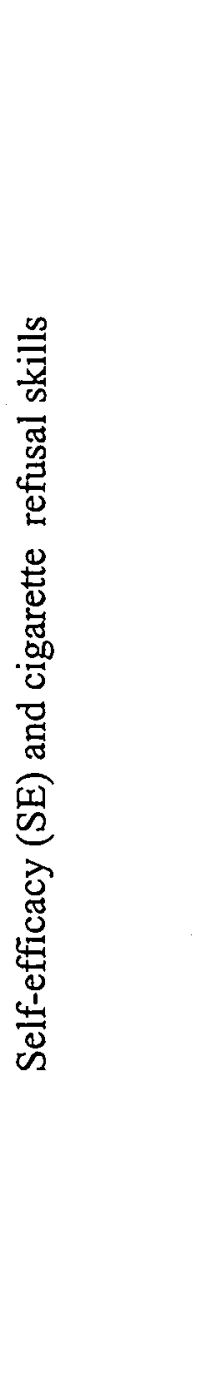 & $\begin{array}{l}\text {-Raising SE in handling } \\
\text { social pressure to smoke } \\
\text {-Raising SE towards finding } \\
\text { alternatives to smoking } \\
\text {-Developing cigarette refusal } \\
\text { skills } \\
\text {-Developing responsibility } \\
\text { and commitment to non- } \\
\text { smoking }\end{array}$ & $\begin{array}{l}\text { Modelling } \\
\text { Skills training } \\
\text { Guided practice } \\
\text { and feedback } \\
\text { Planning coping } \\
\text { responses } \\
\text { Goal setting }\end{array}$ & $\begin{array}{l}\text {-Adolescents on } \\
\text { video who } \\
\text { demonstrated how to } \\
\text { react to pressure to } \\
\text { smoke and showed } \\
\text { several cigarette } \\
\text { refusal techniques } \\
\text {-Adolescents on } \\
\text { video who showed } \\
\text { several alternatives to } \\
\text { smoking } \\
\text { - Role-plays for } \\
\text { students to practice } \\
\text { cigarette refusal skills } \\
\text { and raise levels of SE } \\
\text { in different } \\
\text { challenging situations } \\
\text {-Use of peer leaders } \\
\text { who coordinated the } \\
\text { role- plays and } \\
\text { encouraged the } \\
\text { students to sign the } \\
\text { non-smoking contract } \\
\text { and the non-smoking } \\
\text { poster } \\
\text { - Signing a non- } \\
\text { smoking public } \\
\text { poster } \\
\text { - Signing a non- } \\
\text { smoking contract }\end{array}$ \\
\hline
\end{tabular}

1-The program used similar structure and content with the Dutch smoking prevention program (De Vries et al, 1994), but the video messages were recorded in order to fit Romanian context and culture; they were piloted asking the opinion of several Romanian students, teachers and tobacco control experts 


\section{References}

Aarons, G. A., Brown, S. A., Coe, M. T., Myers, M. G., Garland A. F., Ezzet-Lofstram, R., Hazen, A. L. and Hough, R. L. (1999). Adolescent alcohol and drug abuse and health. Journal of Adolescent Health, 6, 412-421.

Abelson, R. (1985). A variance explanation paradox: When a little is a lot Psychological Bulletin, 97, 129-133.

Abraham, P. (2005). Prevalenta consumukui de droguri in Romania, 2004. (Prevalence of drug use in Romania, 2004). Bucharest: National Agency against Drugs.

Adelmann, P.K. (2005). Social environmental factors and preteen health-related behaviors. Journal of Adolescent Health, 36, 36-47.

Adler, I. and Kandel, D.B. (1981). Cross-cultural perspectives on developmental stages in adolescent drug use. Journal of Studies on Alcohol, 42, 701-715.

Ajzen, I. (1991). The theory of planned behavior. Organizational Behaviour and Human Decision Processes, 50, 179-211.

Alexander, C.S., Ensminger, M.E. and Somerfem, M.R. (1992). Behavioral risk factors for injury among rural adolescents. American Journal of Epidemiology, 136, 673685.

Allison, K. R. (1992). Academic stream and tobacco, alcohol and cannabis use among Ontario high school students. International Journal of the Addictions, 27, 561570.

Andrews, J. A., Hops, H., Ary, D., Lichtenstein, E. and Tildesley, E. (1991). The construction, validation and use of a Guttman scale of adolescent substance use: an investigation of family relationships. Journal of Drug Issues, 21, 557-572.

Anteghini, M., Fonseca, H., Ireland, M. and Blum, R.W. (2001).Health risk behaviours and associated risk and protective factors among brazilian adolescents in Santos, Brazil. Journal of Adolescent Health, 28, 295-302.

Apte, M.V., Wilson, J.S. and Korsten, M.A. (1997). Alcohol-related pancreatic damage. Alcohol Health \& Research World, 21, 13-20.

Archie, C.L., Anderson, M.M. and Gruber, E.L. (1997). Positive smoking history as a preliminary screening device for substance use in pregnant adolescents. Journal of Pediatric and Adolescent Gynecology, 10, 13-17.

Arillo-Santillan, E., Lazcano-Ponce, E., Hernandez-Avila, M., Fernandez, E., Allen, B., Valdes, R. and Samet, J. (2005). Associations between individual and contextual 
factors and smoking in 13,293 Mexican students. American Joumal of Preventive Medicine, 28, 41-51.

Arillo-Santillán, E., Fernández, E., Hernández-Avila, M.,Tapia-Uribe, M., Cruz-Valdés, A. and Lazcano-Ponce, E. (2002). Smoking prevalence and low academic performance in students aged 11-24 years in Morelos, Mexico.Salud Publica de Mexico, 44 suppl 1, 54-66.

Ariza, C., Nebot, M., Tomas, Z., Gimenez, E., Valmayor, S., Tarilonte, V. and De Vries, H (2008). Longitudinal effects of the European smoking prevention framework approach (ESFA) project in Spanish adolescents. European Journal of Public Health, 18, 491-497.

Armitage, C.J. (2004). Evidence that implementation intentions reduce dietary fat intake: A randomized trial, Health Psychology, 23, 319-323.

Armitage, C.J. and Conner, M. (2001). Efficacy of the Theory of Planned Behaviour: A meta-analytic review. British Journal of Social Psychology, 40, 471-499.

Arseneault, L., Cannon, M., Poulton, R., Murray, R., Caspi, A. and Moffitt, T.E. (2002). Cannabis use in adolescence and risk for adult psychosis: longitudinal prospective. British Medical Journal, 325, 1212-1213.

Ary, D.V. and Biglan, A. J. (1988). Longitudinal changes in adolescent cigarette smoking behavior: onset and cessation. Behavioural Medicine, 11, 361-382.

Ausems, M. (2003). Smoking prevention: Comparing in school, tailored out of school and boosters interventions. Dissertation, Maastricht.

Ausems, M., Mesters, I., Van Breukelen, G., De Vries, H., Brug, J., Steenhuis, I. and Van Assema, P. (2002). Short-term effects of a randomized computer-based out-ofschool smoking prevention trial aimed at elementary schoolchildren. Preventive Medicine, 34, 581-589.

Bandura, A. (1977). Social learning theory. Englewood Cliffs, New York: Prentice Hall.

Bandura, A. (1986). Social foundations of thought and action: A social cognitive. Englewood Cliffs, New York: Prentice Hall.

Barrett, S., Tichauer, M., Leyton, M. and Pihl, R. (2006). Nicotine increases alcohol selfadministration in non-dependent male smokers. Drug and Alcohol Dependence, $81,197-204$.

Bartlett, R., Holditch, D. and Belyea, M. (2005). Clusters of Problem Behaviours in Adolescents. Research in Nursing \& Health, 28, 230-239. 
Bartholomew, L., Parcel, G. and Kok, G. (1998). Intervention mapping: a process for developing theory and evidence based health education programs. Health Education and Behaviour, 25,545-563.

Basen-Engquist, K., Edmundson, E.W. and Parcel, G.S. (1996). Structure of health risk behavior among high school students. Journal of Consulting and Clinical Psychology, 64, 764-775.

Best, D., Rawaf, S., Rowley, J., Floyd, K., Manning, V. and Strang, J. (1997). Ethnic and gender differences in drinking and smoking among London adolescents. Ethnicity in Health, 6, 51-57.

Best, J.A., Thomson, S.J., Santi, S.M., Smith, E.A. and Brown, K.S. (1988). Preventing cigarette smoking among school children. Annual Review of Public Health. $9,161-201$.

Biglan, A., Ary, D.V., Smolkowski, K., Duncan, T. and Black, C. (2000). A randomised controlled trial of a community intervention to prevent adolescent tobacco use. Tobacco Control, 9, 24-32.

Black, D.R., Tobler, N.S. and Sciacca, J.P. (1998). Peer helping/involvement: an efficacious way to meet the challenge of reducing alcohol, tobacco, and other drug use among youth? Journal of School Health, 68, 87-93.

Blomqvist, O., Ericson, M., Johnson, D., Engel, J. and Soderpalm, B. (1996). Voluntary ethanol intake in the rat: Effects of nicotine acetylcholine receptor blockade or subchronic nicotine treatment. European Journal of Pharmacology, 314, 257267.

Bonaguro, J.A. and Bonaguro, E.W.(1987). Self-concept, stress symptomatology and tobacco use. Journal of School Health, 57, 56-58.

Bonnie, R.J. and O'Connell, M.E.(2004). Reducing underage drinking-A collective responsibility. Washington, DC: National Academies Press.

Botvin, G.J., Baker, E., Goldberg, C.J., Dusenbury, L and Botvin, E.M.(1992). Correlates and predictors of smoking among black adolescents. Addictive Behaviours, 17 , 97-103.

Bracht, N. (1990). Health Promotion at the Community Level. Newbury Park: Sage Publications.

Brădean, M. (1999). De ce vorbim despre bolile cu transmitere sexuala? (Why we talk about sexually transmitted diseases?). Jurnal Informativ, 9, 6-7. 
Brener, N. and Collins, J. (1998). Co-occurrence of health-risk behaviors among adolescents in the United States. Journal of Adolescent Health, 22, 209-213.

Brook, J. S., Balka, E. B. and Whiteman, M. (1999). The risks for late adolescence of early marijuana use. American Journal of Public Health, 89,1549-1554.

Bruvold, W. (1993). A meta-analysis of adolescent smoking prevention programs. American Journal of Public Health, 83, 872-880.

Bucur, G.E. (1999). Sanatatea elevilor. (Health of pupils). Viata Medicală, 26,1.

Burkholder, G.J. and Harlow L. (2003). An Illustration of a Longitudinal Cross-Logged Design for Larger Structural Equation Models. Structural Equation Modeling, 10, 465-486.

Byrne, D.G., Byrne, A.E., and Reinhart, M.I. (1995). Personality, stress and the decision to commence cigarette smoking in adolescence. Journal of Psychosomatic Research, 39, 53-62.

California Department of Education. (2002). Alcohol, tobacco, other drug and violence prevention: Research update. Sacramento:CDE Press.

Camp, D.E., Klesges, R.C. and Relyea, G. (1993). The relationship between body weight concerns and adolescent smoking. Health Psychology, 12, 24-32.

Center for Health Policies and Services. (2004).Fumatul si sanatatea publica in Romania. Cunostintele, atitudinile si comportamentul legate de fumat in randul populatiei generale. (Smoking and public health in Romania. Knowledge, attitudes and practices regarding tobacco use among general population in Romania). Bucharest: The Center:

Chaloupka, F. J., Pacula, R. L., Farrelly, M., Johnston, L. D.,O'Malley, P. M. and Bray, J. W.(1999). Do higher, cigarette prices encourage youth to use marijuana? Cambridge, MA: National Bureau of Economic Research.

Chaloupka, F.J. and Wechsler, H. (1997). Price, tobacco control policies and smoking among young adults. Journal of Health Economics, 16, 359-373.

Chang, F.C., Lee, C.M, Lai, H.R., Chiang, J.T., Lee, P.H and Chen, W.J. (2006). Social influences and self-efficacy as predictors of youth smoking initiation and cessation: a 3-year longitudinal study of vocational high school students in Taiwan. Addiction, 101,1645-1655.

Charlton, A. and Blair, V. (1989). Predicting the onset of smoking in boys and girls. Social Science and Medicine, 29, 813-818. 
Chassin, L., Presson, C.C., Rose, J.S. and Sherman, S.J. (1996). The natural history of cigarette smoking from adolescence to adolthood: Demographic predictors of continuity and change. Health Psychology, 15, 478-484.

Cohen, J. (1988). Statistical Power Analysis for the Behavioral Sciences. Hillsdale, NJ: Erlbaum.

Cohen, J. (1992). A power primer. Psychological Bulletin, 112,155-59.

Cohen, J. (1994). The earth is round (p<0.05). American Psychologist, 49, 997-1003.

Collins, L. M., Sussman, S., Mestel-Rauch, J., Dent, C. W., Johnson, C. A., Hansen, W. B. and Flay, B. R. (1987). Psychosocial predictors of young adolescent cigarette smoking: A sixteen-month, three-wave longitudinal study. Journal of Applied Social Psychology, 17, 554-573.

Conrad, K. M., Flay, B. R. and Hill, D. (1992). Why children start smoking cigarettes: predictors of onset. British Journal of Addiction, 87, 1711-1724.

Cooper, M.L. (2002). Alcohol Use and Risky Sexual Behavior among College Students and Youth: Evaluating the Evidence. Journal of Studies on Alcohol, Supplement 14, 101-117.

Cuijpers, P. (2002). Effective ingredients of school based drug prevention programs. A systematic review. Addictive Behaviours, 27, 1009-1023.

Currie, C. (2004). Young People's Health in Context: international report from the HBSC 2001/02 survey. Copenhagen: WHO Regional Office for Europe.

De Vries, H. (1989). Smoking prevention in Dutch adolescents. Dissertation, Maastricht.

De Vries, H. (1991). Health Psychology. Maastricht: Maastricht University.

De Vries, H. (1998). Planing and Evaluating Health Promotion. In David, S. and Weston, R., Evaluating Health Promotion. Cheltenham: Stanley Thornes.

De Vries, H. (1999). Smoking and young people: The wider issues. Health Promotion Northern Ireland, 8, 11-13.

De Vries, H. (2000). Smoking prevention and smoking Cessation. In N. Smelser and P. Baltes (Eds.), The International Enciclopedia of the Social \&Behavioural Sciences, Oxford:Pergamon.

De Vries, H. (2007). Comment on "Modifiable family and school environmental factors associated with smoking status among adolescents in Guangzhou, China". Preventive Medicine, 45, 119-120. 
De Vries, H., Backbier, E., Dijkstra, M., Van Breukelen, G.,Parcel, G. and Kok, G. (1994). A Dutch social influence smoking prevention approach for vocational school students. Health Education Research, 9, 365-374.

De Vries, H., Backbier, E., Kok, G. and Dijkstra, M. (1995). The impact of social influences in the context of attitude, self-efficacy, intention and previous behaviour as predictors of smoking onset. Journal of Applied Sociology and Psychology, 25, 237-257.

De Vries, H. and Brug, J. (1999). Computer tailored interventions motivating people to adopt health promoting behaviours: Introduction to a new approach. Patient education and counseling, 36, 99-105.

De Vries, H., Candel, M., Engels, R.C and Mercken, L. (2006a). Challenges to the peer influence paradigm: results for 12-13 year olds from six European countries from the European Smoking Prevention Framework Approach study. Tobacco Control, 15, 83-89.

De Vries, H., Dijk, F., Wetzels, J., Mudde, A., Kremers, S., Ariza C., Vitória P.D, Fielder, A., Holm, K., Janssen, K., Lehtovuori, R. and Candel, M. (2006b). The European Smoking prevention Framework Approach (ESFA): effects after 24 and 30 months. Health Education Research, 2, 116-132.

De Vries, H., Dijkstra, M. and Kok, G. (1992). A Dutch Smoking Prevention Project: An overview. Hygie, XI(2), 14-17.

De Vries, H., Engels, R., Kremers, S., Wetzels, J. and Mudde, A. (2003a). Parents and friends' smoking status as predictors of smoking onset: findings from six European countries. Health Education Research, 18, 627-36.

De Vries, H. and Kok, G.J. (1986). From determinants of smoking behaviour to the implications for a prevention programme. Health Education Research, 1, 85-94.

De Vries, H. and Mudde, A.N. (1998). Predicting stage transitions for smoking cessations applying the Attitude-Social influence-Efficacy model. Psychology and Health, 13, 369-385.

De Vries, H., Mudde, A.N., Kremers, S., Wetzels, J., Uiters, E., Ariza, C., Vitória, P.D., Fielder, A., Holm, K., Janssen, K., Lehtovuori, K., and Candel, M. (2003b) The European Smoking Prevention Framework Approach (ESFA): short-term effects. Health Education Research, 18, 649-663.

De Vries, H., Mudde, A.N., Leijs, I., Charlton, A., Vartiainen, E., Vartiainen, E., Buijs, G., Pais Clemente, M., Storm, H., Navarro,A., Nebot, M., Prins' T. and Kremers, 
S.(2003c). The European Smoking prevention Framework Approach (ESFA): an example of integral prevention. Health Education Reserch, 18, 611-626.

De Vries, H., Van't Riet, J., Panday, S. and Reubsaet, A. (2007). Access point analysis in smoking and nonsmoking adolescents: findings from the European Smoking Prevention Framework Approach study. European Journal of Cancer Prevention, $16,257-265$.

Dierker, L., Lloyd-Richardson, E., Stolar, M., Flay, B., Tiffany, S., Collins, L., Bailey, S., Nichter, M., Nichter, M., and Clayton, R. (2006). The proximal association between smoking and alcohol use among first year sollege students. Drug and Alcohol Dependence, 81, 1-9.

Dijkstra, M., Mesters, I., De Vries, H., Van Breukelen, G. and Parcel, G.S. (1999). Effectiveness of a social influence approach and boosters to smoking prevention. Health Education Research, 14, 791-802.

Dolcini, M.M., Adler, N.E. and Ginsberg, D. (1996). Factors influencing agreement between self-reports and biological measures of smoking among adolescents. Journal of Research on Adolescence, 6, 515-542.

Doll, R. (1998). Uncovering the effects of smoking: Historical Perspective. Statistical method in medical research, 7, 87-117.

Donovan, J.E. and Jessor, R. (1985). Structure of problem behavior in adolescence and young adulthood. Journal of Consulting and Clinical Psychology, 53, 890-904.

Dormitzer, C.M., Gonzalez, G.B., Penna, M., Bejarano, J., Obando, P., Sanchez, M., Vittetoe, K., Gutierrez, U., Alfaro, J., Meneses, G., Bolivar Diaz, J., Herrera, M., Hasbun, J., Chisman, A., Caris, L., Chen, C.Y., and Anthony, J.C. (2004). The PACARDO research project: youthful drug involvement in Central America and the Dominican Republic. Revista Panamericana de Salud Publica, 15, 400-416.

Drummond, C.(1990). The relationship between alcohol dependence and alcohol-related problems in a clinical population Addiction, 85, 357-366.

Dryfoos, J.G. (1990). Adolescents at Risk: Prevalence and Prevention. New York: Oxford University Press.

Duncan, S. C., Duncan, T. E. and Hops, H. (1998). Progressions of alcohol, cigarette, and marijuana use in adolescence. Journal of Behavioral Medicine, 4, 375-388.

Durant, R.H., Smith, J.A., Kreiter S.R. and Krowchuk, D.P. (1999). The relationship between early age of onset of initial substance use and engaging in multiple 
health risk behaviors among young adolescents. Archives of Pediatrics and Adolescent Medicine, 153, 286-291.

Dusenbury, L., Brannigan, R., Falco, M. and Hansen, W.B. (2003). A review of research on fidelity of implementation: implications for drug abuse prevention in school settings. Health Education Research, 18, 237-256.

Ebin, V.J., Sneed, C.D., Morisky, D.E., Rotheram-Borus M.J., Magnusson, A.M. and Malotte, C.K. (2001). Acculturation and interrelationships between problem and health-promoting behaviors among latino adolescents. Journal of Adolescent Health, 28, 62-72.

Eiser, J.R., Morgan, M., Gammage, P., Brook, N. and Kirby, R. (1991). Adolescent health behaviour and similarity attractions: Friends share smoking habits (really), but much more besides. British Journal of Social Psychology, 30, 339-348.

Ellickson, P. L., Hays, R. D. and Bell, R. M. (1992). Stepping through the drug use sequence: longitudinal scalogram analysis of initiation and regular use. Journal of Abnormal Psycholog, 101, 441-451.

Ellickson, P.L., Tucker, J.S., and David, J. K. (2001). High-risk behaviors associated with early smoking: results from a 5-year follow-up. Journal of Adolescent Health, 28, 465-473.

Engels, R.C. and Willemsen, M. (2004). Communication about smoking in Dutch families: associations between anti-smoking socialization and adolescent smoking-related cognitions. Health Education Research, 19, 227-238.

Engels, R.C.M.E, Knibbe, R.A. and Drop, M.J. (1999). Predictability of smoking in adolescence: between optimism and pessimism. Addiction, 94, 115-124.

Engels, R.C.M.E., Finkenauer, C., Kerr, M. and Stattin, H. (2005). Illusions of parental control: Parenting and sinoking onset in Dutch and Swedish adolescents. Journal of Applied Social Psychology, 35, 1912-1935:

Engels, R.C.M.E., Knibbe, R.A., Drop, M.J. and De Haan, Y.T. (1997). Homogeneity of cigarette smoking within peer groups: influence or selection? Health Education \&Behaviour, 24, 801-811.

Ennett, S.T., Bauman, K.E., Foshee, V.A., Pemberton, M. and Hicks, K.A. (2001). Parentchild communication about adolescent tobacco and alcohol use: what do parents say and does it affect youth behavior? Journal of Marriage and the Family, 63, $48-62$. 
English, D.R., Holman, C.D.J, Milne, E., Winter, M.G., Hulse, G.K., Codde, J.P., Bower, C.I., Corti,B. , de Klerk, N., Knuima, M.W., Kurinzuk, J.J., Lewin, G.F. and Ryan, G.A. (1995). The Quantification of Drug Caused Morbidity and Mortality in Australia, 1992. Canberra: Commonwealth Department of Human Services and Health.

European Comission. (2007). Romania-political profile.

http://ec.europa.eu/enlargement/archives/romania/political profile en.htm.

Accesed on July 2007.

Erhard, R. (1999). Peer-led and adult-led programs: student perceptions. Journal of Drug Education, 29, 295-308.

Evans, M. (1991). The problem of analyzing multiplicative composites: Interaction revisited. American Psychologyst, 46, 6-15.

Everett, S.A., Malacher, A.M., Sharp, D.J., Husten, C.G. and Giovino, G.A. (2000). Relationship between cigarette, smokeless tobacco and cigar use and other health risk behaviours among U.S high school students. Journal of School Health, 70, 234-240.

Faeh, D., Viswanathan, B., Chiolero, A., Warren, W., and Bovet, P. (2006). Clustering of smoking, alcohol drinking and cannabis use in adolescents in a rapidly developing country. BMC Public Health, 6, 169.

Farkas, A.J., Gilpin, W. and Pierce, J.P. (2000). Associations between household and workplace smoking restrictions and adolescent smoking. Journal of the American Medical Associations, 284, 717-727.

Farrelly, M., Bray, J. W., Zarkin, G. A., Wendling, B. W. and Pacula, R. L. (1999). The effects of prices and policies on the demand for marijuana: evidence from the National Household Surveys analyses. Cambridge, MA: National Bureau of Economic Research.

Fergusson, D.M., Horwood, L. J. and Swain-Campbell, N. R. (2003). Cannabis dependence and psychotic symptoms in young people. Psychological Medicine, 33, 15-21.

Fetro, J.V., Coyle, K.K. and Pham, P. (2001). Health risk behaviors among middle school students in a large majority-minority district. Journal of School Health, 71, 30-37.

Field, A.E., Austin, S.B., Frazier, A.L., Gillman, M.W., Camargo, C.A. and Colditz, G.A. (2002). Smoking, getting drunk, and engaging in bulimic behaviors: in which order are the behaviors adopted? Journal of American Academy of Child and Adolescent Psychiatry, 41, 846-853. 
Fishbein, M. and Ajzen, I. (1975). Belief, Attitude, Intention, and Behavior: An Introduction to Theory and Research. Reading, MA: Addison-Wesley.

Flay, B. (1993). Youth tobacco use: risks, patterns, and control. In Slade, J. and Orleans, C.T. (Eds.). Nicotine Addiction: Principles and Management. New York: Oxford University Press.

Flay, B.R, D'Avernas, J.R., Best, J.A., Kersell, M.W.and Ryan, K.B. (1983).Cigarette smoking: why young people do it and ways of preventing it. In Mc Grath, P.J. and Firestone, P. (Eds.), Pediatric and adolecent behavioural medicine. New York: Springer.

Flay, B.R., Graumlich, S., Segawa, E., Burns, J.L. and Holliday, M.Y. (2004). Effects of 2 prevention programs on high-risk behaviors among African American youth: a randomized trial. Archives of Pediatrics and Adolescent Medicine, 158, 377-384.

Flay, B.R., Phil, D., Hu, F.B. and Richardson, J. (1998). Psychosocial Predictors of Different Stages of Cigarette Smoking among High School Students. Preventive Medicine, 27, 9-18.

Fleming, R., Leventhal, H., Glynn, K. and Ershler, J. (1989). The role of cigarettes in the initiation and progression of early substance use. Addictive Behaviors, 14, 261272.

Forrester, K., Biglan, A., Severson, H.H. and Smolkowski, K. (2007). Predictors of smoking onset over two years. Nicotine and Tobacco Research, 9, 1259-1267.

Forster, J.L., and Wolfson, M. (1998). Youth access to tobacco: Policies and politics. Annual Review of Public Health, 19, 203-235.

Garfein, R. S., Vlahov, D., Galai, N., Doherty, M. C. and Nelson, K.E. (1996). Viral infections in short -term injection drug users: The prevalence of the hepatitis $C$, hepatitis B, Human Immunodeficiency and Human T-Lymphotropic Viruses. American Journal of Public Health, 86, 655-661.

Giancola, P.R. (2002). Alcohol-Related Aggression during the College Years: Theories, Risk Factors and Policy Implications. Journal of Studies on Alcohol, Supplement 14, 129-139.

Gilmore, A.B. and McKee, M. (2004). Moving East: how the transnational tobacco industry gained entry to the emerging markets of the former Soviet Union-part II: an overview of priorities and tactics used to establish a manufacturing presence. Tobacco Control, 13, 151-160. 
Glanz, K., Rimer, B.K. and Lewis, F.M. (2002). Health Behavior and Health Education. Theory, Research and Practice. San Fransisco: Wiley \& Sons.

Glendinning, A. and Inglis, D. (1999). Smoking behaviour in youth: the problem of low selfesteem? Journal of Adolescence, 22, 673-682.

Gmel, G., Bissery, A., Gammeter, R., Givel, J.C., Calmes, J.M., Yersin, B. and Daeppen, J.B. (2006).Alcohol-Attributable Injuries in Admissions to a Swiss Emergency Room-An Analysis of the Link Between Volume of Drinking, Drinking Patterns, and Preattendance Drinking. Alcoholism: Clinical and Experimental Research, 30, 501-509.

Godin, G. and Kok, G. (1996). The Theory of Planned Behavior: A Review of Its Applications to Health-Related Behaviors. American Journal of Health Promotion, 11, 87-98.

Green, L.W. and Kreuter, M.W. (1990). Health promotion as a Public Health strategy for the 1990s. Annual Review of Public Health, 11, 319-334.

Green, L.W., and Kreuter, M.W. (1991). Health Promotion Planning: An Educational and Environmental Approach. Palo Alto: Mayfield Publishing Co.

Grunbaum J.A, Kann, L., Kinchen, S., Ross, S. and Hawkins, J. (2004). Youth Risk Behavior Surveillance-UnitedStates, 2003. Morbidity and Mortality Weekly Report, 53, 536.

Guilamo-Ramos, V., Litardo, H.A. and Jaccard, J. (2005). Prevention programs for reducing adolescent problem behaviors: Implications of the co-occurrence of problem behaviors in adolescence. Journal of Adolescent Health, 36, 82-86.

Hanna, E.Z., Yi, H.Y., Dufour, M.C. and Whitmore, C.C. (2001). The relationship of earlyonset regular smoking to alcohol use, depression, illicit drug use, and other risky behaviors during early adolescence: results from the youth supplement to the third national health and nutrition examination survey. Journal of Substance Abuse, 13, 265-282.

Hansen, W.B. (1992). School-based substance abuse prevention: a review of the state of the art in curriculum, 1980-1990. Health Education Research, 7, 403-430.

Hansen, W.B., Mallote, K.C. and Fielding, J.E. (1985). The bogus pipeline revisited: the use of the threat as a means of increasing self-reports of tobacco use. Journal of Applied Psychology, 70, 789-792.

Harel, Y. (1999). A cross-national study of youth violence in Europe. International Journal of Adolescent Medicine and Health, 11, 121-134. 
Heath, A.C., Madden, P.A., Grant, J.D., McLaughlin, T.L., Todorov, A.A. and Bucholz, K.C. (1999). Resiliency factors protecting against teenage alcohol use and smoking: influence of religion, religious involvement and values and ethnicity in the Missouri Adolescent Female Twin Study. Twin Research, 2, 145-155.

Henningfield, J. E., Clayton, R. and Pollinn, W. (1990). Involvement of tobacco in alcoholism and illicit drug use. British Journal of Addiction, 85, 279-292.

Hibell, B., Andersson, B., Bjarnason, T., Ahlström, S., Balakireva, O., Kokkevi, A. and Morgan, M. (2004).The ESPAD Report 2003. Alcohol and Other Drug Use Among Students in 35 European Countries. Stockholm: The Swedish Council for Information on Alcohol and Other Drugs (CAN) and the Pompidou Group at the Council of Europe.

Hibell, B., Andersson, B., Ahlström, S., Balakireva, O., Bjarnason, T., Kokkevi, A. and Morgan, M. (2000). The 1999 ESPAD Report. Alcohol and Other Drug Use Among Students in 30 European Countries. Stockholm: The Swedish Council for Information on Alcohol and Other Drugs (CAN) and The Pompidou Group at the Council of Europe.

Hoffman, J.H., Welte, J.W., and Bames, G.M. (2001). Co-occurrence of alcohol and cigarette use among adolescents. Addictive Behaviours, 26, 63-78.

Holm, K., Kremers, S. and De Vries, H. (2003). Why do Danish adolescents take up smoking? European Journal of Public Health, 13, 67-74.

Hoving, C., Reubsaet, A. and De Vries, H. (2007). Predictors of smoking stage transitions for adolescent boys and girls. Preventive Medicine, 44, 485-489.

Hoving, E.F., Mudde, A.N. and De Vries, H. (2006). Predictors of smoking relapse in a sample of Dutch adult smokers; the roles of gender and action plans. Addictive Behaviours, 31, 1177-1189.

Huisman, M., Kunst, A.E. and Mackenbach, J.P. (2005): Educational inequalities in smoking among men and women aged 16 years and older in 11 European countries. Tobacco Control, 14, 106-113.

Huver, R.M.E, Engels, R. C. M. E., Breukelen, G.V and De Vries, H. (2007). Parenting style and adolescent smoking cognitions and behaviour. Psychology and Health, 22, 575-593.

Hyland $_{2}$ A., Li, Q., Bauer, J.E., Giovino, G.A., Bauer, U. and Cummings, K.M. (2006). State and community tobacco-control programs and smoking-cessation rates among 
adult smokers: what can we learn from the COMMIT intervention cohort? American Journal of Health Promotion, 20, 272-281.

Irwin, C.E., Cataldo, M.F., Matheny, A.P. and Peterson, L. (1992). Health consequences of behaviors: Injury as a model. Pediatrics, 90, 798- 807.

Jackson, C., Bee Gates, D.J. and Henriksen, L. (1994). Authorative parenting, child competencies and initiation of cigarette smoking. Health Education Quartely, 21, 103-116.

Jackson, K. M., Sher, K. J., Cooper, M. L. and Wood, P. K. (2002). Adolescent alcohol and tobacco use: onset, persistence and trajectories of use across two samples. Addiction, 97, 517-531.

Jason, L.A. (1998). Tobacco, drug and HIV preventive media interventions. American Journal of Community Psychology, 26,151-187.

Jensen, M.K., Sørensen, T.I., Andersen, A.T., Thorsen, T., Tolstrup, J.S., Godtfredsen, N.S., and Grønbaek, M. (2003). A prospective study of the association between smoking and later alcohol drinking in the general population. Addiction, 98, 355363.

Jernigan, D.H. (2001). Global Status Report: Alcohol and Young People. Geneva: World Health Organization.

Jessor, R. (1991). Risk behavior in adolescence: A psychosocial framework for understanding and action. Journal of Adolescent Health, 12, 597-605.

Johnson, K. and Jennison, K. (1992). The drinking-smoking syndrome and social context. International Journal of the Addictions, 27, 749-792.

Johnson, P. B., Boles, S. M., Vaughan, R. and Kleber, H. D. (2000). The co-occurrence of smoking and binge drinking in adolescence. Addictive Behaviors, 25, 779-783.

Johnston, L. D., Bachman, J.G., and O'Malley, P. M. (1997). Monitoring the future: Questionnaire responses from the nation's high school seniors, 1995. Ann Arbor, Ml: Institute for Social Research.

Jøsendal, O., Aarø, L.E. and Bergh, I.H. (1998). Effects of a school-based smoking prevention program among sub-groups of adolescents. Health Education Research, 13, 215-224.

Josendal, O., Aaro, L.E., Torsheim, T. and Rasbash, J. (2005). Evaluation of the schoolbased smoking-prevention program BE smokeFREE. Scandinavian Journal of Psychology, 46, 189-199. 
Kandel, D. and Yamaguchi, K. (1993). From beer to crack: Developmental patterns of drug involvement. American Journal of Public Health, 83,851-855.

Kandel, D. B. and Faust, R. M. A. (1975). Sequence and stages in patterns of adolescent drug use. Archives of General Psychiatry, 32, 923-932.

Kandel, D. B., Yamaguchi, K. and Chen, K. (1992). Stages of progression in drug involvement from adolescence to adulthood:further evidence for the gateway theory. Journal of Studies on Alcohol, 53, 447-457.

Kaplan, C., Zabkiewicz, D., McPhee, S., Nguyen, T., Gregorich, S., Disogra, C., Hilton, J. and Jenkins, C. (2003). Health-compromising behaviors among Vietnamese adolescents: the role of education and extracurricular activities. Journal of Adolescent Health, 32, 374-383.

Kim, Y.H. (2005). Korean adolescents' smoking behavior and its correlation with psychological variables. Addictive Behaviors, 30, 343-350.

King, A.C. and Epstein, A.M. (2005). Alcohol dose-dependent increases in smoking urge in light smokers. Alcoholism: Clinical and Experimental Research, 29, 547-552.

Kirby, D. (1995). A review of educational programs designed to reduce sexual risk-taking behaviors among school-aged youth in the United States. Santa Cruz: ETR Associates.

Klepp, K.I., Tell, G. and Vellar, O. (1993). Ten-year follow-up of the Oslo Youth Study Smoking Prevention Program. Preventive Medicine, 22, 453-462.

Klingemann, H. and Gmel, G. (2001). Mapping the Social Consequences of Alcohol Consumption. The Netherlands: Kluwer Academic Publishers.

Kolbe, L.J., Kann, L. and Collins, J.L. (1993). Overview of the Youth Risk Behavior Surveillance System. Public Health Reports, 108, Suppl 1, 2-10.

Kolip, P. and Schmidt, B. (1999). Gender and health in adolescence. Copenhagen: WHO Regional Office for Europe.

Kremers, S. P.J, Visscher, T. L .S, Seidell, J.C. Van Mechelen,W. and Brug, J. (2005). Cognitive Determinants of Energy Balance-Related Behaviours: Measurement Issues. Sports Medicine, 35, 923-933.

Kremers, S.P.J., Mudde A.N., and De Vries, H. (2001). Subtypes within the precontemplation stage of adolescent smoking acquisition. Addictive Behaviours, $26,237-251$. 
Kremers, S.P.J., Mudde, A.N. and De Vries, H. (2004a). Model of Unplanned Smoking Initiation of Children and Adolescents (MUSICA): an integrated stage model of smoking behavior. Preventive Medicine, 38, 5, 643-651.

Kremers, S.P.J., Mudde, A.N., De Vries, N.K., Brug, J. and De Vries, H. (2004b). Unplanned smoking initiation: new insights and implications for interventions. Patient Education and Counseling, 55, 345-352.

Kremers, S.P.J, Mudde, A.N., De Vries, H. (2004c) Development and longitudinal test of an instrument to measure behavioral stages of smoking initiation. Substance Use and Misuse, 39, 225-252.

Kroeze, W., Werkman, A. and Brug, J. (2006). A systematic review of randomized trials on the effectiveness of computer tailored education on physical activity and dietary behaviours. Annals of Behavioural Medicine, 31, 205-223.

Ku, L., Sonenstein, F.L. and Pleck, J.H. (1992). Patterns of HIV risk and preventive behaviors among teenage men. Public Health Reports, 107, 131-138.

Kulbok, P.A. and Cox, C.L. (2002). Dimensions of Adolescent Health Behavior. Journal of Adolescent Health, 31, 394-400.

Lantz, P.M., Jacobson, P.D., Warner, K.E., Wasserman, J., Pollack, H.A., Berson, J. and Ahlstrom, A. (2000). Investing in youth tobacco control: a review of smoking prevention and control strategies. Tobacco Control, 9, 47-63.

Laza, V. and Lotrean L.M. (2003). Smoking among Romanian young people. ENYPAT Newsletter-Interaction, 28, 16.

Lazcano-Ponce, E. C., Hernandez, B., Cruz-Valdez, A., Allen, B., Diaz, R., Hernandez, C., Anaya, R. and Hernandez-Avila, M. (2003). Chronic disease risk factors among healthy adolescents attending public schools in the state of Morelos, Mexico. Archives of Medical Research, 34, 222-236.

Lewinsohn, P. M., Rohde, P. and Brown, R. A. (1999). Level of current and past adolescent smoking as predictors of future substance use disorders in young adulthood. Addiction, 94, 913-921.

Lippe, J., Brener, N., Kann, L., Kinchen, S., Harris, W., McManus, T. (2008). Youth risk behavior surveillance--Pacific Island United States Territories, 2007.Morbidity and Mortality Weekly Report, 57, 28-56.

Lipsey, M. (1990). Design sensitivity: Statistical power for experimental research. Newbury Park, Ca: Sage Publications: 
Lo, S.K., Blaze Temple, D., Binns, C.W. and Ovenden, C. (1993). Adolescent cigarette consumption: the influence of attitudes and peer drug use. International Journal of the Addictions, 28, 1515-1530.

Lopez, A.D., Collishaw, N.E. and Tapani, P. (1994). A descriptive model of the cigarette epidemic in developed countries. Tobacco Control, 3, 242-247.

Lotrean, L.M. and Laza, V. (2001). Knowledge, attitude and behaviour of students of a romanian university center concerning HIV/AIDS. Central European Journal of Ocupational and Environmental Medicine, 7, 45-52.

Lotrean, L.M. and Laza, V. (2002).Opinions and practices of students from Cluj-Napoca regarding drug use. Clujul Medical, 2, 187-192.

Lotrean, L.M., Ionut, C. and De Vries, H. (2005). De ce fumeaza adolescentii romani? (Why do Romanian adolescents smoke?). In Proceedings of Jubilee Scientific Meeting. Cluj-Napoca, Romania: Institute of Public Health from Cluj-Napoca.

Lotrean, L.M, Laza, V., Ionut, C., De Vries H. (2008). Assessment of health risk behaviors and their interrelationship among Romanian young people. In Proceedings of the XVIII International Congress of Epidemiology. Porto Alegre, Brasil: International Society of Epidemiology.

Lotrean, L.M., Mesters, I., Ionut, C. and De Vries, H. Predictability of smoking onset among Romanian adolescents, manuscript submitted for publications.

Lotrean, L.M., Ionut, C. and De Vries, H. (2006). Tobacco use among Romanian youth. Salud Publica de Mexico, 48 suppl 1, 107-112.

Lowry, R., Kann, L., Collins, J.L. and Kolbe, L.J. (1996). The effect of socioeconomic status on chronic disease risk behaviors among US adolescents. Journal of American Medical Association, 276, 792-806.

Macaskill, P., Pierce, J.P. and Simpson, J.M. (1992). Mass media-led antismoking campaign can remove the education gap in quitting behavior. American Journal of Public Health, 82, 96-98.

Markham,W.A, Aveyard, P., Thomas, H. Charlton, A., Lopez, M.L and De Vries, H.( 2004). What determines future smoking intentions of 12-to13 year old UK AfricanCaribbean, Indian, Pakistani and white young people? Health Education Research, 19,15-28.

Mathers, M., Toumbourou, J.W., Catalano, R.F., Williams, J. and Patton, G.C. (2006). Consequences of youth tobacco use: a review of prospective behavioral studies. Addiction, 101, 948-958. 
Mayor, S. (2001). Alcohol and drug misuse sweeping world, says WHO. British Medical Journal, 322 (7284), 449.

McCool, J.P., Cameron, L.D. and Petrie, K.J. (2001). Adolescent perceptions of smoking imagery in film. Social Science and Medicine, 52, 1577-1587.

McDermott, R.J., Sarvela, P.D., Hoalt, P.N., Bajracharya, S.M., Marty, P.J. and Emery, E.M. (1992). Multiple correlates of cigarette use among high school students. Journal of School Health, 62, 146-150.

McNeil, A.D., Jarvis, M.J., Stapleton, J.A., Russel, M.A., Eiser, J.R., Gammage, P. and Gray, E.M. (1988). Prospective study of factors predicling uptake of smoking in adolescents. Journal of Epidemiology and Community Health, 43, 72-78.

Mellanby, A.R., Rees, J. and Tripp, J.H. (2000). Peer-led and adult-led school health education: a critical review of available comparative research. Health Education Research, 15, 533-545.

Merrill, J.C., Kleber, H.D., Shwartz, M., Liu, H. and Lewis, S.R. (1999). Cigarettes, alcohol, marijuana, other risk behaviors, and American youth. Drug and Alcohol Dependence, 56, 205-212.

Mihailide, M. (1999). Speranta se muta in mileniul trei. (The hope is moving to the third millennium). Viaţa Medicală, 46, 1-2.

Mpofu, E., Caldwell, L., Smith, E., Flisher, A.J., Mathews, C., Wegner, L. and Vergnani, T. (2006). Rasch modeling of the structure of health risk behavior in South african adolescents. Journal of Applied Measurement, 7, 323-334.

Milton, B., Cook, P.A. and Dugdill, L. (2004). Why do primary school children smoke? A longitudinal analysis of predictors of smoking uptake during pre-adolescence. Public Health, 118, 247-255.

Milne, S., Orbell, S., and Sheeran, P. (2002). Combining motivational and volitional interventions to promote exercise participation: protection motivation theory and implementation intentions. British Journal of Health Psychology 7,163-184.

Murray, D. and Perry, C.L. (1987). The measurement of substance use among adolescents. When is the "bogus pipeline" method needed? Addictive Behaviours, 2, 225-233. Murray, D., Perry, C., Griffin G., Harty, K., Jacobs, D., Schmidt, L., Daly, K. and Pallonen, U.(1992). Results from a statewide approach to adolescent tobacco use prevention. Preventive Medicine, 21, 449-472. 
Murray, D.M., O'Connell, C.M., Schmid, L.A. and Perry, C.L. (1987). The validity of smoking self-reports by adolescents: a re-examination of the bogus pipeline procedure. Addictive Behaviors, 12, 7-15.

National Center for Chronic Disease Prevention and Health Promotion. (2003). YRBSS:

Youth Risk Behavior . Surveillance System

http://www.cdc.gov/healthyyouth/yrbs/trends.htm. Accessed on March 2003.

National Center for Chronic Disease Prevention and Health Promotion. (2004a). Global

Youth Tobacco Survey http://www.cdc.gov/tobacco/global/GYTS/factsheets/

2004/pdf/Romania factsheet2004.pdf. Accessed on February 2006.

National Center for Chronic Disease Prevention and Health Promotion. (2004b). Global Youth Tobacco Survey.

http://www.cdc.gov/tobacco/global/gyts/GYTS_countryreports.htm. Accessed on February 2006.

National Center for Disease Control and Prevention. (1993). Smoking-attributable mortality and years of potential life lost-United States, 1990.Morbidity and Mortality Weekly Report, 42, 645-648.

National Center for Disease Control and Prevention. (2002). Behavioral Risk Factor Surveillance System. http://www.cdc.gov/brfss/questionnaires/pdfques/2002brfss.pdf. Accessed on January 2006.

National Institute of Statistics. (2004). Veniturile si chetuielile popuatiei. (Income and expenses among population). http://www.insse.ro/cms/files/pdf/ro/cap4.pdf. Accessed on January 2004.

Nebot, M., Tomas, Z., Ariza, C., Valmayor, S., López, M.J. and Juárez, O. (2004). Factors associated with smoking onset: 3-year cohort study of schoolchildren. Archivos de Bronconeumologia, 40, 495-501.

Neumark-Sztainer, D., Story, M., Toporoff, E., Himes, J.H., Resnick, M.D. and Blum, R.W. (1997). Covariations of eating behaviors with other health-related behaviors among adolescents. Journal Of Adolescent Health, 20, 450-458.

Nierkens, V., De Vries, H. and Stronks, K. (2006). Smoking in immigrants: do socioeconomic gradients follow the pattern expected from the tobacco epidemic? Tobacco Control, 15, 385-391.

Nierkens, V., Stronks, K., Van Oel, C.J. and De Vries, H. (2005). Beliefs of Turkish and Moroccan immigrants in The Netherlands about smoking cessation: implications for prevention. Health Education Research, 20, 622-634. 
Oakley, A., Brannen, J. and Dodd, K. (1992). Young people, gender and smoking in the United Kingdom. Health Promotion International, 7, 75-88.

Olweus, D. (1987). School-yard bullying - Grounds for intervention. School Safety, 6, 4-11. Oman, R.F., McLeroy, K.R., Vesely, S., Aspy, C.B., Smith, D.W. and Penn, D.A. (2002). An adolescent age group approach to examining youth risk behaviors. American Journal of Health Promotion, 16,167-176.

Orpinas, P.K., Basen-Engquist, K., Grunbaum, J. and Parcel, G.J. (1995). The co-morbidity of violence-related behaviors with health-risk behaviors in a population of high school students. Journal of Adolescent Health, 16, 216-225.

Paavola, M., Vartiainen, E. and Haukkala, A. (2004). Smoking, Alcohol Use, and Physical Activity: A 13-Year Longitudinal Study Ranging from Adolescence into Adulthood. Journal of Adolescent Health, 35, 238-244.

Panday, S., Reddy, S.P, Ruiter, R.A.C, Bergström, E., and De Vries, H. (2005). Determinants of smoking cessation among adolescents in South Africa. Health Education Research, 20, 586-599.

Parcel, G.S. (1995). Difussion research: The Smart Choices Project. Health Education Research, 10, 279-281.

Parcel, G.S., Ericksen, M.P., Lovato, C.Y., Gotlieb, N.H., Brink, S.G., and Green, L. W. (1989). The diffusion of a school based tobacco use prevention program: Project description and Baseline Data. Journal of Health Education, 4, 111-124.

Pasick, R.J. (1997). Socioeconomic and Cultural factors in the development and use of theory. In Glanz, K., Lewis, F.M. and Rimer, B.K., (eds). Health behaviour and Health Education. Theory, Research and Practice $\left(2^{\text {nd }}\right.$ ed.). California: JosseyBass.

Patton, G.C., Coffey, C., Carlin, J.B., Degenhardt, L., Lynskey, M. and Hall, W. (2002). Cannabis use and mental health in young people: cohort study. British Medical Journal, 325, 1195-1198.

Pederson, L.L. and Lefcoe, N.M. (1987). Short- and long-term prediction of self reported cigarette smoking in a cohort of late adolescents: report of an 8-year follow-up of public school students. Preventive Medicine, 16, 432-447.

Perkins, K.A., Fonte, C. and Grobe, J.E. (2000). Sex differences in the acute effects of cigarette smoking on the reinforcing value of alcohol. Behavioral Pharmacology $, 11,63-70$. 
Perry, C., Kelder, S., Murray, D. and Klepp, K. (1992). Community-wide smoking prevention: long-term outcomes of the Minnesota Heart Health Program and the Class of 1989 Study. American Journal of Public Health, 82, 1210-1216.

Peterson, A.V., Kealey, K.A., Mann, S.L., Marek, P.M. and Sarason, I.G. (2000). Hutchinson Smoking Prevention Project: long-term randomized trial in school-based tobacco use prevention--results on smoking. Journal of_National Cancer Institute, 92, 1979-1991.

Peto, R., Darby, S., Deo, H., Silcocks, P., Whitley, E., and Doll, R. (2000). Smoking, smoking cessation and lung cancer in the UK since 1950: combination of national statistics with two case control studies. British Medical Journal, 321, 322-329.

Pierce, J. P. and Gilpin, E.A. (1996). How long will today's adolescent smoker be addicted to cigarettes? American Journal of Public Health, 86, 253-256.

Piperakis, S.M., Garagouni-Araiou, F. and Argyracouli, E. (2008). A survey on smoking habits and attitudes among adolescents in Greece. Journal of Adolescent Medicine and Health, 20, 63-71.

Potthoff, S.J., Bearinger, L.H., Skay, C.L., Cassuto, N., Blum, R.W. and Resnick, M.D. (1998). Dimensions of risk behaviors among American Indian youth. Archives of Pediatrics and Adolescence Medicine, 152, 157-163.

Prochaska, J. O. and DiClemente, C. C. (1983). Stages and processes of self-change of smoking: Toward an integrative model of change. Journal of Consulting and Clinical Psychology, 51, 390-395.

Prochaska, J.O. and Velicer, W.F. (1997). The transtheoretical model of health behavior change. American Journal of Health Promotion, 12, 38-48.

Prochorov, A.V. and Alexandrov, A.A. (1992). Tobacco smoking in Moscow school students. British Journal of Addiction, 87, 1469-1476.

Proescholdbell, R.J., Chassin, L. and McKinnon, D.P. (2000). Home smoking restrictions and adolescent smoking. Nicotine and Tobacco Research, 2, 159-167.

Radu-Loghin, C. (2003). Romania-political mapping and advocacy strategy in tobacco control. Open Society Institute; http://www.policy.hu/radu/. Accesed on February 2006.

Rasbash, J., Browne, W., Goldstein, H., Yang, M., Plewis, I., Healy, M. Woodhouse, G., Draper, D., Langford, I. and Lewis, T. (2000). A User's Guide to MLWIN. Version 2.1. Multilevel Models Project, London: Institute of Education, University of London. 
Reedy, S.P., Meyer Weitz, A., Van den Borne, B. and Kok, G. (2000). Determinants of condom use behaviour among STD clinic attenders in South Africa. International Journal of STD and AIDS, 11, 521-530.

Reddy, P., Resnicow, K., Omardien, R. and Kambaran, N. (2007). Prevalence and correlates of substance use among high school students in South Africa and the United States. American Journal of Public Health. 97, 1859-1864.

Reid, D.J., McNeill, A.D. and Glynn, T.J. (1995). Reducing the prevalence of smoking in youth in Western countries: an international review. Tobacco Control, 4, 266277.

Ritchey, P.N., Reid, G.S. and Hasse, L.A. (2001).The relative influence of smoking on drinking and drinking on smoking among high school students in a rural tobaccogrowing county. Journal of Adolescent Health, 29, 386-394.

Ridolfo, B. and Stevenson, C. (2001). The quantification of drug-caused mortality and morbidity in Australia, 1998. Canberra: Australian Institute of Health and Welfare.

Rodham, K., Hawton, K., Evans, E. and Weatherall, R. (2005). Ethnic and gender differences in drinking, smoking and drug taking among adolescents in England: a self-report school-based survey of 15 and 16 year olds. Journal of Adolescence, 28, 63-73.

Rogers, E.M. (1983). Diffusion of innovations, 3rd Edn. New York: Free Press.

Romanian Ministry of Health. (2004). The European School Survey Project on alcohol and other drugs. Bucharest: The Ministry.

Romanian Ministery of Health. (2005). Studiul sanatatii reproducerii:Romania 2004. Study of sexual health: Romania, 2004. Bucharest: Romanian Ministery of Health

Romanian Multisectorial HIV/AIDS Commission. (2005). Country progress report; Romania.http://data.unaids.org/pub/Report/2006/2006 country progress_report $r$ omania en.pdf. Accesed on July 2007.

Rooney, B.L. and Murray, D.M. (1996). A meta-analysis of smoking prevention programs after adjustment for errors in the unit of analysis. Health Education Quarterly, 1, 48-64.

Rosenbaum, D. and Kandel, B. (1990). Early Onset of Adolescent Sexual Behavior and Drug Involvement. Journal of Marriage and the Family, 52, 783-798.

Rosenthal, R. (1990). How are we doing in soft psychology? American Psychologist, 45,775-777. 
Sayette, M.A., Martin, C.S., Wert, J.M., Perrott, M.A and Peters, A.R. (2005). The effects of alcohol on cigarette craving in heavy smokers and tobacco chippers. Psychology of Addictive Behavior. 19, 263-270.

Scarinci, I.C., Robinson, L.A., Alfano, C.M., Zbikowski, S.M. and Klesges, R.C. (2002). The relationship between socioeconomic status, ethnicity, and cigarette smoking in urban adolescents. Preventive Medicine, 34, 171-178.

Scheer, S.D. and Unger, D.G. (1997). Russian adolescent drug use and comparisons to United States adolescents. Substance Use \&Misuse, 32, 2151-2162.

Schlecht, N. F., Franco, E. L., Pintos, J., Negassa, A., Kowalski, L.P., Oliveira, B. V. and Curado, M. P. (1999). Interaction between tobacco and alcohol consumption and the risk of cancers of the upper aero-digestive tract in Brazil. American Journal of Epidemiology, 150, 1129-1137.

Shafey, O., Dolwick, S. and Guindon, G.E. (Eds.). (2003). Tobacco Control Country Profiles 2003. Atlanta, GA: American Cancer Society.

Shrier, L.A., Emans, J., Woods, E.R. and Durant, R.H. (1996). The association of sexual risk behaviors and problem drug behaviors in high school students. Journal of Adolescent Health, 20, 377-383.

Siegel, M., Biener, L., and Rigotti, N.A. (1999). The effect of local tobacco sales on adolescent smoking initiation. Preventive Medicine, 29, 334-342.

Single, E. (1997). Public drinking, problems and prevention measures in twelve countries: results of the WHO project on public drinking. Contemporary drug problems, 24, $425-448$.

Soteriades, E.S. and DiFranza, J.R. (2003). Parent's socioeconomic status, adolescents' disposable income and adolescents' smoking status in Massachusetts. American Journal of Public Health, 93,1155-1160.

Sperber, A.D., Peleg, A., Friger, M. and Shvartzman, P. (2001). Factors associated with daily smoking among Israeli adolescents: a prospective cohort study with a 3-year follow-up. Preventive Medicine, 33, 73-81.

Sowden, Ai.; Arblaster, L. and Stead, L. (2003). Community interventions for preventing smoking in young people. Cochrane Database of Systematic Reviews, 1, CD001291.

Stėa'd, 'M., Hastings, G. and Tudor-Smith, C. (1996). Preventing adolescent smoking: a review of options. Health Education Journal, 55, 31-54. 
Steggles, N. and Jarvis, M.J. (2003). Do mobile phones replace cigarette smoking among teenagers? Tobacco Control, 12, 339-340.

Sussman, S., Dent, C.W., Flay, B.R., Hansen, W.B. and Johnson, C.A. (1987). Psychosocial predictors of cigarette smoking onset by white, black, Hispanic and Asian adolescents in Southern California. Morbidity and Mortality Weeklly Report, 36, $11-17$.

Sutherland, I. and Shepherd, J. P. (2001). The prevalence of alcohol, cigarette and illicit drug use in a stratified sample of English adolescents. Addiction , 96, 637-640.

Sutherland, I. and Willner, P. (1998). Patterns of alcohol, cigarette and illicit drug ue in English adolescents. Addiction, 93, 1199-1208.

Szilágyi, T. and Chapman, S. (2003). Hungry for Hungary: examples of tobacco industry's expansionism. Central European Journal of Public Health, 11, 38-43.

Takakura, M., Nagayama, T., Sakihara, S. and Willcox, C. (2001a). Patterns of health risk behaviour among Japanese high school students. Journal of Adolescent Health, 71, 23-29.

Takakura, M., Ueji, M. and Sakihara, S. (2001b). Covariation of cigarette smoking and other health-risk behaviors among Japanese high school students: a preliminary study. Journal of Epidemiology, 11, 224-228.

Taylor, M., Dlamini, S.B., Kagoro, H., Jinabhai, C.C. and De Vries, H. (2003). Understanding high school students' risk behavior to help reduce the HIV/AIDS epidemic in KwaZuluNatal, South Africa. Journal of School Health, 73, 97-100.

Telch, M.J., Miller, L.M., Killen, J.D., Cooke, S. and Maccoby, N. (1990). Social influences approach to smoking prevention: the effects of videotape delivery with and without same-age peer leader participation. Addictive Behaviors, 15, 21-28.

The Global Youth Tobacco Survey Collaborative Group (2002). Tobacco use among youth: a cross-country comparison. Tobacco Control, 11, 252-270.

The Official Gazette of Romania no 165. (1999). Law no.55/1999, Romania.

The Official Gazette of Romania no 534. (2002). Law no.504/2002, Romania.

The Official Gazette of Romania no. 359. (2000). Law no. 148/2000, Romania.

The Official Gazette of Romania no. 435. (2002). Law no. 349/2002, Romania.

The Official Gazette of Romania no. 1067. (2004). Law no 147/ 2004, Romania.

Thomas, R. (2003). School-based programmes for preventing smoking. Cochrane Database of Systematic Reviews, 1, CD001293 
Thomas, R. and Perera ${ }_{2}$ R. (2006). School-based programmes for preventing smoking. Cochrane Database of Systematic Reviews, 3, CD001293.

Tobler, N. and Straton, H. (1997). Effectiveness of school based drug prevention programs: A meta analysis of the research. Journal of Primary Prevention, 18, 71-128.

Tobler, N.S., Roona, M.R., Ochshorn, P., Marshall, D.G., Streke, A.V. and Stackpole, P.M. (2000). School-based adolescent drug prevention programs: 1998 meta-analysis. Journal of Primary Prevention, 20, 275-336.

Tones, K. and Tilford, S. (2001). Health Promotion: Effectiveness and Efficiency. Cheltenham: Stanley Thornes.

Torabi, M. R., Bailey, W. J. and Jabbari, M. M. (1993). Cigarette smoking as a predictor of alcohol and other drug use by children and adolescents: evidence of the 'gateway drug effect'. Journal of School Health, 63, 302-306.

Torres, R.R.M. and Fernandez, F.P. (1995). Self-esteem and value of health as determinants of adolecent health behaviour. Journal of Adolescent Health, 16, 60-63.

Trofor, A. and Loghin, C.R. (2004). Fumatul de la obicei la boala. (Smoking from habit to disease). Iasi: Tehnopress.

Tuakly, N., Smith, M.A. and Heaton, C. (1990). Smoking in adolescence: Methods for health education and smoking cessation. Journal of Family Practice, 31, 369-374.

Tucker J.S, Ellickson, P.L. and Klein, D.J. (2003). Predictors of the transition to regular smoking during adolescence and young adulthood. Journal of Adolescent Health, 32, 314-324.

Turner, R.A., Irwin, C.E., Tschann, J.M. and Millstein, S.G. (1993). Autonomy, relatedness, and the initiation of health risk behaviors in early adolescence. Health Psychology, 12, 200-208.

Tyas, L.S. and Pederson, L. (1998). Psychosocial factors related to adolescent smoking: a critical review of the literature. Tobacco Control, 7, 409-420.

UNAIDS (2006). Report on the global AIDS epidemic 2006. http://www.unaids.org/en/HIV data/2006GlobalReport/default.asp. Accesed on July 2007.

US Department of Health and Human Services. (1994a). Preventing Tobacco Use Among Young People: A Report of the Surgeon General. Atlanta, GA: USDHHS.

US Departement of Health and Human Services. (1994b). Morbidity and Mortality Weekly Report: Guidelines for School Health Programs to Prevent Tobacco Use and Addiction. Washington DC: U.S Government Printing Office. 
US Department of Health and Human Services. (2000). Reducing Tobacco Use: A Report of the Surgeon General. Atlanta, GA.:USDHHS.

UNFPA (2006). Natality in Romania. Press report. http://www.unfpa.ro/presa/com presa/ natalitatea/Accesed on July 2008.

Vaidya, S.C., Vaidya, J.S. and Naik, U.D. (1999). Sports sponsorship by cigarette companies influences the adolescent childrens' mind and helps initiate smoking: results of a national study in India. Journal of the Indian Medical Associations, 97, 354-359.

Van Den Bree, M.B.V., Whitmer, M.D. and Pickworth, W.B. (2004). Predictors of smoking development in a population-based sample of adolescents: A prospective study. Journal of Adolescent Health, 35, 172-181.

Van De Ven, M.O., Engels ${ }_{2}$ R.C., Otten R, Van Den Eijnden, R.J. (2007).A longitudinal test of the theory of planned behavior predicting smoking onset among asthmatic and non-asthmatic adolescents. Journal of Behavioral Medicine 30,435-445.

Van Osch, L., Lechner, L., Reubsaet, A., Wigger, S. and De Vries, H. (2008). Relapse Prevention in a National Smoking Cessation Contest: Effects of Coping Planning. British Journal of Health Psychology, 13, 525-535.

Vartiainen, E., Puska, P., Koskela, K. and Nissinen, A. (1986). Ten-year results of a community-based anti-smoking program (as part of the North Karelia Project in Finland). Health Education Research, 1, 175-184.

Vartiainen, E.,Pennanen, M., Haukkala, A., Dijk, F., Lehtovuori, R. and De Vries, H. (2007).The effects of a three-year smoking prevention programme in secondary schools in Helsinki. The European Journal of Public Health , 17, 249-256.

Vickers, R.R., Conway, T.L. and Hervig, L.K. (1990). Demonstration of replicable dimensions of health behaviors. Preventive Medicine, 19, 377-401.

Virgili, M., Owen, N. and Severson, H.H. (1991). Adolescents smoking behaviour and risk perceptions. Journal of Substance Abuse, 3, 315-324.

Vitoria, P.D., Kremers, S.P., Mudde, A.N., Pais-Clemente, M., and De Vries, H. (2006). Psychosocial factors related with smoking behaviour in Portuguese adolescents. European Journal of Cancer Prevention, 15, 531-540.

Wakefield, $M$ and Chaloupka, F. (2000). Effectiveness of comprehensive tobacco control programmes in reducing teenage smoking in the USA. Tobacco Control, 9, 177186.

Wakefield, M., Kloska, D., O'Malley, P., Johnston, L., Chaloupka, F., Pierce, J., Giovino, G., Ruel, E., and Flay, B. (2004). The role of smoking intentions in predicting 
future smoking among youth: findings from Monitoring the Future data. Addiction, 99, 914-922.

Wandersman, A. and Florin, P. (2003). Community Interventions and Effective Prevention. American Psychologist, 58, 441-448.

Wang, M.Q., Fitzhugh, E.C., Green, B.L., Turner, L.W., Eddy, J.M. and Westerfield, R.C. (1999). Prospective social psychological factors of adolescent smoking progression. Journal of Adolescent Health, 24, 2-9.

Wang, M.Q., Fitzuch, E.C., Westerfield, R.C and Eddy, J.M. (1994). Predicting smoking status by symptoms of depression for US adolescents. Psychological Reports, 75, 919-914.

Walton, R., Johnstone, E., Munafo, M., Neville, M. and Griffiths, S. (2001). Genetic clues to the molecular basis of tobacco addiction and progress towards personalized therapy. Trends in Molecular Medicine, 7, 70-76.

Wasserman, J., Manning, W.G. and Newhouse, J.P. (1991). The effects of excise taxes and regulations on cigarette smoking. Journal of Health Economics, 10, 43-64.

Weitzman, E.R. and Chen, Y. (2005). The co-occurrence of smoking and drinking among young adults in college: national survey results from the United States. Drug and Alcohol Dependence, 80, 377-386.

Wenter, D., Blackwell, S., Davis, K., and Farrelly, M. (2002). First look report: Using multiple strategies in tobacco use prevention education: American Legacy Foundation. http://repositories.cdlib.org/context/tc/article/1204/type/pdf/viewcontent/. Accesed on June 2007.

Werch, C.E., Moore, M. J., DiClemente, C. C., Owen, D. M., Carlson, J. M. and Jobli, E. (2005). Single vs. multiple drug prevention: Is more always better? A pilot study. Substance Use \&Misuse, 40, 1085-1101.

West, P., Sweeting, H. and Young, R. (2007). Smoking in Scottish youths: personal income, parental social class and the cost of smoking. Tobacco Control, 16, 329-335.

Wetzels, J.J.L., Kremers, S.P.J., Vitória, P.D. and De Vries, H. (2003). The alcohol-tobacco relationship: A prospective study among adolescents in six European countries. Addiction. 98, 1755-1763.

White, H.R., Violette, N.M., Metzger, L. and Stouthamer-Loeber, M. (2007). Adolescent risk factors for late-onset smoking among African American young men. Nicotine and Tobacco Research, 9,153-161. 
Wilks, J., Callan, V.J. and Austin, D.A. (1989). Parent, peer and personal determinants of adolescent drinking. British Journal of Addiction, 84, 619-630.

Willey, C., Laforge, R., Blais, L., Pallonen, U., Prochaska, J. and Boelho, R. (1996). Public Health and the science of behaviour change. Current Issues Public Health, 2, 1825.

World Bank. (1999). Curbing the epidemic: governments and the economics of tobacco control. Washington DC: World Bank.

World Bank. (2007). Romania. Nota privind politicile educationale. (Romania. Report regarding the school policies ).Bucharest: World Bank.

World Health Organization. (1997). Young People and Sexually Transmitted Diseases. WHO Fact Sheet No. 186. Geneva: WHO.

World Health Organization. (2005). Sexually Transmitted infections among adolescents-The role of health care services. Geneva: WHO.

World Health Organization. (2002a). The European Report on Tobacco Control Policy. Copenhagen: WHO Regional Office for Europe.

World Health Organization. (2002b). World report on violence and health. Geneva: WHO.

World Health Organization. (2007) WHO European tobacco control rapport, 2007 http://www.euro.who.int/Document/E89842.pdf. Accessed on June 2008.

Yeaton, W. and Sechrest, L. (1981). Meaningful measures of effect. Journal of Consulting and Clinical Psychology, 49, 766-767.

Young, M. and Werch, C.E. (1990). Relationship between self-esteem and substance use among students in the fourth through twelfth grade. Wellness Perspectives: Research, Theory and Practice, 7, 31-44.

$\mathrm{Za} \mathrm{k}$ h a r i, S. (1997). Alcohol and the cardiovascular system: Molecular mechanisms for beneficial and harmful action. Alcohol Health \& Research World, 2 1, 2 1-29.

Zhu, B.P., Liu, M., Shelton, D. and Giovino, G.A. (1996). Cigarette smoking and its risk factors among elementary school students in Beijing. American Journal of Public Health, 86, 368-375. 


\section{Summary}

In 2003, at the onset of this project, few data were available in Romania regarding healthrelated behaviours of Romanian young people and factors associated with these risk behaviours. Moreover, the health education of Romanian young people had many weaknesses; the missing of theory-driven interventions, of long-term strategies as well as of effect evaluations of the health education programmes was noticed. In the first part, this thesis assesses the prevalence of health-risk behaviours among Romanian young people and investigates the relationship existing between several health-risk behaviours. In the second part, it focuses on smoking prevention, as a first step to promoting a healthy lifestyle among Romanian young people.

The thesis starts in chapter 1 by providing an overview of the prevalence and consequences of several health-related behaviours. Next, a description of the factors associated with smoking behaviour is given. An overview of several smoking prevention strategies is also presented. The first chapter ends with the outline of the research projects on which this thesis was built.

Chapters 2 and 3 explore patterns of health-risk behaviours among Romanian young people and examine if a relationship and an accumulation of health-risk behaviours exists. In chapter 2, the prevalence of different health-related behaviours is described among Romanian young people aged 11-25 years consisting of junior high school, senior high school and university students. The interrelationship between different health-compromising behaviours is also examined, as well as age and gender differences with respect to health-risk behaviours. The results showed that, as expected, many of the health-related behaviours were interrelated, particularly smoking, alcohol use and precocious sexual intercourse. Moreover, factor analysis showed that the students from the three groups participated in distinct combinations of health-risk behaviours that together created profiles of risk, which captured the complexity of adolescent health-compromising behaviours. The prevalence and accumulation of health-risk behaviours were generally higher among boys than among girls in all three groups, but no significant differences were found regarding the relationship between several risk behaviours. These findings raise the question of whether to address the promotion of healthy lifestyles among youth in one overall programme or by dealing with them as separate topics and of whether the same approach has to be taken for younger and older adolescents. Health care providers must be also aware of the interrelationship existing between health-risk behaviours in order to identify, treat and prevent correctly healthcompromising behaviours.

Chapter 3 depicts the cross-sectional and prospective relations between alcohol and tobacco use among Romanian adolescents aged 15 to 17 , giving special attention to possible gender differences. The results showed that alcohol and cigarette use were linked reciprocally. Moreover, among girls smoking predicted alcohol use better than the converse, while for boys a reversed pattern was found. The findings suggested that prevention of alcohol use might be more successful if it is linked closely to the prevention of cigarette use, and vice versa. It is important for future studies of adolescent substance use to investigate systematically gender differences in the tobacco-alcohol relationship.

The second part of the thesis focuses on smoking prevention. Chapter 4 describes the data regarding smoking prevalence as well as individual and contextual influences on the smoking behaviour among Romanian young people. The chapter outlines that, following the change of the political regime in 1989, Romania was confronted with an aggressive promotion campaign developed by the transnational tobacco companies, accompanied by the 
lack of sustainability in the field of tobacco control. Under these circumstances, it is not surprising that the social acceptance and prevalence of smoking increased among Romanian young people.

Understanding the psychosocial determinants is one of the first crucial analyses that should be undertaken in order to identify the specific beliefs to be addressed in intervention programmes. Chapter 5 thus reports on factors associated with the smoking behaviour among Romanian adolescents aged 15-17 years, using both cross-sectional and longitudinal data. In sum, the significance of self-efficacy expectations with regard to the association with smoking behaviour was stressed by both cross-sectional and longitudinal results. As regards the social influences toward smoking, both cross-sectional and longitudinal results confirmed the strong influence of smoking friends on adolescents' smoking behaviour. The influence of smoking parents was not confirmed in the cross-sectional study or in the longitudinal study. The comparison of the findings of our cross-sectional and longitudinal studies of smoking determinants revealed some differences. In going from cross-sectional associations to longitudinal predictors, several significant associations declined or disappeared, which is not an isolated finding. Both attitudes regarding smoking as well as intention to smoke in the next year were associated with the smoking behaviour of Romanian adolescents in the crosssectional study. Despite this, attitudes regarding smoking or intention to smoke in the next year did not predict regular smoking onset among Romanian adolescents over a period of one year. These results showed that Romanian smoking prevention programme should strengthen self-efficacy beliefs and resistance against peer influences and help Romanian young people to develop skills as well as action plans in order to cope with pressure to smoke and with challenging situations, findings that are similar to those from other international studies.

Chapter 6 presents the process and effect evaluation of a school-based peer-led smoking prevention programme on video implemented among Romanian adolescents aged 13 and 14 years. The programme used the social influence approach and focused on the enhancement of self-efficacy and the acquisition of refusal skills. The effect evaluation revealed that 9 months after the pre-test regular smoking initiation was significantly lower in the experimental group (4.5\%) than in the control condition $(9.5 \%)$. The non-smokers at the pre-test who did not participate into the smoking prevention programme had two times higher risk of becoming regular smokers as compared with those from the experimental conditions. Furthermore, significant effects of the programme on smoking-related beliefs were observed. In the experimental group, this resulted in a more negative attitude towards smoking, increased social self-efficacy levels and a more negative intention towards smoking. The results of the process evaluation showed that students liked the peer-led approach, the content and the structure of the programme. Girls were more positive than boys about the programme and they liked more the peer-led approach.

The last chapter summarizes and discusses the main findings of the studies of this thesis, addressing also the limitation of the study designs. Lastly, recommendations for tobacco control and health education in Romania as well as implications for future research are discussed. 


\section{Samenvatting}

In 2003, aan de start van dit project, waren weinig gegevens beschikbaar in Roemenie wat betreft gezondheidsgerelateerd gedrag van jonge Roemenen en factoren die invloed hebben op dat gedrag. Daarnaast waren er ook zwakke punten in de gezondheidsvoorlichting, zoals een gebrekkige gezondheidsvoorlichitng aan Roemeense jongeren; een gebrek aan theoretisch onderbouwde interventies, een gebrek aan lange termijn strategieën en een gebrek aan effectevaluaties van gezondheidsvoorlichtingsprogramma's. Het eerste deel van dit proefschrift heeft zich gericht op het bestuderen van de prevalentie van gezondheidsgerelateerd risicogedrag onder Roemeense jongeren en de relatie tussen bestaande gewoonten met gezondsheidsrisico's. In het tweede deel staat rookpreventie centraal, als eerste stap om een gezonde levensstijl te bevorderen onder Roemeense jongeren.

Het proefschrift geeftt in hoofdstuk één een overzicht van de prevalentie en de gevolgen van verschillende gezondheidsgerelateerde gewoonten. Vervolgens wordt een beschrijving gegeven van de factoren, die volgens diverse studies geassocieerd kunnen worden met het rookgedrag. Daarnaast wordt een overzicht gegeven van verschillende strategieën met betrekking tot rookpreventie. Hoofdstuk één wordt afgesloten met een beschrijving van het kader van het onderzoeksproject dat de basis was voor dit proefschrift.

In hoofdstuk twee en drie worden de patronen in gezondheidsgerelateerde risicodragende gewoonten onder Roemeense jongeren verkend en wordt onderzocht of sprake is van een relatie en een versterkend effect tussen deze gedragsvormen. In hoofdstuk twee is de prevalentie van de verschillende gezondheidsgerelateerde gewoonten bij Roemeense jongeren van 11 tot 24 jaar beschreven. De groep bestond uit middelbare scholieren (boven- en onderbouw) en universitaire studenten. De relatie tussen verschillende gedragsvormen met negatieve gezondheidseffecten is bestudeerd, evenals de verbanden van deze gedragsvormen met leeftijd en sekse. De resultaten lieten, zoals verwacht, zien dat veel van de gedragsvormen verband met elkaar hielden, in het bijzonder roken, alcohol gebruik en seksuele activiteiten op jonge leeftijd.

Daarnaast bleek uit de factoranalyse, dat bij de jongeren van de drie deelnemende groepen, onderscheidende combinaties bestaan van gedragsvormen met gezondheidsrisico's. Deze combinaties vormen samen risicoprofielen, die de complexiteit van het gezondheidsgerelateerd risicogedrag van tieners omvatten. De prevalentie en het versterkend effect van gedragsvormen met gezondheidsrisico's waren over het algemeen hoger bij jongens dan bij meisjes in alle drie de groepen. Er zijn echter geen significante verschillen gevonden voor relaties tussen verschillende gedragsvormen met gezondheidsrisico's. De resultaten bevestigen de noodzaak om een veelomavvtend programma te ontwikelen om een gezonde levensstijl te bevorderen onder jongeren van de groep met de laagste leeftijd. Hoewel dit mogelijk voor jongeren kan geschieden in een programma lijkt voor oudere jongeren een meer gedifferentieerde aanpak nodig. Gezondheidszorgaanbieders moeten zich bewust zijn van de onderlinge verbanden tussen de verschillende gedragsvormen met gezondheidsrisico's om op een juiste manier het schadelijke gedrag te kunnen identificeren, behandelen en voorkomen.

Hoofdstuk drie beschrijft de cross-sectionele relatie en de verwachtingen voor alcohol- en tabakgebruik onder Roemeense jongeren van vijftien tot zeventien jaar oud. Hierbij is speciale aandacht besteed aan mogelijke verschillen tussen de seksen. De resultaten lieten zien dat gebruik van alcohol en roken onderling gerelateerd zijn. Bovendien voorspelde het rookgedrag onder meisjes het alcohol gedrag beter dan andersom, terwijl bij jongens een omgekeerd patroon werd gevonden. Deze bevindingen suggereren dat 
alcoholpreventie misschien succesvoller is als dit wordt gekoppeld aan rookpreventie, en vice versa. Voor toekomstige studies die het middelengebruik van jongeren bestuderen, is het belangrijk om systematisch de verschillen tussen de verschillende sexes te onderzoeken in de relatie tussen alcoholgebruik en rookgedrag.

Het tweede deel van het proefschrift is gericht op rookpreventie. Hoofdstuk vier beschijft de data met betrekking tot rookprevalentie en individuele en contextuele invloeden op het rookgedrag van Roemeense jongeren. Het hoofdstuk wijst erop dat, na de val van het politieke regime in 1989, Roemenië werd geconfronteerd met een agressieve promotiecampagne ontwikkeled door de transnationale tabaksfabrikanten, welke samenging met een gebrek aan duurzaamheid op gebied van de tabakscontrole. Onder deze omstandigheden is het toegenomen rookgedrag van jonge Roemenen en de sociale acceptatie daarvan niet verbazend.

Het begrijpen van de belangrijkste psychosociale determinanten is één van de eerste cruciale analyses, die moeten worden uitgevoerd om te begrijpen welke opvattingen moeten worden aangepakt in interventieprogramma's. Hoofdstuk 5 beshrijft de factoren die geassocieerd worden met het rookgedrag van Roemeense jongeren van vijftien tot zeventien jaar oud, waarbij gebruik is gemaakt van zowel cross-sectionele als longitudinale data.

De resultaten van de cross secionale als ook longitudinale analyses onderschrijven het belang van het hebben van hoge eigen effectiviteitsverwachtingen om roken te kunnen weerstaan als belangrijke determinant van het niet roken. Met betrekking tot de sociale invloeden op het rookgedrag, bevestigen zowel de cross-sectionele als longitudinale resultaten de sterke invloed van rokende vrienden op het rookgedrag van jongeren. De invloed van rokende ouders werd niet bevestigd bij zowel de cross-sectionele studie als de longitudinale studie.

Vergelijking van de cross-sectionale en longitudinale studies levert enkele verschillen op. De longitudinale analyses lieten minder vaak en minder sterke relaties zijn dan de cross-sectionaele analyses. Zowel de houding wat betreft roken als de intentie om in het volgende jaar te roken waren geassocieerd met het rookgedrag van Roemeense tieners in de cross-sectionale studie. Desondanks gaven de houding en de intentie om het jaar daarop te roken, geen voorspelling voor een reguliere aanzet voor rookgedrag onder Roemeense tieners voor een periode van één jaar.

Het vergelijken van de cross-sectionele en longitudinale studies met betrekking tot determinanten van het roken resulteert in enige verschillen. Van cross-sectionele associaties naar longitudinale voorspellers gaande, werden verschillende significante associaties kleiner of verdwenen. Dit is geen op zichzelf staande bevinding. Zowel attitudes met betrekking tot roken als de intentie om te roken in het daaropvolgende jaar, werden geassocieerd met rookgedrag van Roemeense adolescenten in de cross-sectionele studie. Ondanks dit, waren zowel attitudes met betrekking tot roken als de intentie om te roken in het daaropvolgende jaar geen voorspeller voor regelmatig roken bij Roemeense adolescenten voor een periode van één jaar.

De resultaten lieten zien dat Roemeense rookpreventieprogramma's de eigeneffectiviteitsverwachting en de weerbaarheid tegen invloeden van de directe omgeving moeten versterken. De programma's moeten Roemeense jongeren helpen bij het ontwikkelen van vaardigheden en actieplannen, zodat ze kunnen omgaan met de druk om te roken en met uitdagende situaties. Deze resultaten zijn vergelijkbaar met die van andere internationale studies.

Hoofdstuk 6 beschrijft het proces en de effectevaluatie van een op scholen gericht en door leeftijdsgenoten geleid rookpreventieprogramma op video. Het programma is ontwikkeld voor Roemeense jongeren van dertien en veertien jaar. Het programma maakte gebruik van de sociale invloed benadering en richtte zich op verbetering van de eigeneffectiviteitsverwachting en het leren beheersen van 'vaardigheden om sigaretten te 
weigeren'. De effectevaluatie toonde aan dat negen maanden na de pre-test, het 'beginnen met roken' significant lager was in de experimentele groep (4,5\%) dan in de controle groep $(9,5 \%)$. De niet-rokers die bij de pre-test niet deelnamen aan het rookpreventieprogramma hadden een twee keer zo groot risico om een reguliere roker te worden, ten opzichte van degenen uit de experimentele groep. Daarnaast werden significante effecten van het programma op, aan roken gerelateerde opvattingen waargenomen. In de experimentele groep leidde dit tot een negatievere houding ten opzichte van roken, een toegenomen sociaal eigeneffectiviteitsverwachtingsniveau en een meer negatieve intentie om te gaan roken. Het resultaat van de procesevaluatie liet zien dat studenten de aanpak vanuit de directe omgeving met leeftijdsgenoten, de inhoud en de structuur van het programma prettig vonden. Meisjes waren positiever dan jongens over het programma en vonden de gehanteerde aanpak met leeftijdsgenoten prettiger.

Het laatste hoofdstuk bevat een samenvatting en discussie van de belangrijkste resultaten van de studies binnen dit proefschrift. Daarbij worden ook de beperkingen van de studieopzet besproken. Ten slotte worden aanbevelingen voor tabakscontrole en gezondheidsonderwijs in Roemenië en de gevolgen voor toekomstig onderzoek bediscussieerd. 


\section{Acknowledgements}

I offer my sincere gratitude and appreciation to all people and institutions who have contributed to the completion of this thesis.

First of all, I thank my supervisors Hein de Vries and Carmen Ionut, whose expert guidance made possible my development as a researcher and the finalization of this thesis. It has been an honour and a privilege to work under their supervision and to learn from them.

I am also grateful to my co-supervisor llse Mesters, who offered me an advice anytime I needed, showing me in practice that indeed motivational interview can illuminate people' mind and actions.

I extend my gratitude to several organizations for their financial assistance, which supported the development of the research studies from this thesis:

-The National University Research Council (CNCSIS) from Romania which offered me a research grant for $\mathrm{PhD}$ students

- The Netherlands Organization for international cooperation in higher education who offered me a Huygens scholarship

-The Royal Embassy of Netherlands in Romania which funded through a Matra KAP grant the implementation of the smoking prevention program

- The International Union against Cancer which supported through a UICC Cancer Technology Transfer Fellowship the evaluation of the smoking prevention program

I am also indebted to my colleagues from Maastricht University-Stef Kremers, Froukje Dijk, Math Candel, Leon Kolenburg-for all their help during the process of analyzing the research data. During my research activities I also received a lot of support from my colleagues from the department of Environmental Health from Iuliu Hatieganu University of Medicine and Pharmacy, in particular Monica Popa and Valeria Laza.

I would like to say thanks! to everybody that helped me during the implementation of the smoking prevention program-Daniela Georgescu from Romanian National Agency against Drugs and my colleagues from the non-governmental organization Aer Pur, Romania: Cornel Radu Loghin, Antigona Trofor, Daniel Mardare, Marius Eremia and Florin Mihaltan.

I want to thank also to my wonderful Dutch friends Nelleke de Kruik, Lonneke Timmers and Ivo Kokje, Linda Verniers and Pieter Out, whose support gave me the courage to come in the Netherlands several time to work for my $\mathrm{PhD}$ thesis, even as a pregnant woman or as a mother with a little baby.

Over the last few months, I also received a lot of support from my paranimfen Marja Vissers and Pieter Out, who I want to thank for their kindness and important contribution in organizing the procedures for the public defence of my dissertation.

Last, but definitely not least, 1 express my gratitude to my parents, Maria and Craciun, with my deepest regret that my father did not live to see this moment.

I also thank to my husband Sorin for his continuous support during my work for this project and to my little boy Darius who practically grow up together with this thesis. 


\section{Curriculum vitae}

Lucia Maria Lotrean was born on January 11, 1976 in Alba Iulia, Romania. She graduated Horia, Closca and Crisan high school from Alba lulia in 1994. In the same year she started her study at the Faculty of Medicine of the Iuliu Hatieganu University of Medicine and Pharmacy from Cluj-Napoca, Romania. She received her diploma of medical doctor in 2000 and in 2005 she becomes a specialist physician in the field of Child and Youth Hygiene, Food and Nutrition Hygiene and Environmental Hygiene. During the period 2004-2007 she received several scholarships in order to perform research stages at the University of Maastricht in the Department of Health Education and Promotion. In the present she is assistant professor at the Department of Environmental Health of Iuliu Hatieganu University of Medicine and Pharmacy from Cluj-Napoca, Romania. 